\title{
Climate Change, Inequality, and Human Migration*
}

\author{
Michal Burzynski | Christoph Deuster \\ Frederic Docquier I Jaime de Melo
}

C Michal Burzynski, LISER, Luxembourg Institute of Socio-Economic Research (Luxembourg). michal.burzynski@liser.lu

C Christoph Deuster, IRES, UCLouvain (Belgium), and Universidade Nova de Lisboa (Portugal). christoph.deuster@outlook.com

Frederic Docquier, LISER (Luxembourg), FNRS and IRES, UCLouvain (Belgium), and FERDI (France). frederic.docquier@liser.lu

Jaime de Melo, Scientific Director at FERDI and Emeritus Professor at the University of Geneva. jaime.demelo@unige.ch

\section{Abstract}

This paper investigates the long-term implications of climate change on local, interregional, and international migration of workers. For nearly all of the world's countries, our microfounded model jointly endogenizes the effects of changing temperature and sea level on income distribution and individual decisions about fertility, education, and mobility. Climate change intensifies poverty and income inequality creating favorable conditions for urbanization and migration from low- to high- latitude countries. Encompassing slow- and fast-onset mechanisms, our projections suggest that climate change will induce the voluntary and forced displacement of 100 to 160 million workers (200 to 300 million climate migrants of all ages) over the course of the 21st century. However, under current migration laws and policies, forcibly displaced people predominantly relocate within their country and merely $20 \%$ of climate migrants opt for long-haul migration to OECD countries. If climate change induces generalized and persistent conflicts over resources in regions at risk, we project significantly larger crossborder flows in the future. 


\section{Introduction}

How will long-term climate change (henceforth CLC) affect human mobility over the course of the 21st century? This question has been the source of much controversy in recent literature and has gained unprecedented attention in public discourse as global warming projections for the coming decades get worse. ${ }^{1}$ Anthropogenic temperature changes and sea level rise constitute two major threats of CLC envisaged by climatologists (Stocker et al., 2013). Moreover, CLC manifests itself through increased frequency and intensity of both extreme weather events and natural disasters (Stott, 2016). Along with altering ecosystems, CLC is expected to drastically affect numerous economic outcomes, such as labor productivity, individual health, and regional conflicts over resources (Dell et al., 2014). Modeling and predicting the consequences of these phenomena for economic prosperity and human mobility is a complex task, as climate-specific factors are often difficult to isolate from other determinants of migration and development. Scant evidence from the past suggests that the scale and type of mobility responses to CLC are highly uncertain and context-specific. ${ }^{2}$

Damages resulting from CLC will vary across space for two reasons. First, regions are heterogeneously exposed to sea level rise. Second, the economic effects of changes in temperature will vary across industries and by latitude, as the relationship between temperature and productivity is sector-specific and nonlinear (i.e., the effects are dependent on current levels of temperature). Low-latitude countries in general, and their agricultural sectors in particular, have contributed the least to CLC but will be the most adversely affected. Many believe that CLC will likely trigger mass emigration from developing to developed countries, as human mobility is often considered a first-order adaptation mechanism to CLC. This paper provides a quantitative economic evaluation of the size and composition of these CLC-induced migration flows.

To estimate the mobility responses to CLC, we set up a dynamic model of the world economy that builds on the state-of-the-art developments in migration literature. We model migration decisions as an outcome of a micro-founded, random utility maximization (RUM) model, which jointly accounts for the main migration mechanisms highlighted in the recent literature. In particular, changes in the mean level and volatility of temperature

\footnotetext{
${ }^{1}$ There is strong evidence that the global mean surface temperature of the world and the sea level have already increased since the beginning of the 19th century (by $+0.9^{\circ}$ Celsius and by +0.2 meters, respectively), and that the process has intensified since 1980. Climatologists estimate that temperatures might increase by 1 to $3^{\circ}$ Celsius over the 21 st century, and recent studies suggest that, once adding an increment from storm surge, the sea level is expected to rise 1 to 2 meters by 2050 (e.g., Rigaud et al., 2018).

${ }^{2}$ For example, Fagan (2008) documents that a $2^{\circ}$ Celsius rise in temperature during the Medieval warm period between the $9^{t h}$ and the $14^{t h}$ century resulted in a large relocation of people and a reshaping of economic activity. It is, of course, hard to extrapolate these conclusions to the present day.
} 
affect expected income and incentives to migrate (as in Dallmann and Millock, 2017; Desmet and Rossi-Hansberg, 2015; Shayegh, 2017). The associated sea level rise forces people and firms to move (as in Desmet et al., 2018b; Rigaud et al., 2018). CLC is also likely to stir refugee crises by provoking conflicts over resources (as in Abel et al., 2019; Burke et al., 2015b).

Compared to existing studies, our framework presents six main advantages. Firstly, the RUM structure allows us to model the long-term mobility responses to CLC at various spatial scales, taking into account the interplay between alternative forms of migration, namely local (i.e., very-short-distance), rural-to-urban (i.e., short-distance), and international (here captured by long-haul migration to the OECD countries). Secondly, it accounts for the high degree of heterogeneity in migratory behavior between people of different places of origin and levels of education. In our framework, each country is populated by two types of agents (college graduates and the less educated) living in two regions (agricultural and non-agricultural) that are heterogeneously affected by sea level rise (flooded and non-flooded areas). Thirdly, it allows us to distinguish between forced displacement (linked to sea level rise and conflicts) and voluntary migration (driven by economic incentives). Fourthly, the deterministic part of our RUM model is itself an outcome of a (second-stage) utility-maximization problem over consumption, fertility, and education. Consequently, we allow CLC to affect the dynamics of the size and structure of populations in an overlapping generation (OLG) setup. Fifthly, these endogenous migration decisions are embedded into a general equilibrium framework. The effects of CLC on human mobility, population growth, global income inequality, and extreme poverty are, therefore, jointly determined. Finally, the parameters of the RUM model (reflecting all legal barriers as well as the private monetary and psychic costs of moving) can be calibrated to exactly match international mobility and urbanization data from the last 30 years. Relying on simpler frameworks and ignoring CLC, the backcast exercises conducted in Dao et al. (2018) and Burzyński et al. (2019) demonstrate that such a model accurately fits the past migration trends and generates sensible projections. This provides us with some confidence that our approach can suitably predict the long-term consequences of CLC.

The first set of simulations focuses on slow-onset mechanisms; we account for foreseeable climate-related productivity losses and forced displacement induced by sea level rise. We find that CLC induces small positive effects on the worldwide average level of income per worker. However, the global distribution of income becomes more unequal due to CLC. Workers employed in countries located between the north and south 35th parallels suffer income losses, particularly those employed in agriculture. CLC also increases extreme poverty around the world at both the extensive and intensive margins. Thus, 
CLC creates conditions that are conducive to increasing urbanization and international migration. Relative to the state of the world with no CLC and under current migration laws and policies, the worldwide number of working-age movers is projected to increase by 100 to 160 million during the 21st century, depending on the intensity of CLC. ${ }^{3}$ Overall, we find similar levels of climate migration to Rigaud et al. (2018), but we offer additional insight on the type and spatial structure of mobility responses. Firstly, in our median scenario, we find that $60 \%$ to $70 \%$ of these climate migrants will be forcibly displaced due to sea level rise. Secondly, far more climate migrants will move within their own countries than across borders: $60 \%$ of movers will relocate within their region of origin (from flooded to non-flooded areas) and 18\% migrate interregionally (from rural areas to cities). Hence, only $22 \%$ will opt for long-haul migration to an OECD destination country. Depending on its magnitude, CLC will lead to a 20- to 50-million increase in the number of international adult migrants over the whole century, which translates into a 7- to 17-million average variation in the stock of migrants worldwide. For the median scenario, the induced 7 million migrants per year corresponds to $0.2 \%$ of the world population, $1 / 20$ of the no-CLC worldwide migration rate, and 1/5 of the gradual increase predicted for the 21 st century. ${ }^{4}$

The second set of simulations accounts for fast-onset mechanisms. We link the evolution of the distribution of temperatures to health costs, labor productivity losses, and natural disasters. Despite the fact that fast-onset variables deepen extreme poverty and income inequality, we find that they increase the stock of international migrants by only 6 million. Overall, when focusing on traditional economic mechanisms, the predicted impact of CLC on future international migration pressures is limited.

Results become significantly larger when accounting for conflicts over resources. Burke et al. (2015b) and Abel et al. (2019) argue that the effect of CLC on conflict occurrence is particularly relevant for countries undergoing political transformation or poverty crises. Building on these two studies, we simulate a climate-related persistent conflict in seven Western Asian countries and in ten countries with significant levels of poverty. This simulation increases the projected number of international climate migrants by about 50 million over the 21st century, and the long-run proportion of international migrants by 0.5 percentage points. Without tight security policies, we conclude that the conflict channel is likely to increase future migration pressures, leading to severe climate-related humanitarian crises.

Our paper contributes to the growing literature on the links between CLC and mi-

\footnotetext{
${ }^{3}$ This roughly implies 200-300 million migrants of all ages.

${ }^{4}$ The latter trend is mostly driven by the differential in population growth between developing and developed countries, and by acquisition of education all over the world.
} 
gration. Recent reviews of the literature are provided in Perch-Nielsen et al. (2008), Piguet et al. (2011), Millock (2015), Berlemann and Steinhardt (2017) or Cattaneo et al. (2019). ${ }^{5}$ The literature has mostly looked at the short-term impact of fast-onset variables (e.g., weather anomalies, storms, hurricanes, torrential rains, floods, landslides, etc.), as opposed to long-run CLC or slow-onset variables (e.g., temperature trends, desertification, rising sea level, coastal erosion, etc.). Methodological diversity is reflected in the heterogeneity of findings. The meta-analysis in Beine and Jeusette (2018) identifies four important methodological choices governing the results. ${ }^{6}$

While CLC has consistently emerged as a potent driver of internal migration (Barrios et al., 2006; Dallmann and Millock, 2017; Henderson et al., 2017; Kubik and Maurel, 2016; Piguet et al., 2011), its effect on international migration is not consensual. Some studies find important international migration outflows that are directly associated with weather shocks (Backhaus et al., 2015; Cai et al., 2016; Coniglio and Pesce, 2015) or indirectly induced by CLC-driven pressures on living standards in urban areas (Beine and Parsons, 2015; Marchiori et al., 2012, 2017). Others attempt to explain why migration responses to climate shocks have been small, non-existent, or even negative (Black et al., 2013, 2011; Cattaneo et al., 2019). ${ }^{7}$ Overall, using empirical approaches to predict the migration responses to global warming poses three major problems. Firstly, identifying a clear-cut effect of CLC on migration is difficult as climate variables closely interact with other economic and political drivers of migration. Secondly, mobility decisions are contextspecific and can be influenced by a large number of factors that vary across regions and countries (such as the country's size, the level of economic development, political situation, migrants' networks or specific cultural characteristics). Thirdly, the predicted effects of CLC have barely started to materialize. Long-run extrapolation of existing estimates is

\footnotetext{
${ }^{5}$ Earlier studies show that millions of people will migrate in the future as a result of climate change (Gemenne, 2011; Piguet et al., 2011). In response to the diversity of findings across studies, the paradigm has gradually changed, with recent studies seeing migration as one adaptation strategy among many (and not the least costly one).

${ }^{6}$ The first is the measurement of the dependent variable. Some studies focus on international migration (to all countries or to selected destinations) while others tackle internal migration and urbanization (Henderson et al., 2017). The second is the decision to include or exclude indirect effects of CLC. An indirect link is identified when climate variables affect mobility decisions through other variables, such as changes in productivity and income (Beine and Parsons, 2015; Marchiori et al., 2012) or conflicts over resources (Gleditsch, 2012; Miguel et al., 2004). The third is the analytical specification of the transmission technology. The literature distinguishes between monotonic or unconditional specifications (i.e., models capturing responses that are independent of the context) and conditional specifications that allow the eventual outcome to depend on socioeconomic and political characteristics of the individuals, households or regions exposed to climatic events. Finally, the fourth is the identification strategy.

${ }^{7}$ Cattaneo and Peri (2016) report that a gradual increase in the level of temperature reduces migration outflows from poor countries due to the presence of financial constraints. Bazzi (2017) finds similar results for Indonesia, as does Findley (1994) for Mali. On the contrary, Jayachandran (2006), Gray and Mueller (2012), and Mueller et al. (2014) find that landless households respond more strongly than wealthy ones in India, Pakistan and Bangladesh, respectively.
} 
questionable, and there are insufficient theoretical insights on the consequences of CLC.

In light of these limitations, we propose an alternative, micro-founded model that accounts for between- and within-country heterogeneity in mobility responses to CLC. Our study is a part of an incipient literature pioneered by Desmet and Rossi-Hansberg (2015) (henceforth DRH), who investigate the economic costs of CLC by modeling the interaction of mobility and production changes in the "almost continuous" space. ${ }^{8}$ Unlike DRH, we assume that each economy is composed of two regions, agricultural and non-agricultural; this assumption allows us to accommodate empirical estimates, which consistently suggest that CLC's impact on productivity will be greater on agriculture than on manufacturing. We are looking for first-order effects of CLC on individuals and countries in a framework that takes into account the fact that the (endogenous) geography of skills affects migration choices through differences in incentives, fertility decisions, and migration costs. Another related study is Shayegh (2017), which models the effect of CLC on fertility rates, income inequality and human capital accumulation in developing countries. He assumes that the probability of emigration is skill-specific and increasing with temperature without microfoundations. As to the effects of CLC, DRH and Shayegh (2017) model the effect of the change in temperature on productivity. Compared to these studies, we use an improved migration technology that combines the six advantages listed above, including an excellent predictive power for the period 1980 to 2010; we also account for sea level rise, which affects countries differentially, and implement additional mechanisms of transmission, such as the costs of natural disasters, health and productivity effects of heat waves, and conflicts over resources.

Our model inevitably leaves out a number of relevant features of CLC. Unlike the macro models of Nordhaus and Boyer (2000) and DRH, $\mathrm{CO}_{2}$ emissions are exogenously subsumed in the simulation scenario rather than being a result of explicitly modelled mitigation decisions. One reason for this is that the effects of population change on greenhouse gases concentration and global mean temperature are highly uncertain. In addition, for a given emissions scenario, projections of mean air temperature levels strongly vary across climate models. ${ }^{9}$ We assume that CLC and its direct impacts are exogenous to the economies under investigation. We also disregard the potential mitigation costs underlying the differences between our climate scenarios. Our results will remain unchanged if these costs involve universal taxes that are proportional to income. Furthermore, we model internal migration and long-haul migration to OECD countries only,

\footnotetext{
${ }^{8}$ In DRH all equilibria are spatially symmetric with prices and factor allocations identical for all locations at a given latitude. Desmet et al. (2018b) model the mobility of people and the dynamics of income inequality at a more detailed spatial scale (1x1 degree cells across the globe), but disregard CLC.

${ }^{9}$ Shayegh (2017) shows that endogenizing the CLC response to migration has a negligible impact on the overall results given the small number of migrants relative to the whole population.
} 
leaving aside South-South international mobility. This is because South-South migration mostly involves movements between contiguous countries, which will be affected by similar long-term CLC trends. South-South mobility is likely to increase with the frequency of asymmetric weather shocks. These movements are likely to be temporary and to balance out in the long run, given the spatial autocorrelation in climate shocks. Abstracting from all these features makes our results necessarily somewhat stylized. They should be interpreted as baseline estimates of the migration responses to first-order effects of CLC on living standards, livable space and political instability.

The rest of the paper is organized as follows. Section 2 describes our climate damage functions and illustrates the heterogeneous implications that CLC induces for the world economy. Section 3 describes the two-sector, two-education-groups model used to predict the behavioral and market responses to CLC. Section 4 presents the results obtained under various scenarios. Section 5 concludes.

\section{Climate Damage Functions}

Before accounting for general equilibrium and behavioral responses to CLC (see Section 3), this section describes CLC trends and their economic implications. It also discusses why low-latitude countries in general, and their rural regions in particular, will be the most adversely affected by CLC. In Section 2.1, we define CLC scenarios that combine future variations in global temperature and sea level. Then, Section 2.2 discusses the transmission channels through which CLC affects the world economy and the people's migration decisions.

In the first set of simulations (see Section 4.1), we focus on two slow-onset mechanisms: changes in total factor productivity (TFP) driven by long-term variations in mean temperature, and forced displacements driven by the rise in the sea level. Slow-onset mechanisms are easier to anticipate and are more likely to induce adaptation strategies such as crop switching and migration. Despite this, it is worth noting that there is a huge level of uncertainty in constructing our TFP damage functions. ${ }^{10}$ Hence, as detailed in

\footnotetext{
${ }^{10}$ Most analysts predict that CLC will lead to a gradual rise in the mean surface-temperature and in the sea level over the 21st century. However, the effects of $\mathrm{CO}_{2}$ emissions on the exact magnitudes of global temperature and sea level remain unexplored. Stern (2013) reports that since an increase of $+3^{\circ}$ Celsius has not been experienced for around 3 million years, we are in uncharted territory when it comes to modeling these likely effects (which are expected when the concentration of carbon dioxide in the atmosphere increases from the current 400ppm to $750 \mathrm{ppm}$ ). He lists the effects that might emerge strongly at $+3^{\circ}$ Celsius. Schelling (2007) discusses the climate sensitivity parameter (S), which defines the equilibrium surface warming from a doubling of the stock of $\mathrm{CO}_{2}$ emissions. He concludes that "for a quarter of a century, the range of uncertainty [about S] has been a factor of 3". Potential damages induced by the same warming scenario across different climate models are subject to even more uncertainty, as reviewed by Burke et al. (2015a).
} 
Section 2.1, we consider three long-term CLC scenarios referred to as:

- CLC-Minimalist: $+0.09^{\circ}$ Celsius in global average temperature and $+0 m$ in sea level over the 21st century. Most likely unattainable, this scenario serves as the non-CLC reference.

- $C L C$-Intermediate: $+2.09^{\circ}$ Celsius in global average temperature and $+1.1 \mathrm{~m}$ rise in sea level, which corresponds to the median scenario of the World Bank. In this scenario, these country- and region-specific shocks would affect the worldwide distribution of TFP and induce forced displacements due to the rising sea level.

- $C L C$-Maximalist: $+4.09^{\circ}$ Celsius in global average temperature and $+1.3 m$ in sea level. This scenario would induce larger productivity effects and more displacement due to the rising sea level.

In the second set of simulations (see Section 4.2), we account for additional mechanisms related to fast-onset climate shocks. We will consider the costs induced by natural disasters, the productivity and health costs due to high temperature and heat waves, and conflicts over resources. As these fast-onset shocks account for phenomena that are local, volatile, and generically hard to anticipate, they are more likely to induce severe income losses and additional mobility responses.

\subsection{Climate Scenarios}

As stated above, we consider CLC as exogenous in our model. We thus disregard the endogeneity of CLC, which involves uncertain links between economic activities and policies, $\mathrm{CO}_{2}$ emissions, and the resulting changes in temperature.

Projections of temperature. We follow three steps to construct our projections of global temperature distribution. In a first step, we collect raw data on monthly temperature levels and projections from the Climate Change Knowledge Portal (CCKP) of the World Bank Group. Our variable of interest is the near-surface monthly mean air temperature level. In Appendix A.1, we discuss how raw temperature levels are adjusted to account for within-country disparities in temperature and population density and how climate windows are linked to the time periods of our overlapping generations model. The left panel of Figure 1 illustrates the relationship between mean surface-temperature in 2010 (plotted on the horizontal axis) and latitude of the countries included in our sample (plotted on the vertical axis). Label sizes are proportional to the logarithm of working-age population in each of the 179 countries included in the model. Unsurprisingly, current temperature levels are negatively correlated with latitude. 

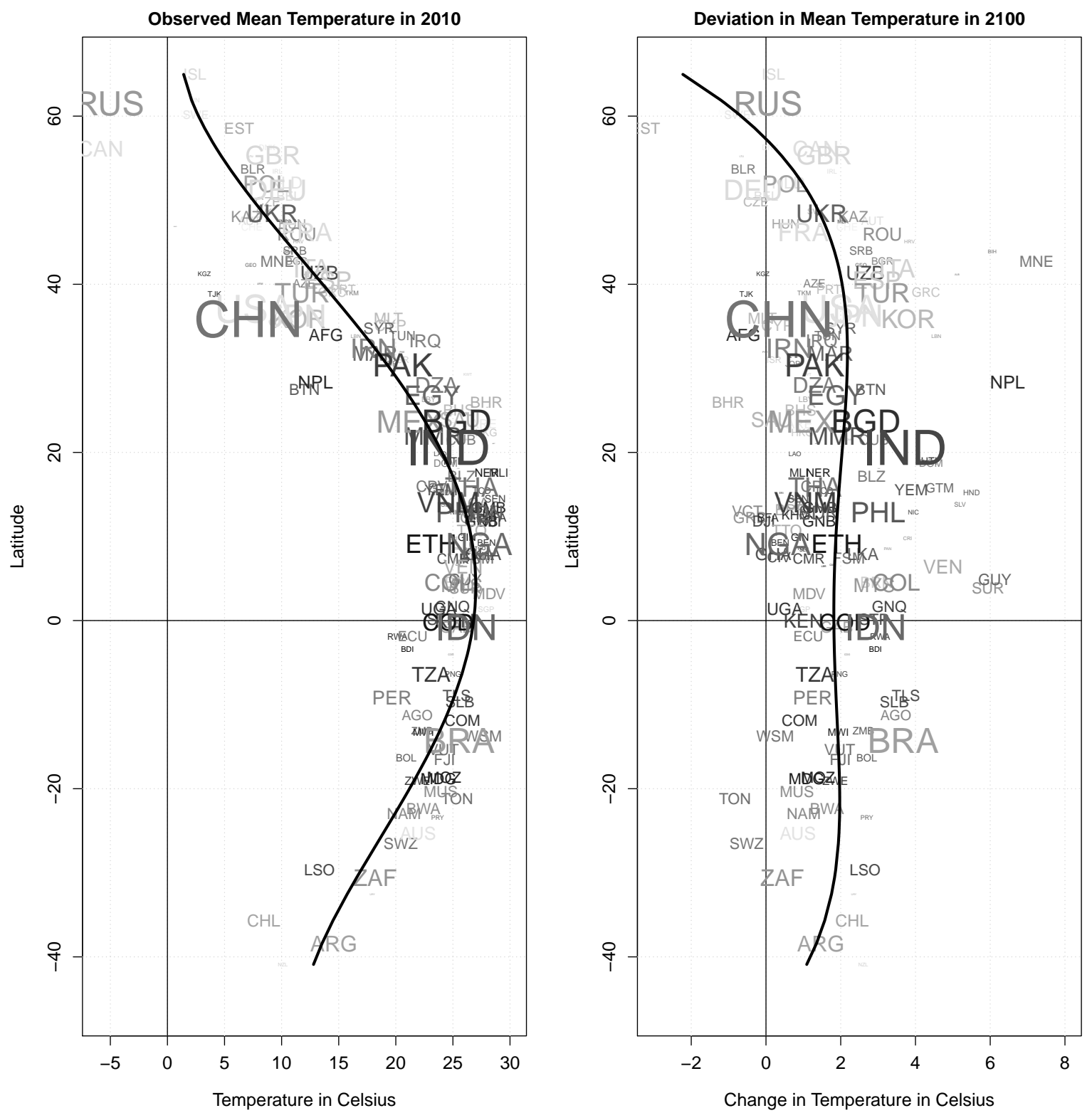

Notes: Latitude (geographic coordinate) is measured on the Y-axis, the size of country labels is proportional to the logarithm of population aged 25 to 64 in 2010, while the darkness of country labels is inversely proportional to GDP per capita in 2010. Solid black lines represent fitted polynomials of degree four.

Figure 1: Observed Temperatures and its Predicted Deviations between 2010 and 2100

As for temperature projections, they are organized in 20-year climatological windows for 2020 to 2039, 2040 to 2059, 2060 to 2079, and 2080 to 2099. The CCKP projections are obtained from the Coupled Model Intercomparison Project Phase 5 (CMIP5) distribution (Taylor et al., 2012), which distinguishes between several scenarios for the Representative Concentration Pathways (RCP) (Moss et al., 2010). The median-emission scenario is called RCP-4.5. In addition, for each RCP, the CCKP provides data for 16 models obtained from different research institutes. When these models are ranked in 
ascending order according to the yearly temperature anomaly for the 2080 to 2099 climatological window, the medium resolution model of the Institute Pierre Simon Laplace (the $i p s l_{-} c m 5 a \_m r$ variant) takes the 8th (median) position in RCP-4.5. We select this ipsl_cm5a_mr variant as our Intermediate scenario.

This Intermediate scenario predicts that the temperature levels will continue to increase gradually in virtually all countries and that the mean surface temperature of the world will increase by $2.09^{\circ}$ Celsius during the 21 st century. The right panel of Figure 1 plots the 2010 to 2100 deviations in the yearly average temperature by latitude for the 179 countries. For almost all countries, this difference takes a positive value between $0^{\circ}$ and $4^{\circ}$ Celsius. Overall, the correlation between latitude and the predicted temperature change is small, except in the highest latitude areas. Hence, most countries will experience an increase in temperature (an average of $+2.09^{\circ}$ Celsius) and all country types (small and large, rich and poor) will be affected with a similar intensity.

In the Minimalist scenario, we start from the Intermediate and uniformly decrease the temperature levels in 2100 by $2^{\circ}$ Celsius in all countries, which basically shifts the estimated curve in the right panel of Figure 1 by $2^{\circ}$ Celsius to the left. Hence, this scenario predicts that the mean surface temperature will increase by $0.09^{\circ}$ Celsius over the course of the 21st century, virtually implying the absence of global warming. The Minimalist scenario roughly corresponds to the most optimistic variant under RCP-2.6.

In contrast, the Maximalist scenario uniformly increases the temperature levels in 2100 by $2^{\circ}$ Celsius in all countries, which shifts the estimated curve by $2^{\circ}$ Celsius to the right. Hence, it predicts that the mean surface-temperature will increase by $4.09^{\circ}$ Celsius. The Maximalist scenario roughly corresponds to the median variant under RCP-8.5.

Sea level rise (SLR). The second impact of long-term CLC is the rise in the sea level. ${ }^{11}$ According to IPCC (2014), millions of individuals living at an altitude of less than one meter will be affected during the 21st century. Vermeer and Rahmstorf (2009) developed a methodology that links global SLR to global mean temperature on time scales of decades to centuries. They estimate the SLR for each global temperature scenario of IPCC (2014), which involves a global temperature change above $2^{\circ}$ Celsius. The estimated relationship between the sea level variation and the global change in the mean surface-temperature $(\Delta T)$ is concave if $S L R$ is forced to be equal to zero for $\Delta T=0$, and almost linear if $\operatorname{SLR}(0)$ is not specified. ${ }^{12}$

\footnotetext{
${ }^{11}$ This abstracts from ecological damage, loss of biodiversity and perturbation of habitats.

${ }^{12}$ Based on past data, SLR is very well predicted using a log-linear function: $S L R=0.89+0.3 \ln (\Delta T)$; the R-squared of this regression equals 0.985 . The shape of the function and the proxied observations are depicted in Figure A.1b in the Appendix. We use this function to predict future SLR, although there is no guarantee that the relationship will remain concave or linear in the future.
} 
In the Intermediate temperature scenario $\left(+2.09^{\circ}\right.$ Celsius $)$, this curve implies that the sea level is expected to rise by $1.1 \mathrm{~m}$ in 2100 . Given the gradual change in temperature in our baseline scenario, the sea level is predicted to rise by $0.78 \mathrm{~m}$ in 2040 and by $0.99 \mathrm{~m}$ in 2070. In another study, DeConto and Pollard (2016) model the impact of the Antarctic ice cap on overall SLR. In their reference estimation, they find changes that closely correspond to our projections: under the RCP-4.5 scenario, they predict a mean elevation of $1.05 \mathrm{~m}$ and a confidence interval of $\pm 0.30 \mathrm{~m}$, which is very similar to our Intermediate scenario.

In the Minimalist scenario, we assume a constant sea level which, coupled with the assumption of constant mean surface temperature, generates an overly optimistic scenario. It serves as our no-CLC point of reference. In the Maximalist scenario, the projected increase in average temperature by $4.09^{\circ}$ Celsius yields a $1.3 \mathrm{~m}$ SLR by $2100(0.97 \mathrm{~m}$ in 2040 and 1.18m in 2070), according to the methodology of Vermeer and Rahmstorf (2009).

Uncertainty about SLR is large because the dynamics of ocean heat uptake as well as the creation and decay of ice sheets and glaciers are poorly understood. Until recently, climate models have been unable to replicate the estimated sea level swings reconstructed from geological data during the Pliocene (about 100,000 years ago); at this time the concentration of $\mathrm{CO}_{2}$ was about the same as now, temperatures were $0^{\circ}$ to $2^{\circ}$ Celsius higher than today, and the sea level was 6 to $9 m$ higher. ${ }^{13}$ Rigaud et al. (2018) predict a sea level rise of $2 m$ for 2050 in their benchmark scenario. For the purpose of comparison, we also consider more extreme scenarios concerning SLR in Section 4.

\subsection{Channels of Transmission}

The "damage function" is central for estimating the economic implications of global temperature and sea level variations in our first-step projections. Two channels of transmission are systematically accounted for in our simulations. Firstly, we allow changes in temperature to affect the level of TFP in agricultural and in non-agricultural sectors. ${ }^{14}$ Secondly, SLR induces forced displacements of people. This leads to substantial costs as

\footnotetext{
${ }^{13}$ DeConto and Pollard (2016) have calibrated the sea level swings of the Pliocene, projecting an increase in the sea level above $1 m$ in 2100. They estimate that the Antarctica ice sheet cannot be saved even with extraordinary success in cutting emissions. This would lead to a locking of the sea level rise of more than $5 \mathrm{~m}$.

${ }^{14}$ In unreported results, we also account for the potential productivity losses due to the rising sea level. We use the NASA database and estimate of the fraction of land that could be flooded. Using population and land data, we compare the density of people in flood-risk areas and in the rest of the region and assume, in line with Desmet and Rossi-Hansberg (2015), that disparities in population density reflect disparities in total factor productivity. For each country, we produce region-specific estimates of the productivity loss caused by the sea level rise. These productivity losses are small (in countries with access to the sea, we obtained an average loss of $1.2 \%$ in urban regions and of $0.7 \%$ in rural regions), either because the share of population located in flooded areas is small, or because productivity differences are small. For this reason, this mechanism is not included in the model.
} 
flooded areas are usually the most densely populated parts of many region. ${ }^{15}$ In a second step, we consider additional channels of transmission related to fast-onset variables and to conflicts over resources.

Temperature and productivity. To model the effect of temperature, we follow DRH, who estimate an inverted-U-shaped relationship between temperature $(T)$ and total factor productivity in agricultural and manufacturing sectors. They include a quadratic scale factor $G_{r}(T)$ in the TFP of sector $r$ that depends on the level of temperature. It can be expressed as:

$$
G_{r}(T)=\max \left\{g_{0 r}+g_{1 r} T+g_{2 r} T^{2} ; 0\right\}
$$

where $\left(g_{0 r}, g_{1 r}, g_{2 r}\right)$ is a triplet of sector-specific parameters, and $r=(a, n)$ denotes agriculture $(a)$ and non-agriculture $(n)$. If $g_{1 r}>0$ and $g_{2 r}<0$, the ideal temperature in sector $r$ is given by $T_{r}^{*}=-g_{1 r} / 2 g_{2 r}$. The level of TFP increases with temperature in regions with average temperature below $T_{r}^{*}$; it decreases with temperature in warmer regions.

Agronomic studies have been used to calibrate the quadratic relationship between TFP and temperature in agriculture (Lobell and Burke, 2010; Mendelsohn et al., 1994). To account for the possibility of adapting to climate change by switching between crops, DRH estimate the envelope of the quadratic relationships obtained for different crops. This gives $\left(g_{0 a}, g_{1 a}, g_{2 a}\right)=(-2.24,0.308,-0.0073)$, which implies an optimal temperature $T_{a}^{*}$ of $21.1^{\circ}$ Celsius. It also imposes that agricultural yields are nil when temperature $T_{a}$ is below $9.4^{\circ}$ Celsius or greater than $32.9^{\circ}$ Celsius. The top panel of Figure 2 shows the relationship between temperature and agricultural productivity (in solid gray line), after fitting $G_{a}(T)$ with a Gaussian function to avoid negative productivity levels. The maximal productivity level is normalized to one.

To estimate the quadratic relationship in the non-agricultural sector, DRH use data on population density (a proxy for economic development) by latitude. They consider 1,000 bands of $9.6 \mathrm{~km}$ each, and estimate the relationship between (smoothed) levels of population density and temperature. They obtain $\left(g_{0 n}, g_{1 n}, g_{2 n}\right)=(0.3,0.08,-0.0023)$, which gives an optimal temperature $T_{n}^{*}$ of $17.4^{\circ}$ Celsius. The quadratic relationship is compatible with the findings of Dell et al. (2014), who show that industrial output decreases by $2 \%$ for a $1^{\circ}$ Celsius increase in temperature; it is also compatible with specialization and trade patterns by level of latitude. Although the curve is flatter than in agriculture, non-agricultural productivity is nil when temperature $T_{n}$ is below $-3^{\circ}$ Celsius or above $38^{\circ}$ Celsius. The dashed line in the top panel of Figure 2 shows the relationship

\footnotetext{
${ }^{15}$ On average, low elevation coastal zones (situated at an altitude of less than ten meters) account for $2.2 \%$ of dry land and contain $10.5 \%$ of the world population (see McGranahan et al., 2007).
} 

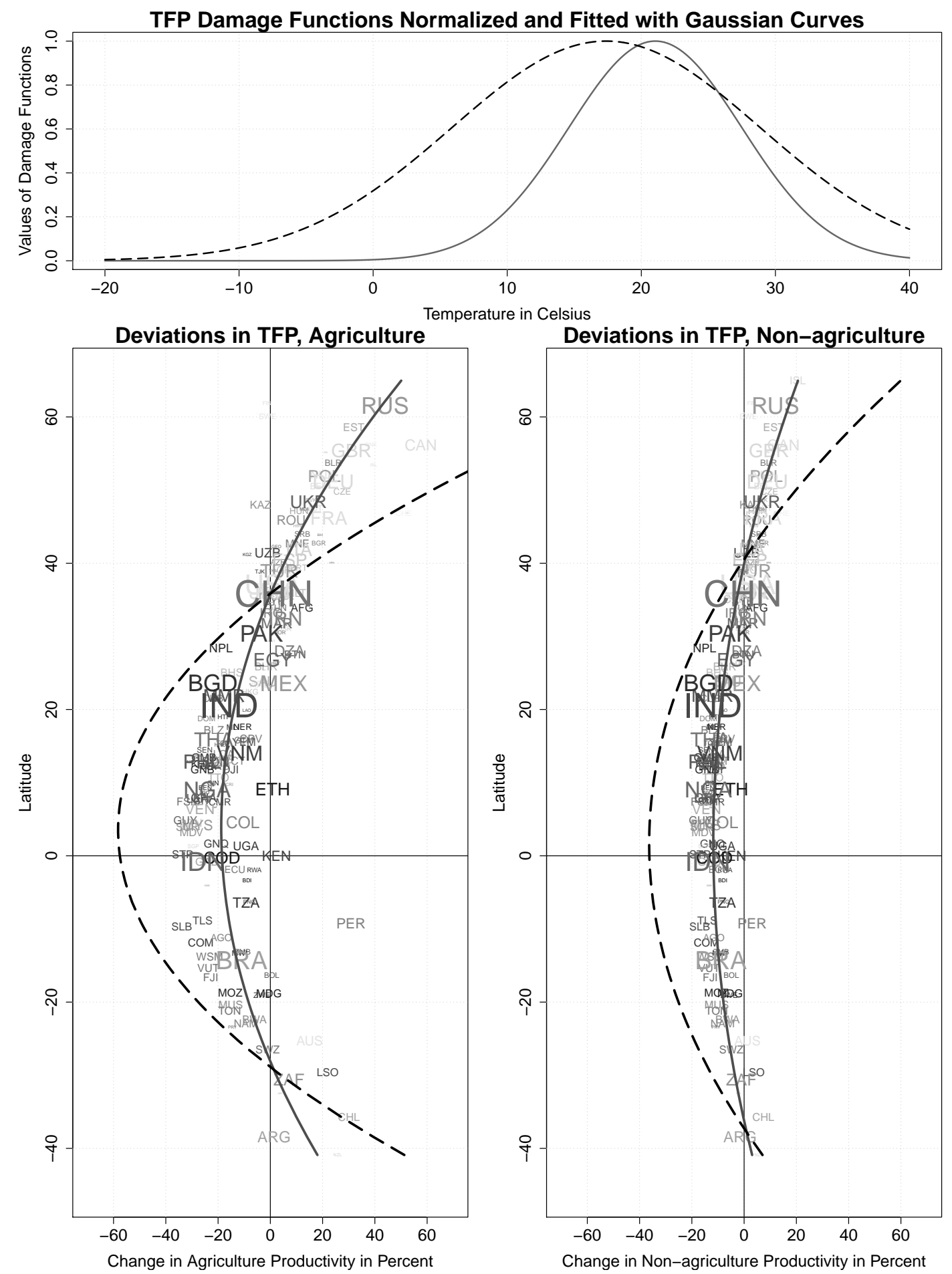

Notes: The top panel of Figure 2 plots normalized Gaussian curves that fit damage functions for agriculture (gray solid line) and non-agriculture (black dashed line) as a function of temperature (in Celsius degrees). In the bottom panels, latitude (geographic coordinate) is measured on the Y-axis, and sectorspecific productivity changes between 2010 and 2100 are measured on the X-axis (as \% of deviation from the 2010 level). The size of country labels is proportional to the logarithm of population aged 25 to 64 in 2010, while the darkness of country labels is inversely proportional to GDP per capita in 2010. Solid gray (dashed black) lines represent fitted quadratic trends for Intermediate (Maximalist) scenarios.

Figure 2: Damage Functions and Long-term Productivity Changes (2010-2100) 
between temperature and non-agricultural productivity, after smoothing $G_{n}(T)$ using a Gaussian function and normalizing the maximal productivity level at unity. For each country and period $t$, we plug in the monthly levels of temperature, $T_{m, t}$, in $G_{a}($.$) and$ $G_{n}($.$) , thereby accounting for the anticipated variability in temperature within a given$ year. We then compute the averages of these TFP levels for each period $t$ :

$$
G_{r, t}=\frac{1}{12} \sum_{m=1}^{12} G_{r}\left(T_{m, t}\right) .
$$

Recall from the right panel of Figure 1 that expected variations in temperature are weakly correlated with latitude. On the contrary, the current level of temperature is highly correlated with latitude (left panel of Figure 1): countries above the 35th parallel have average temperature levels under $20^{\circ}$ Celsius, while countries at lower latitude have a higher average temperature. Hence, the same variation in temperature will induce dramatically different effects on productivity. The bottom-left panel of Figure 2 depicts the predicted percentage variation in agricultural productivity by latitude caused by the change in temperature between 2010 and 2100. On average, in the Intermediate scenario (gray solid line), agricultural productivity decreases by $20 \%$ to $25 \%$ in countries close to the equator and increases by the same amount at high latitudes. The bottom right panel in Figure 2 shows the corresponding damage function in the non-agricultural sector. On average, non-agricultural productivity decreases by $10 \%$ to $15 \%$ in countries close to the equator, and increases slightly at high latitude levels. ${ }^{16}$ The bottom panel of Figure 2 also gives the predicted percentage variation in productivity implied by the Maximalist with respect to the Minimalist (the black dashed lines). In both sectors, the productivity responses are roughly twice as large as those induced by the Intermediate scenario.

SLR and forced displacements. To proxy the number of people affected by SLR, we need to determine the fraction of the population living in low-elevation coastal areas. We use the NASA database on the distribution of the population by elevation, by country, and by region type (urban versus rural). ${ }^{17}$ In OECD countries, we assume that sea walls or other solutions will be constructed to protect vulnerable populations from rising sea levels. On the contrary, SLR will induce forced displacements in non-OECD countries. For each non-OECD country, we produce region-specific estimates of the fraction of population living at an elevation under $1.1 \mathrm{~m}$ or under $1.3 \mathrm{~m}$ using a third order polynomial of the NASA data. Figure 3 focuses only on those countries in which the share of population

\footnotetext{
${ }^{16}$ Both graphs include the 3 -order polynomial trend, which gives an R-squared of 0.33 for the agricultural sector and 0.41 for the non-agricultural sector.

${ }^{17}$ We assume rural regions are totally specialized in agriculture and urban regions only produce nonagricultural goods.
} 
living in low-lying areas exceeds $4 \%$. Bars represent the percentage of the population by country living in low-lying areas in 2010. ${ }^{18}$ This includes about 60 million people aged 25 to 64 who were living at an elevation under $1.1 \mathrm{~m}$. NASA predicts this number will approach 80 million by 2040. In a few countries, the percentage of population living at an elevation below $1.1 \mathrm{~m}$ is larger than $10 \%$, with the largest share in the Maldives.

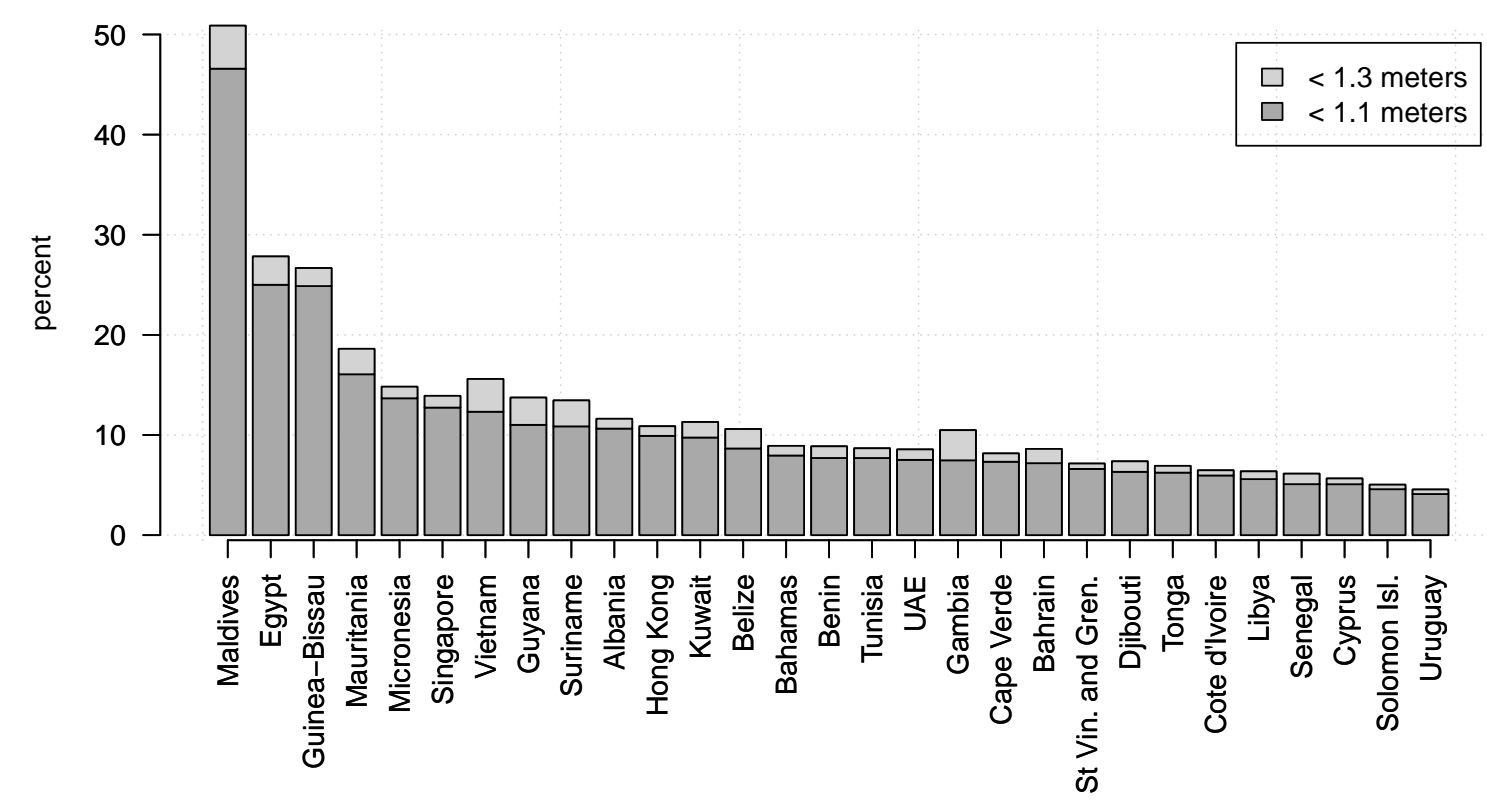

Notes: Dark (light) gray bars depict the share of population living below 1.1 (1.3) meters in non-OECD countries. Own calculations based on NASA data.

Figure 3: Forced Displacements due to SLR in non-OECD Countries

Overall, Figure 3 shows that the most affected countries are not necessarily the poorest ones. SLR mostly affects countries with a large share of population located along the coasts of all seas and oceans or in the major river deltas and estuaries. The relative exposure of some South and East Asian and West African countries is also significant. Some Pacific islands situated a few centimeters above sea level are extremely vulnerable. Clearly, both rich and poor countries are going to be adversely affected by the SLR. It would certainly be an exaggeration to assume that roughly 80 million flooded individuals will all migrate internationally in the near future. Some of them will certainly move to another region or country, but others will relocate within the same region or invest in building sea defences (in OECD countries). Our micro-founded model endogenizes forced displacements due to SLR in non-OECD countries only.

\footnotetext{
${ }^{18}$ Although the 2010 shares differ from the long-run (endogenous) population shares which will be impacted during the 21st century (i.e., in 2040, 2070 and 2100), they give an indication of the scale of forced displacements induced by SLR.
} 
Effects of fast-onset climate shocks. While CLC usually refers to long-term changes in mean temperature and sea level, climatologists also predict changes in the frequency of extreme weather shocks (droughts, floods, storms, heat waves, etc.). To account for these fast-onset shocks, we consider more pessimistic scenarios in which natural disasters and high temperatures induce additional income losses that can hardly be avoided through long-term adaptation strategies. The extensive and intensive margins (i.e., frequency and intensity) of these fast-onset weather shocks are highly uncertain. However, their frequencies are likely to be correlated with higher moments of the regional temperature distribution, including the weights of upper tails of these distributions, which are expected to deviate significantly in the future. Figure 4 compares the mean distribution of average daily temperatures of the world in 2010 and 2100; we compute it as the populationweighted average of country-specific distributions. It shows that changes in the mean surface temperature (represented by the vertical dashed lines) will be accompanied by a net increase in the fraction of days with temperatures above $20^{\circ}$ or $30^{\circ}$ Celsius (light and dark gray surfaces, respectively). These extreme temperature events tend to be important sources of economic costs at the local scale.

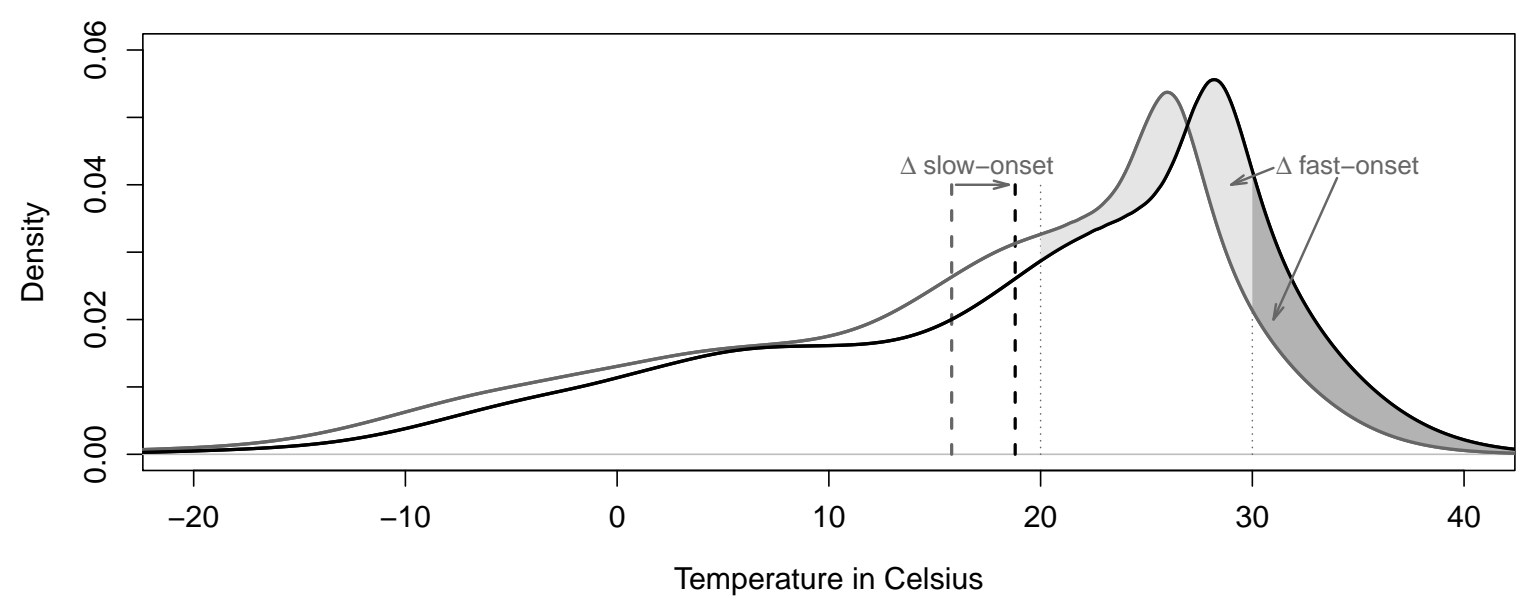

Notes: Figure 4 depicts the population-weighted global distribution of temperatures in 2010 (gray line) and in 2100 (black line) assuming the Intermediate temperature scenario. The dashed vertical lines represent global average temperatures.

Figure 4: Annual Distribution of World Temperatures in 2010 and 2100

We consider three additional sources of climate-driven costs and model them as a decrease in disposable income (which is equivalent to a tax on income). Firstly, we assume that weather-related natural disasters (i.e., floods, storms/hurricanes, and droughts) induce direct income losses. Using the EM-DAT database, which collects information on human and material losses generated by disasters over the last six decades, we regress the average shares of GDP lost due to extreme weather events on the annual mean level 
of temperature, controlling for a time trend. We use this estimation to predict future losses as a function of temperature forecasts. Secondly, we assume that heat waves induce a direct income loss due to increased health issues and medical expenditures. Using the data on monthly minimal, mean, and maximal temperatures in all countries, we construct three-parameter distributions of temperature by month and by country, and compute the frequency of heat waves with temperature above $30^{\circ}$ Celsius (represented by the dark gray area in Figure 4). Using data from the US, we quantify the cost of heat waves as a share of national income, and predict the income losses in all countries. Thirdly, we assume that high levels of temperature translate into TFP losses due to lower labor efficiency. With a three-parameter distribution of temperatures, we compute the shares of working days that have a temperature above $20^{\circ}$ Celsius (the net light gray area on Figure 4 ). We link labor productivity to high temperature levels using the coefficients estimated by Dell et al. (2014).

CLC and conflicts. In contexts of high political and social instability, CLC can also contribute to the onset and propagation of (violent) conflicts driven by the deterioration of governance capacities and the increase in inequality among groups (Gleditsch, 2012; Miguel et al., 2004). The relationship between CLC and conflict has been investigated in a number of studies, which have produced mixed results (Cattaneo et al., 2019). Using a hierarchical meta-analysis of 55 studies, Burke et al. (2015b) find that deviations from moderate temperatures and precipitation patterns systematically increase conflict risk (including interpersonal conflict, such as assault and murder, and intergroup conflict, such as riots and civil war). On average, one standard-deviation rise in temperature increases interpersonal conflict by $2.4 \%$ and intergroup conflict by $11.3 \%$. In turn, these conflicts lead to forced displacement.

Abel et al. (2019) examine the link between climate, conflict, and forced migration from 2006 to 2015. They find that climate shocks affect the likelihood of armed conflict and the outflows of asylum seekers. The effect of climate on conflict occurrence is particularly relevant for countries undergoing political transformation (i.e., Western Asia after the Arab Spring) or poverty crisis (i.e., war episodes in sub-Saharan Africa). Subject to a conflict, their point estimates suggest that existence of conflict increases the outflows of asylum seekers by 100 to $150 \%$. Similar findings were reported in Dao et al. (2018), who show that severe armed conflicts increase the dyadic stock of migrants twofold in the long-term. ${ }^{19}$

In our simulations, we model conflicts as changes in amenity differentials between origin and destination countries. We assume that conflicts decrease net international mi-

\footnotetext{
${ }^{19}$ It increases the dyadic stock of migrants by a factor of four in the medium-term.
} 
gration costs in seven Western Asian countries (Iraq, Jordan, Israel, Lebanon, West Bank, Syria, and Iran) and in ten countries with high levels of poverty (Burundi, Cameroon, Eritrea, Guinea, Mozambique, Nepal, Tanzania, East Timor, Togo, and Zimbabwe). In these 17 countries, the decrease in net emigration costs is such that their emigration stocks would increase twofold at current wage rates, as explained in Appendix C. This shock is identical across skill groups and regions.

\section{Behavioral and Market Responses}

We now explain how the damage functions defined in Section 2 translate into behavioral and price responses. To do so, we construct an overlapping generations model of the world economy that represents a set of countries and regions populated by agents, who live for two periods (childhood and adulthood). One period stands for the active life of one generation (30 years); we ignore the retirement period for simplicity.

Our framework is similar to Delogu et al. (2018) and Burzyński et al. (2019) but relies on different technological assumptions and accounts for more sources of heterogeneity between people. Our priority is to capture the high degree of heterogeneity in exposure to CLC and in migratory behavior across individuals. Given that education is a key determinant of migration decisions, we distinguish between two types of adults in each period, with $s \in\{h, l\}$ denoting college-educated workers $(h)$ and the less educated $(l)$. In addition, we distinguish two sectors/regions with heterogeneous productivity, with $r \in\{a, n\}$ denoting agriculture $(a)$ and non-agriculture $(n)$ in each country. Each region consists of two areas of time-varying size, with $b \in\{f, d\}$ denoting the flooded area $(f)$ and the non-flooded/dry area $(d)$. The model endogenizes the levels of productivity in both sectors/regions as a function of both the temperature and the average level of schooling of the resident workers. There is no economic activity and no one can live in the flooded area.

Adults are the only decision makers. They maximize their utility and decide where to live, how much to consume, and how much to invest in the quantity and quality of their children. As far as the location decision is concerned, each new adult decides whether to stay in the region where she grew up (if the area of birth does not get flooded), to move locally within the same region (if the area of birth gets flooded), to emigrate to the other region within the same country, or to emigrate abroad. This choice depends on economic disparities across regions and countries, on moving costs, and on the area type. Fertility and education decisions are governed by a warm-glow motive. Adults directly value the quality and quantity of children. It follows that the dynamic structure of the model is totally recursive. In this section, we describe our technological and preference 
assumptions, derive the profit and utility maximization conditions, and define the worldeconomy intertemporal equilibrium. We also summarize our parameterization strategy.

\subsection{Technology}

Production is feasible only in the non-flooded area of each region $r$. We assume that output is proportional to labor in efficiency units. ${ }^{20}$ Each country is characterized by a pair of constant elasticity of substitution (CES) production functions with two types of workers (as in Burzyński et al., 2019; Gollin et al., 2014; Vollrath, 2009). For simplicity, we assume that firms in both sectors produce the same good. Hence, contrary to DRH or Shayegh (2017), we disregard variations in the relative price of the agricultural good, and we normalize the price of the single good to unity. In theory, change in relative price can mitigate or reinforce the impact of CLC. DRH show that CLC has uncertain effects on the relative price because it induces a rise in agricultural productivity in the North and a decline in the South. ${ }^{21}$ In addition, Burzyński et al. (2019) show that responses to productivity and migration policy reforms are quantitatively similar when considering that agricultural and non-agricultural goods are identical or imperfect substitutes as in Boppart (2014). Compared to Burzyński et al. (2019), our model formalizes the link between CLC and the productivity gap between regions.

The output level in region $r$ at time $t$ is given by:

$$
Y_{r, t}=A_{r, t}\left(\frac{\eta_{r, t}}{1+\eta_{r, t}} \ell_{r, h, t}^{\frac{\sigma_{r}-1}{\sigma_{r}}}+\frac{1}{1+\eta_{r, t}} \ell_{r, l, t}^{\frac{\sigma_{r}-1}{\sigma_{r}}}\right)^{\frac{\sigma_{r}}{\sigma_{r}-1}} \quad \forall t, r
$$

where $A_{r, t}$ denotes the productivity scale factor in sector $r$ at time $t$ (referred to as TFP henceforth), $\eta_{r, t}$ is a sector-specific variable governing the relative productivity of collegeeducated workers at time $t$ (i.e., a skill bias in productivity), and $\sigma_{r}$ is the sector-specific elasticity of substitution between the two types of worker. The number of adult workers of type $s$ employed in region $r$ at time $t$ is denoted by $\ell_{r, s, t}$, which differs from the total

\footnotetext{
${ }^{20}$ Such a model without physical capital features a globalized economy with a common international interest rate. Assuming a first-stage, Cobb-Douglas production function with physical capital $(K)$ and composite labor $(Q), Y_{r}=\widehat{A}_{r}\left(K_{r} / Q_{r}\right)^{\alpha} Q_{r}$, and assuming that capital is internationally mobile with an exogenous international price of capital $(R),\left(K_{r} / Q_{r}\right)^{1-\alpha}=\left(\alpha \widehat{A}_{r} / R\right)$ would give $Y_{r}=A_{r} Q_{r}$ where $A_{r}=\widehat{A}_{r}^{1 /(1-\alpha)}\left(\alpha \widehat{A}_{r} / R\right)^{\alpha /(1-\alpha)}$ is a modified TFP level. This hypothesis is in line with Kennan (2013) or Klein and Ventura (2009) who assume that capital "chases" labor in efficiency units in the long-term. Our model abstracts from potential (endogenous) variations in the international price of capital and their impacts on income inequality.

${ }^{21}$ When we consider heterogeneous goods in a small open economy context, variations in the relative price of the agricultural good can mitigate or reinforce the urbanization process. It is mitigated if CLC decreases the share of agriculture in the world's total output (i.e., if the output loss in low-latitude countries exceeds the output gain in the North). In the benchmark scenario of DRH (Figure 4), changes in relative price are small. If the relative price of agricultural goods increases, the migration responsiveness predicted by our model can be considered an upper bound.
} 
population, $L_{r, s, t}$ (as explained below).

Wage rates are determined by the marginal productivity of labor and there is no involuntary unemployment. This yields:

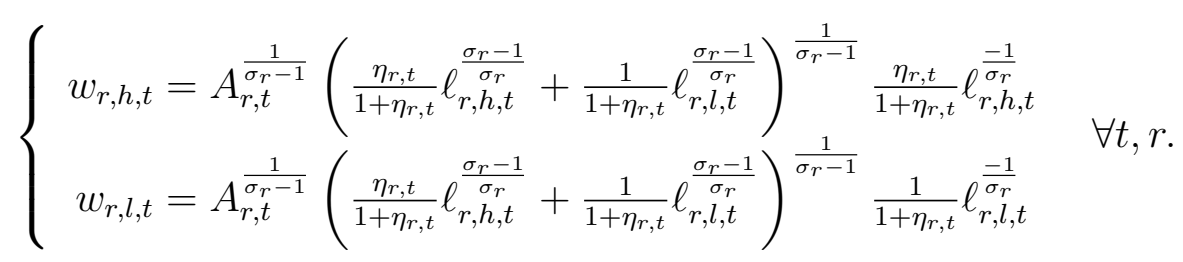

It follows that the wage ratio between high-skilled and low-skilled workers in region $r$ at time $t$ is given by:

$$
\varpi_{r, t} \equiv \frac{w_{r, h, t}}{w_{r, l, t}}=\eta_{r, t} z_{r, t}^{\frac{-1}{\sigma_{r}}} \quad \forall t, r
$$

where $z_{r, t} \equiv \ell_{r, h, t} / \ell_{r, l, t}$ is the skill ratio in employment in region $r$ at time $t$.

In this setting, CLC affects production and income differentials through two channels. Firstly, in line with Section 2.2, variations in temperature influence TFP in agriculture and in the non-agriculture sector. Secondly, CLC affects fertility, education, and mobility decisions, which in turn impact both the skill ratio in the labor force and technology. To account for these effects, damage functions and two types of technological externalities are factored in. For TFP, we assume that the aggregate TFP level in each sector depends on the temperature level and the average level of workers' education. We have:

$$
A_{r, t}=\gamma^{t} \bar{A}_{r} G\left(T_{r, t}\right) F\left(z_{r, t}\right) \quad \forall t, r
$$

where $\gamma^{t}$ is a time trend in productivity which is common to all countries $(\gamma>1), \bar{A}_{r}$ is the exogenous component of TFP in region $r$ (reflecting specific local factors such as the proportion of arable land, soil fertility, land ruggedness, etc.), $G\left(T_{r, t}\right)$ is the inverted-U-shaped function of temperature $\left(T_{r, t}\right)$ described in Section 2.2, while $F\left(z_{r, t}\right)$ is a simple Lucastype aggregate externality (see Lucas, 1988) capturing the fact that college-educated workers facilitate innovation and/or the adoption of advanced technologies. We assume $F\left(z_{r, t}\right)=z_{r, t}^{\epsilon_{r}}$ is a concave function of the skill ratio in employment, where $\epsilon_{r} \in(0,1)$ is the sector-specific elasticity of TFP to the skill ratio in sector $r$.

As far as the skill bias is concerned, we assume directed technical change that affects different types of workers non-uniformly. As technology improves, the relative productivity of college-educated workers increases, particularly in the non-agricultural sector (Acemoglu, 2002; Restuccia and Vandenbroucke, 2013). For example, Autor et al. (2003) show that computerization is associated with declining relative industry demand for routine manual and cognitive tasks, and increased relative demand for non-routine cognitive tasks. The observed relative demand shift favors college-educated versus non-college- 
educated labor. We write:

$$
\eta_{r, t}=\bar{\eta}_{r} z_{r, t}^{\kappa_{r}} \quad \forall t, r
$$

where $\bar{\eta}_{r}$ is an exogenous term and $\kappa_{r} \in(0,1)$ is the sector-specific elasticity of the skill bias to the skill ratio in sector $r$.

\section{$3.2 \quad$ Preferences}

The number of new native adults of type $s$ at time $t$ is denoted by $N_{r, s, t}$. Depending on the elevation structure of the region and on the sea level rise, part of the region may be flooded at the beginning of the period. If so, a fraction $\Theta_{r, t}$ of the native population is forced to leave. We label the number of forcibly displaced people as $N_{r, s, t}^{f}=\Theta_{r, t} N_{r, s, t}$, and the rest of the native population as $N_{r, s, t}^{d}=\left(1-\Theta_{r, t}\right) N_{r, s, t}$. Only the latter may decide not to move. New adults make consumption, fertility, education and migration decisions in early adult life. As illustrated in Figure 5, those who grew up in the non-flooded area of the region have the choice between staying in the region (at no cost), emigrating to another region $r^{\prime}$ within the same country (at a cost $x_{r r^{\prime}}$ ), or emigrating to an OECD country (at a cost $x_{r F}$ ). Individuals who grew up in the flooded area have the possibility of relocating within the same region (from flooded to non-flooded area). They lose their residential capital and incur a welfare loss that corresponds to a fraction $x_{r r}$ of their lifetime utility. They can also emigrate to another region or to another country at the same cost as those who grew up in the non-flooded area.

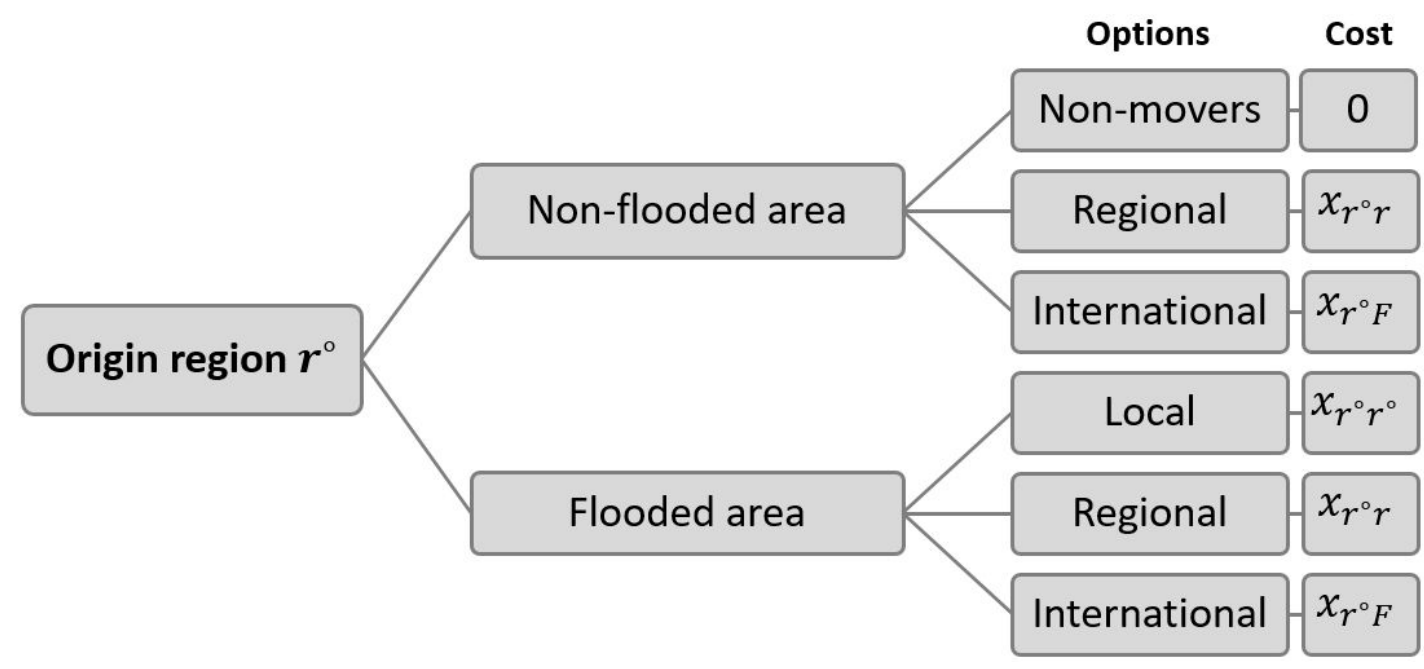

Figure 5: Migration Options and Associated Costs 


\subsubsection{Individuals Raised in Non-flooded Areas}

We first focus on people who grew up in the non-flooded area $(d)$ of their region of birth. Individual decisions to emigrate result from the comparison of discrete alternatives: staying in the region of birth, emigrating to either another region or a foreign country. To model these decisions, we use a logarithmic outer utility function with a deterministic and a random component. The utility of an adult of type $s$, born in the non-flooded part of region of origin $r^{\circ}$, moving to the non-flooded part of region/country $r$ is given by:

$$
U_{r^{\circ} r, s, t}^{d}=\ln v_{r, s, t}^{d}+\ln \left(1-x_{r^{\circ} r, s, t}^{d}\right)+\xi_{r^{\circ} r, s, t}^{d} \quad \forall s, t, r^{\circ}, r
$$

where $v_{r, s, t}^{d} \in \mathbb{R}$ is the deterministic level of utility that can be reached in the location $r$ at period $t$ (governed by the inner utility function described below) and $x_{r^{\circ} r, s, t}^{d} \leq 1$ captures the effort required to migrate from region $r^{\circ}$ to location $r$ (such that $x_{r^{\circ} r^{\circ}, s, t}^{d}=$ $0)$. Migration costs are exogenous; they vary across location pairs and education levels. The individual-specific random taste shock for moving from region $r^{\circ}$ to $r$ is denoted by $\xi_{r^{\circ} r, s, t}^{d} \in \mathbb{R}$ and follows an iid Type I Extreme Value distribution with a common scale parameter $\mu>0$. This scale parameter governs the responsiveness of migration decisions to changes in $v_{r, s, t}^{d}$ and $x_{r^{\circ} r, s, t}$. Although $\xi_{r^{\circ} r, s, t}^{d}$ is individual-specific, we omit individual subscripts for notational convenience.

In line with Galor and Weil (2000), Galor (2011), De La Croix and Doepke (2003, 2004), or Delogu et al. (2018), the inner utility $\ln v_{r, s, t}^{d}$ is a function of consumption $\left(c_{r, s, t}^{d}\right)$, fertility $\left(n_{r, s, t}^{d}\right)$, and the probability that each child becomes highly skilled $\left(p_{r, s, t}^{d}\right)$ :

$$
\ln v_{r, s, t}^{d}=\ln c_{r, s, t}^{d}+\theta \ln \left(n_{r, s, t}^{d} p_{r, s, t}^{d}\right) \quad \forall s, t, r,
$$

where $\theta \in(0,1)$ is a preference parameter for the quantity and quality of children.

The probability that a child becomes highly skilled increases with the share of time that is spent in education $\left(q_{r, s, t}^{d}\right)$ :

$$
p_{r, s, t}^{d}=\left(\pi_{r}+q_{r, s, t}^{d}\right)^{\lambda} \forall s, t, r
$$

where $\pi_{r}$ is an exogenous parameter that is region-specific and $\lambda$ governs the elasticity of knowledge acquisition to education investment.

A type-s adult in region $r$ receives a wage rate $w_{r, s, t}$ per unit of time worked. Raising a child requires a time cost $\phi$ (thereby reducing the labor market participation rate) and each unit of time spent by a child in education incurs a cost equal to $E_{r, t}$. The budget constraint writes as:

$$
c_{r, s, t}^{d}=w_{r, s, t}\left(1-\phi n_{r, s, t}^{d}\right)-n_{r, s, t}^{d} q_{r, s, t}^{d} E_{r, t}
$$


It follows that the labor supply of each type-s adult in region $r$ at time $t$ is given by:

$$
\ell_{r, s, t}^{d}=1-\phi n_{r, s, t}^{d}
$$

In the following sub-sections, we solve the optimization problem backwards. We first derive the optimal fertility rate and investment in education in a given location $r$ by individuals of type $s$ at time $t$, which determines the optimal level of utility, $v_{r, s, t}^{*}$. We then characterize the choice of the optimal location.

Education and fertility. Each adult in region $r$ maximizes her utility (7) subject to (8) and (9). Solving the system of two first-order conditions and the budget constraints yields the following interior solution:

$$
\left\{\begin{array}{l}
q_{r, s, t}^{*}=\frac{\lambda \phi w_{r, s, t}-\pi_{r} E_{r, t}}{(1-\lambda) E_{r, t}} \equiv q\left(w_{r, s, t}, E_{r, t}, \pi_{r}\right) \\
n_{r, s, t}^{*}=\frac{\theta(1-\lambda)}{1+\theta} \cdot \frac{w_{r, s, t}}{\phi w_{r, s, t}-\pi_{r} E_{r, t}} \equiv n\left(w_{r, s, t}, E_{r, t}, \pi_{r}\right) \\
c_{r, s, t}^{*}=w_{r, s, t}\left(1-\phi n_{r, s, t}^{*}\right)-n_{r, s, t}^{*} q_{r, s, t}^{*} E_{r, t} \equiv c\left(w_{r, s, t}, E_{r, t}, \pi_{r}\right)
\end{array} \quad \forall s, t, r\right.
$$

The deterministic indirect utility function can be obtained by substituting the firstorder conditions into (7). This yields:

$$
\ln v_{r, s, t}^{*}=\ln c_{r, s, t}^{*}+\theta \ln \left(n_{r, s, t}^{*}\right)+\theta \lambda \ln \left(\pi_{r}+q_{r, s, t}^{*}\right) .
$$

Migration. Given their taste characteristics (captured by $\xi$ ), each individual chooses the location that maximizes her utility, defined in Equation (6). Under the Type I Extreme Value distribution of $\xi$ with a scale parameter $\mu$, McFadden (1974) shows that the probability of choosing region $r$ originating from region $r^{\circ}$ is governed by a logit expression. Therefore, the emigration rate is given by:

$$
\frac{M_{r^{\circ} r, s, t}^{d}}{N_{r^{\circ}, s, t}^{d}}=\frac{\exp \left(\ln \left(v_{r, s, t}^{*}\left(1-x_{r^{\circ} r, s, t}^{d}\right)\right)^{1 / \mu}\right)}{\sum_{k} \exp \left(\ln \left(v_{k, s, t}^{*}\left(1-x_{r^{\circ} k, s, t}^{d}\right)\right)^{1 / \mu}\right)}=\frac{\left(v_{r, s, t}^{*}\right)^{1 / \mu}\left(1-x_{r^{\circ} r, s, t}^{d}\right)^{1 / \mu}}{\sum_{k}\left(v_{k, s, t}^{*}\right)^{1 / \mu}\left(1-x_{r^{\circ} k, s, t}^{d}\right)^{1 / \mu}} .
$$

Skill-specific emigration rates are endogenous and fall between 0 and 1. Individuals who grew up in region $n$ (resp. a) choose between staying in their region of origin $n$ (resp. a), moving to the other region $a$ (resp. $n$ ), or emigrating to a foreign country $F$. The emigration rates from $r^{\circ}$ to a particular destination $r$ depend on the utility levels attainable in all regions $k$ of the world. The choices of emigrating internally or internationally are thus interdependent.

Staying rates $\left(M_{r^{\circ} r^{\circ}, s, t}^{d} / N_{r^{\circ}, s, t}^{d}\right)$ are governed by the same logit model. It follows that 
the emigrant-to-stayer ratio $\left(m_{r^{\circ} r, s, t}\right)$ is governed by the following expression:

$$
m_{r^{\circ} r, s, t}^{d} \equiv \frac{M_{r^{\circ} r, s, t}^{d}}{M_{r^{\circ} r^{\circ}, s, t}^{d}}=\left(\frac{v_{r, s, t}^{*}}{v_{r^{\circ}, s, t}^{*}}\right)^{1 / \mu}\left(1-x_{r^{\circ} r, s, t}^{d}\right)^{1 / \mu} .
$$

Equation (13) is a gravity-like migration equation, which states that the ratio of emigrants from region $r^{\circ}$ to location $r$ to stayers in region $r^{\circ}$ (i.e., individuals born in $r^{\circ}$ who remain in $r^{\circ}$ ) is an increasing function of the utility in the destination location $r$ and a decreasing function of the utility in $r^{\circ}$. The proportion of migrants from $r^{\circ}$ to $r$ also decreases with the bilateral migration cost $x_{r^{\circ} r, s, t}$. Labor is not perfectly mobile across sectors/regions; internal migration costs $\left(x_{a n, s, t}\right.$ and $\left.x_{n a, s, t}\right)$ capture all private costs that migrants must incur to move between regions. In line with Young (2013), internal mobility is driven by self-selection (i.e., skill-specific disparities in utility across regions as well as heterogeneity in individual unobserved characteristics). Similarly, international migration costs $\left(x_{a F, s, t}\right.$ and $\left.x_{n F, s, t}\right)$ capture private costs and the legal/visa costs imposed by the destination countries. They are also assumed to be exogenous. Heterogeneity in migration tastes implies that emigrants select all destinations for which $x_{r^{\circ} r, s, t}<1$ (if $x_{r^{\circ} r, s, t}=1$, the corridor is empty).

\subsubsection{Forcibly Displaced People}

Individuals raised in the flooded area of region $r^{\circ}$ (denoted by the superscript $f$ ) are forced to move. If they relocate into the non-flooded area of their region of birth $r^{\circ}$, they face a local relocation cost equivalent to $x_{r^{\circ} r^{\circ}, s, t}^{f}>0$. If they move to another country or region, they face the same moving costs as individuals born in the non-flooded area (i.e., $x_{r^{\circ} r, s, t}^{f}=x_{r^{\circ} r, s, t}^{d} \forall r \neq r^{\circ}$ ). The local relocation cost is modeled as an effort to move within one's region of birth; consequently it does not affect workers' budget constraints or their optimal consumption, fertility, and education decisions. Hence, from Equations (11) and (12) we have $q_{r, s, t}^{f}=q_{r, s, t}^{d}=q_{r, s, t}^{*}, n_{r, s, t}^{f}=n_{r, s, t}^{d}=n_{r, s, t}^{*}, c_{r, s, t}^{f}=c_{r, s, t}^{d}=c_{r, s, t}^{*}$ and $v_{r, s, t}^{f}=v_{r, s, t}^{d}=v_{r, s, t}^{*}$. However, the local relocation cost influences decisions to emigrate to another region or country. The emigrant-to-stayer ratio $\left(m_{r^{*} r, s, t}^{f}\right)$ for forcibly displaced people is governed by:

$$
m_{r^{\circ} r, s, t}^{f} \equiv \frac{M_{r^{\circ} r, s, t}^{f}}{M_{r^{\circ} r^{\circ}, s, t}^{f}}=\left(\frac{v_{r, s, t}^{*}}{v_{r^{\circ}, s, t}^{*}}\right)^{1 / \mu}\left(\frac{1-x_{r^{\circ} r, s, t}^{f}}{1-x_{r^{\circ} r^{\circ}, s, t}^{f}}\right)^{1 / \mu}
$$

Since $x_{r^{\circ} r^{\circ}, s, t}^{f}>0, m_{r^{\circ} r, s, t}^{f}>m_{r^{\circ} r, s, t}^{d}$, forcibly displaced people tend to migrate more than those who grew up in non-flooded regions. 


\subsection{Dynamics and Inter-temporal Equilibrium}

We can characterize the equilibrium structure of the resident population in the non-flooded area of the region $\forall s, t, r:{ }^{22}$

$$
\left\{\begin{array}{l}
L_{n, s, t}=\frac{N_{n, s, t}^{d}}{1+m_{n a, s, t}^{d}+m_{n F, s, t}^{d}}+\frac{N_{n, s, t}^{f}}{1+m_{n a, s, t}^{f}+m_{n F, s, t}^{f}}+\frac{m_{a n, s, t} N_{a, s, t}^{d}}{1+m_{a n, s, t}^{d}+m_{a F, s, t}^{d}}+\frac{m_{a n, s, t}^{f} N_{a, s, t}^{f}}{1+m_{a n, s, t}^{f}+m_{a F, s, t}^{f}} \\
L_{a, s, t}=\frac{N_{a, s, t}^{d}}{1+m_{a n, s, t}^{d}+m_{a F, s, t}^{d}}+\frac{N_{a, s, t}^{f}}{1+m_{a n, s, t}^{f}+m_{a F, s, t}^{f}}+\frac{m_{n a, s, t} N_{n, s, t}^{d}}{1+m_{n a, s, t}^{d}+m_{n F, s, t}^{d}}+\frac{m_{n a, s, t}^{f} N_{n, s, t}^{f}}{1+m_{n a, s, t}^{f}+m_{n F, s, t}^{f}}
\end{array}\right.
$$

The total labor supply is given by:

$$
\left\{\begin{array}{l}
\ell_{n, s, t}=\frac{N_{n, s, t}^{d} \ell_{n, s, t}^{d}}{1+m_{n a, s, t}^{d}+m_{n F, s, t}^{d}}+\frac{N_{n, s, t}^{f} \ell_{n, s, t}^{f}}{1+m_{n a, s, t}^{f}+m_{n F, s, t}^{f}}+\frac{m_{a n, s, t} N_{a, s, t}^{d} \ell_{n, s, t}^{d}}{1+m_{a n, s, t}^{d}+m_{a, s, t}^{d}}+\frac{m_{a n, s, t}^{f} N_{a, s, t}^{f} d_{n, s, t}^{d}}{1+m_{a n, s, t}^{f}+m_{a F, s}^{f}} \\
\ell_{a, s, t}=\frac{N_{d, s, t}^{d} \ell_{a, s, t}^{d}}{1+m_{a n, s, t}^{d}+m_{a F, s, t}^{d}}+\frac{N_{a, s, t}^{f} \ell_{a, s, t}^{f}}{1+m_{a n, s, t}^{f}+m_{a F, s, t}^{f}}+\frac{m_{n a, s, t} N_{n, s, t}^{d} \ell_{a, s, t}^{d}}{1+m_{n a, s, t}^{d}+m_{n F, s, t}^{d}}+\frac{m_{n a, s, t}^{f} N_{n, s, t}^{f} \ell_{a, s, t}^{d}}{1+m_{n a, s, t}^{f}+m_{n F, s, t}^{f}}
\end{array} .\right.
$$

Together with the number and the structure of the resident population at time $t$, fertility and education decisions $\left(n_{r, s, t}^{b}, q_{r, s, t}^{b} \forall r, b, s\right)$ determine the size and structure of the native population before migration $\left(N_{r, s, t+1} \forall r, s\right)$ at time $t+1$. For all $t, r$, we have:

$$
\left\{\begin{array}{l}
N_{n, h, t+1}= \\
\sum_{s}\left[\frac{N_{n, s, t}^{d} n_{n, s, t}^{d} p_{n, h, t}^{d}}{1+m_{n a, s, t}^{d}+m_{n F, s, t}^{d}}+\frac{N_{n, s, t}^{f} n_{n, s, t}^{f} p_{n, h, t}^{f}}{1+m_{n a, s, t}^{f}+m_{n F, s, t}^{f}}+\frac{m_{a n, s, t} N_{a, s, t}^{d} n_{n, s, t}^{d} p_{n, h, t}^{d}}{1+m_{a n, s, t}^{d}+m_{a F, s, t}^{d}}+\frac{m_{a n, s, t}^{f} N_{a, s, t}^{f} n_{n, s, t}^{d} p_{n, h, t}^{d}}{1+m_{a n, s, t}^{f}+m_{a F, s, t}^{f}}\right] \\
N_{a, h, t+1}= \\
\sum_{s}\left[\frac{N_{a, s, t}^{d} n_{a, s, t}^{d} p_{a, h, t}^{d}}{1+m_{a n, s, t}^{d}+m_{a F, s, t}^{d}}+\frac{N_{a, s, t}^{f} n_{a, s, t}^{f} p_{a, h, t}^{f}}{1+m_{a n, s, t}^{f}+m_{a F, s, t}^{f}}+\frac{m_{n a, s, t} N_{n, s, t}^{d} n_{a, s, t}^{d} d_{a, h, t}^{d}}{1+m_{n a, s, t}^{d}+m_{n F, s, t}^{d}}+\frac{m_{n a, s, t}^{f} N_{n, s, t}^{f} n_{a, s, t}^{d} p_{a, h, t}^{d}}{1+m_{n a, s, t}^{f}+m_{n F, s, t}^{f}}\right]
\end{array}\right.
$$

Similar expressions characterize the evolution of the low-skilled population, except that $p_{r, s, t}^{b}$ must be replaced by $\left(1-p_{r, s, t}^{b}\right)$ on the numerator of each term.

Finally, the cost of education is assumed to be proportional to the high-skilled wage in the region, multiplied by a fixed, region-specific factor $\psi_{r, t}$ (capturing education policy/quality, population density, average distance to schools, etc.):

$$
E_{r, t}=\psi_{r, t} w_{r, h, t} \quad \forall r, s
$$

An inter-temporal equilibrium for the world economy can be defined as following:

Definition 1 For a set $\{\gamma, \theta, \lambda, \phi, \mu\}$ of common parameters, a set $\left\{\sigma_{r}, \epsilon_{r}, \kappa_{r}\right\}$ of sectorspecific elasticities, a set $\left\{\bar{A}_{r, t}, \bar{\Gamma}_{r, t}^{\eta}, x_{r^{\circ} r, s, t}, \psi_{r}, \pi_{r}\right\}$ of country- and region-specific exogenous characteristics, and a set $\left\{N_{r, s, 0}\right\}$ of predetermined variables, an intertemporal equi-

\footnotetext{
${ }^{22}$ In the OECD member states, these variables should be supplemented by the the inflow of immigrants, $I_{r, s, t}$. For simplicity, we assume that the distribution of immigrants by destination is time-invariant, calibrated on 2010. Equation (13) also determines the outflow of international migrants by education level.
} 
librium is a set $\left\{A_{r, t}, \eta_{r, h, t}, w_{r, s, t}, n_{r, s, t}, q_{r, s, t}, v_{r, s, t}, E_{r, t}, m_{r^{\circ} r, s, t}, N_{r, s, t+1}, L_{r, s, t}, \ell_{r, s, t}\right\}$ of endogenous variables, which simultaneously satisfies technological constraints (4), (5), and (17), profit maximization conditions (2), utility maximization conditions (11), (12) and (13) in all countries and regions of the world, and such that the equilibrium structure and dynamics of population satisfy (14), (15) and (16).

The equilibrium level of the other variables described above (in particular, $\Gamma_{r, t}^{\ell}, \Gamma_{r, t}^{\eta}$, $\Gamma_{r, t}^{w}$, as well as urbanization rates and international migration outflows and inflows) can be computed as a by-product of the reduced set of endogenous variables. Note that equilibrium wage rates are obtained by substituting the labor force variables into the wage equation (2), thereby assuming full employment. By the Walras law, the market for goods is cleared.

\subsection{Parameterization}

We summarize our parameterization strategy for 145 developing countries and for the entire set of 34 OECD countries. ${ }^{23}$ More details can be found in the Appendix (Section A). In particular, Table A.1 summarizes the calibration outcomes. Our strategy is such that our intermediate CLC scenario matches socio-demographic and economic data for 1980 and 2010, as well as reasonable socio-demographic prospects for 2040.

Economic data sources. We collect data on socio-demographic and economic characteristics of 179 countries in 1980 and 2010. We use data on Gross Domestic Product (GDP) from the United States Department of Agriculture (USDA) and the agriculture share in value added from the Food and Agriculture Organization of the UN (FAOSTAT). As for the structure of the resident labor force by education level and by sector, we use the estimates described in Burzyński et al. (2019). Data on wages by education level are obtained from Biavaschi et al. (2019) for the non-agricultural sector and from the Gallup World Polls for the agricultural sector. We model international migration to OECD countries only. From the Database on Immigrants in OECD and non-OECD countries (DIOC), we extract the number of emigrants by education level for 2010. Within each country, we split the number of emigrants to OECD by region of origin and education level, assuming that the structure of migration aspirations (obtained from the Gallup World Polls) is identical to the structure of actual emigration stocks. To proxy the average fertility rate, we divide the total native population of adults in 2010 by the resident population of adults in 1980, both taken from the UN Population Division. We use the Gallup World

\footnotetext{
${ }^{23}$ With the exceptions of Macao, North-Korea, Somalia, and Taiwan, all countries that are not covered by our sample have less than 100,000 inhabitants.
} 
Polls and extract the average number of children per household in urban and rural regions by skill level for 2010 .

Technological parameters. For each region, we collect the data on cross-country income gaps between college graduates and the less educated. We calibrate the elasticity of substitution between college graduates and less educated workers, relying on existing studies: For the non-agricultural sector we follow Ottaviano and Peri (2012), who suggest setting the elasticity close to 2, whereas for the agricultural sector, it is usually assumed that the substitution is perfect (e.g. Lucas, 2009; Vollrath, 2009). We then calibrate the skill-bias term, $\eta_{r, t}$, so as to match the observed income ratio between skill groups. Magnitudes of technological externalities are calibrated using constructed data on labor supply, region-specific incomes, and wage gaps.

Preference parameters. The literature indicates some common values of several preference parameters. We assign the following values to the parameters that are timeinvariant and equal for all countries: $\theta=0.25, \lambda=0.5, \phi=0.14, \mu=1.4 .^{24}$

The education cost parameters $\pi_{r}$ and $\psi_{r, t}$ affect people's fertility and education decisions. We calibrate them to match the population dynamics between 1980 and 2010, i.e., the transition from the resident population in 1980 and the native population in 2010 . We obtain international and internal migration costs from Equation (13). For the latter, we assume positive migration from rural to urban regions (i.e., $x_{a n, s, t}<1$ and $x_{n a, s, t}=1$ ). Using a similar parameterization strategy, Burzyński et al. (2019) predict variations in the dyadic stocks of migrants between 1950 and 1980 and obtain a close fit to the observed values.

Projection parameters. Our set of parameters enables the model to match the geographic disparities in income, population, and human capital in 2010 and their evolution between 1980 and 2010. The philosophy of our baseline projection exercise is to predict future trends in income, population, and human capital if all parameters remain constant, with the exception of the parameters governing access to education. More precisely, we constrain our baseline trajectory to be compatible with medium-term official demographic projections, as reflected by the UN projections of the national adult population and the proportion of college graduates for 2040. Within the model, we allow the region-specific cost of education, $\psi_{r, t}$ to change between 2010 and 2040. We calibrate its variations so

\footnotetext{
${ }^{24}$ Given the expression in (9), this assumption reflects setting the bound of the maximal number of children equal to 7 (i.e., 14 children per couple). See Docquier et al. (2017) for a brief review of studies using similar parameter values. Consult Bertoli and Fernández-Huertas Moraga (2013), who find a value between 0.6 and 0.7 for the migration elasticity $1 / \mu$.
} 
as to minimize the sum of squared differences in population and human capital stock between our baseline simulations and the UN projections for 2040. Using our two data points, we empirically identify a process of quadratic convergence in $\psi_{r, t}$. For subsequent years, our baseline scenario assumes a continuation of this convergence process, in line with the new Sustainable Development Agenda of the United Nations. Under this assumption, Burzyński et al. (2019) show that the model simulations fit the official sociodemographic projections very well. The success of such a stylized model in generating realistic projections of population, human capital, and urbanization proves our concept of modeling.

\section{Results}

In Section 4.1, we focus on slow-onset mechanisms (i.e., changes in productivity due to rising temperature and forced displacements due to SLR) and analyze their economic, demographic, and mobility implications. Then, Section 4.2 starts from the Intermediate scenario and supplements it with fast-onset mechanisms and conflicts over resources.

\subsection{Slow-onset Mechanisms}

We first consider the three scenarios (Intermediate, Minimalist, and Maximalist) defined in Section 2.1 and discuss the worldwide effects of CLC on income per capita, income inequality, the size and structure of population, human capital, urbanization, and international migration. Then, we highlight the cross-country heterogeneity in the effect of CLC before quantifying internal and international migration responses.

Aggregate effects. The average effects on the world economy and by region are depicted in Table 1. The bottom lines of this table give the worldwide responses, computed as the weighted averages of the positive and negative effects observed in high-income and developing countries. The values in bold characters are the projections obtained in the Minimalist scenario, maintaining constant temperature and sea levels. The values below are the variations induced by the Intermediate and Maximalist scenarios, expressed as percentages of deviation from the Minimalist scenario (for GDP and population) or as percentage points of variation (for the share of college graduates, the urban share, or the international emigration rate).

In the Intermediate scenario, we find that CLC increases the worldwide levels of income as well as income per worker, but makes the world distribution of income less equal. World GDP increases by $2.8 \%$ in 2100 and population decreases by $0.4 \%$. However, total GDP 
and GDP per worker decrease in non-OECD regions. The largest losses are observed in sub-Saharan Africa and Latin America, where income per worker decreases by $10.3 \%$ and 7.9\%, respectively. East Asian countries and Pacific islands also incur severe losses. The effects are roughly twice as large in the Maximalist scenario.

These results are due to multiple factors. Firstly, higher temperature levels induce positive changes in TFP at high levels of latitude (where income per worker is initially higher) and negative changes in TFP close to the equator (where income per worker is initially lower). Secondly, in developing countries, CLC reallocates people from lowerproductivity rural regions to higher-productivity urban regions. Thirdly, CLC reallocates people from poorer countries to richer countries.

Given existing disparities in education access, urbanization and international migration tend to reduce population growth and stimulate human capital acquisition. This suggests that CLC could have a detrimental impact on the welfare of the first generation affected, while enhancing future living standards. ${ }^{25}$ However, our simulations do not support such an intergenerational trade-off. Overall, the effects of CLC on the size of the world population and on the share of college graduates are small. Compared to the Minimalist scenario, the global effects are virtually nil in 2040. We identify population movements from non-OECD to OECD countries, but predict no effect on the world population. By the end of the century, the world population size would only decrease by $0.4 \%$ in the Intermediate scenario and $0.9 \%$ in the Maximalist scenario. An increase in population is observed in OECD countries only, due to increased immigration. As for the share of college-educated workers, it increases by 0.15 percentage points in the Intermediate scenario and 0.38 percentage points in the Maximalist scenario (i.e., 1/130 and 1/50 of the Minimalist level, respectively). In most non-OECD regions, CLC reduces the level of human capital, while brain drain offsets the positive effects of urbanization on access to education.

In OECD countries, human capital decreases as well; new immigrants from the South are less educated than native citizens. Hence, CLC slightly increases the worldwide average proportion of college graduates but, due to skill selection in climate migration, the level of human capital decreases in virtually all of the world's regions. This is because climate migrants are more educated than those left behind but less educated than host-country natives.

\footnotetext{
${ }^{25}$ This is suggested by Young (2005) in the case of the AIDS epidemic in South Africa.
} 


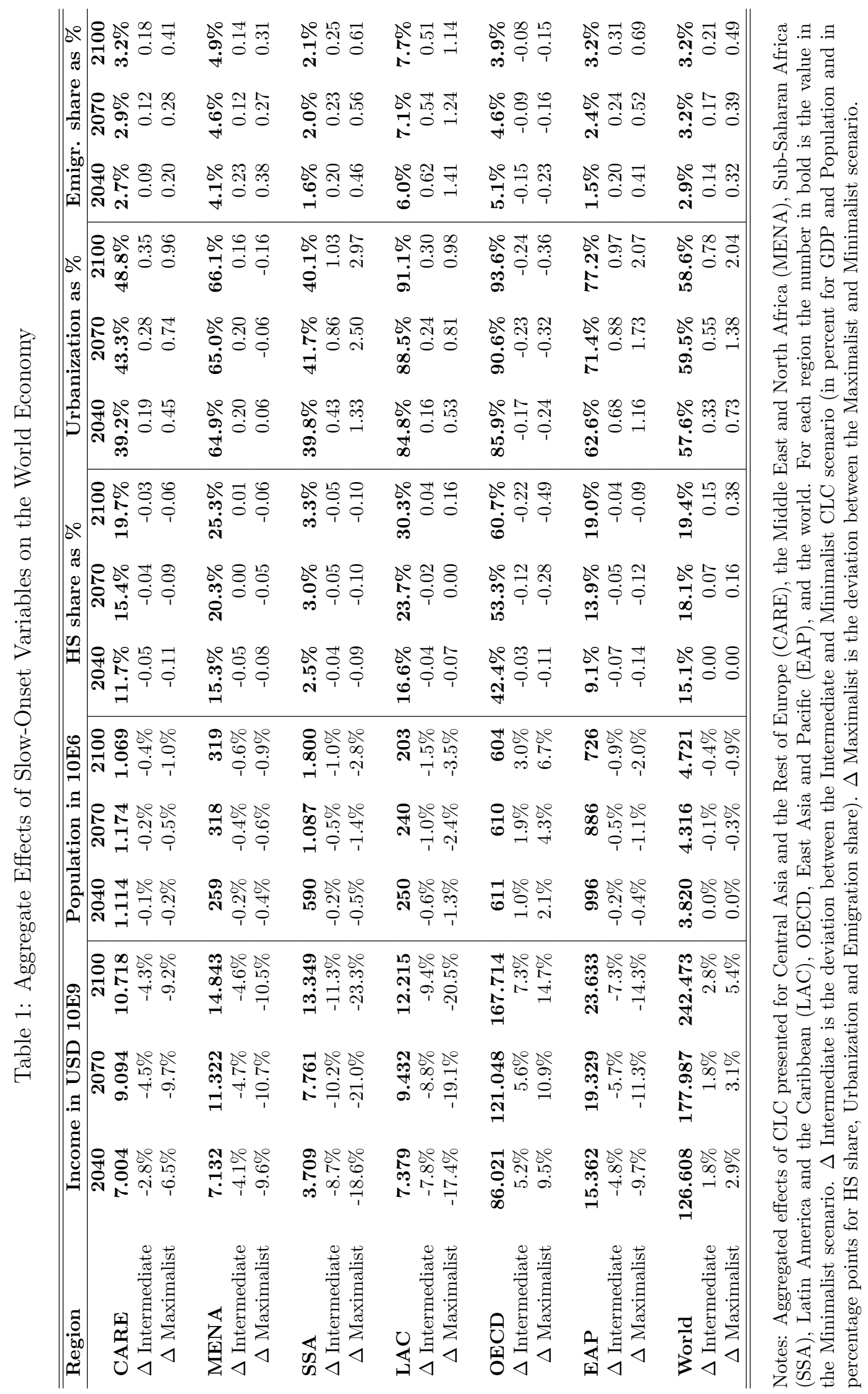


Consistently, the effects of CLC on interregional and international mobility are limited. Compared to the Minimalist scenario, the Intermediate scenario in 2040 yields an increase in world urbanization rate by 0.33 percentage points and an increase in the world proportion of international migrants by 0.14 percentage points. Hence, under a constant structure of migration costs, we estimate that interregional mobility responses exceed the international ones by factor of 2.4. By 2100, the effects are greater: the world urban share will have increased by 0.78 percentage points (i.e., $1 / 75$ of the Minimalist level) and the world proportion of international migrants will have increased by 0.21 percent (i.e., $1 / 15$ of the Minimalist level). The mobility responses are estimated to be roughly 2.5 times larger in the Maximalist scenario.

Country-specific effects. The country-specific effects of CLC are depicted in Figure 6. We report the relative differences in 2100 between the Intermediate and the Minimalist scenarios with country labels. As before, the label font size is proportional to the log of population of the country and the font darkness decreases with the level of GDP per worker (i.e., poor countries are labeled in dark characters). The third-degree polynomial trends in solid gray lines represent the difference between the Intermediate and Minimalist scenarios. Conversely, the polynomial trends in dashed black lines represent the difference between the Maximalist and Minimalist scenarios.

Focusing on the Intermediate scenario, Figure 6 shows that CLC will reduce income per worker by $15 \%$ relative to non-CLC (i.e., relative to the Minimalist scenario) in countries close to the equator, and will increase it by $10 \%$ at high levels of latitude. Hence, the income gap between the richest and poorest countries will increase by $25 \%$ over the course of the 21st century. Given the assumed timing of CLC, unreported results reveal that most of the effect will occur in the first half of the century.

In developing countries, the negative effect on income results from four mechanisms (in line with the aggregate effects discussed above). The first is the fall in TFP in both sectors documented in Figure 2: at the equator, TFP decreases by $25 \%$ in agriculture and by $15 \%$ in non-agriculture. The second effect is the rise in urbanization illustrated in the second graph of Figure 6, which attenuates the TFP shocks because the average level of labor productivity is greater in non-agriculture than in agriculture. The third effect is the rise in emigration (see the third panel of Figure 6). Fourthly, urbanization and international migration affect human capital accumulation. Although urbanization increases access to education in poor countries, rising international emigration reduces human capital accumulation in developing countries. The reason is that high-skilled people face smaller migration costs, which implies that migration is skill biased. In poor countries, college graduates migrate 20 times more than the less educated. CLC reduces 
the intensity of positive selection by only $10 \%$, as shown in the fifth panel of Figure 6 . Hence, the positive effect of CLC on emigration rates tends to reduce the share of college graduates in the origin country. For the sake of comparability, the effect of CLC on the skill bias in internal migration is similar to that of long-haul migration, as illustrated in the last panel of Figure 6. Combining these effects, the share of college graduates decreases slightly in developing countries, as illustrated in the fourth panel of Figure 6.

The effects are more pronounced in the Maximalist scenario (the dashed black line on Figure 6). In countries close to the equator, the impacts of CLC on income and human capital are twice as large, while urbanization and emigration responses are 2.5 times greater. Table B.2 in Appendix B reports the effect of CLC on the country-wide level of income per worker for the 20 most adversely affected countries in 2100. Countries close to the equator experience a long-run decrease in income per worker, which varies between $14 \%$ and $22 \%$ when the temperature increases by $2^{\circ} \mathrm{C}$. The most affected countries include several African, South American, Asian, and Pacific countries.

Income distribution and extreme poverty. The income loss is even greater for the poorest workers trapped in the poorest regions (i.e., rural regions). Extreme poverty is usually measured as the percentage of population living with less than $\$ 1.90$ per day in PPP value. Nevertheless, in our secular context with a constant rate of productivity growth and two skill groups only, we need to use a relative poverty line. We measure extreme poverty as the percentage of adults below $2 \%$ of the worldwide average level of income per worker.

Figure 7 compares the world distribution of income in 2100 across CLC scenarios. The income level of all types of worker is expressed as percentage of the world average. The relative poverty line is represented by the vertical gray line. Figure 7 clearly indicates that CLC adversely impacts extreme poverty. In the Minimalist scenario, we identify about 600 million individuals, who would be in extreme poverty by 2100 (about $12.8 \%$ of the world population). This is greater than the level observed in 2010 because of the differential in population growth between poor and rich countries/regions. 

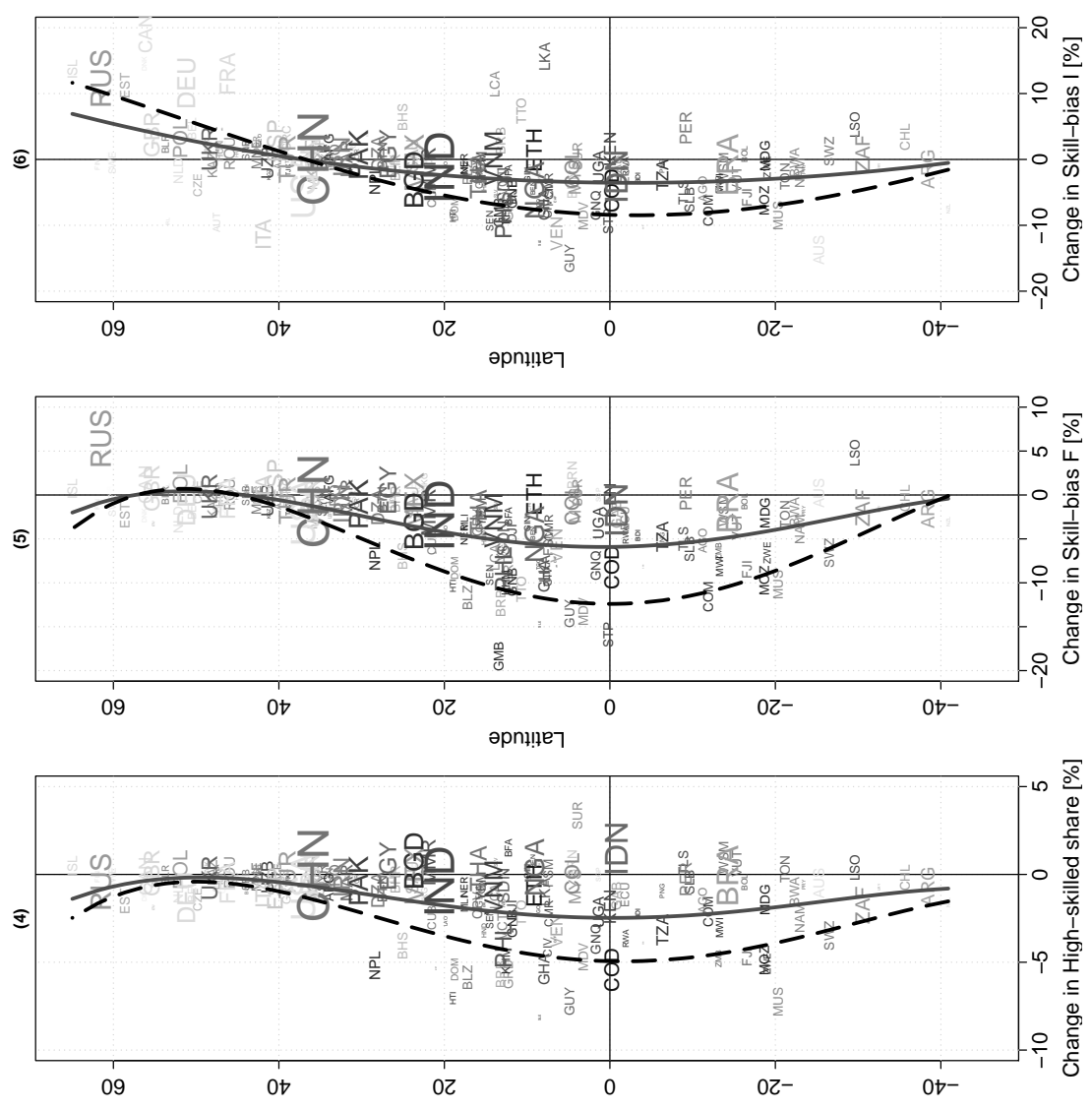

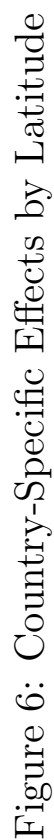

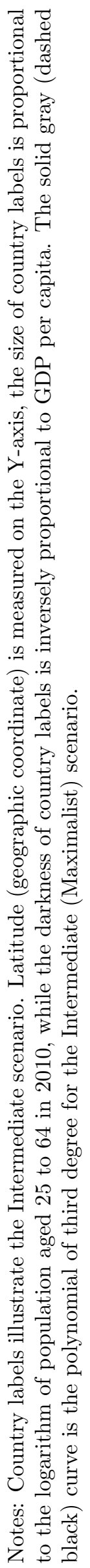




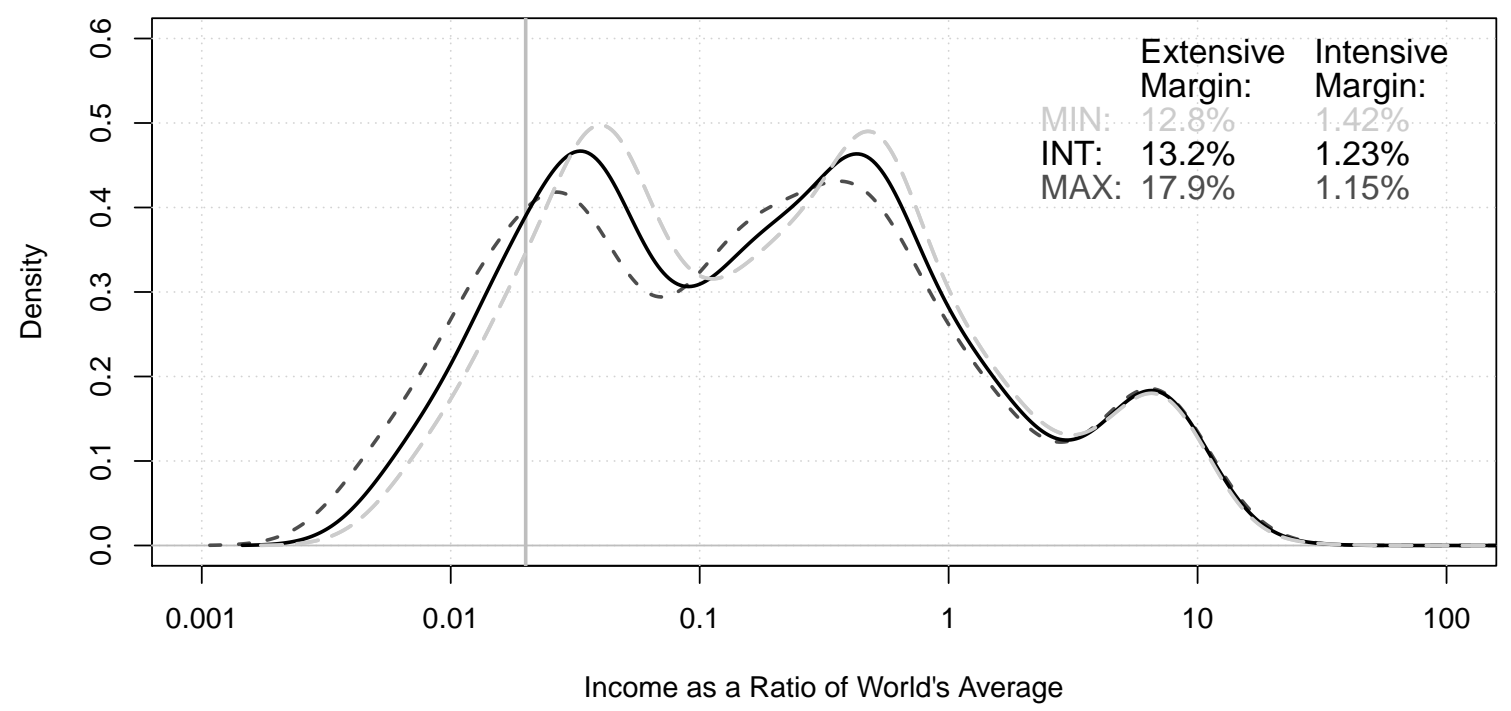

Notes: Figure 7 depicts smoothed predicted distributions of income in 2100 under the Minimalist (light gray dashed curve), Intermediate (black solid curve), and Maximalist (dark gray dashed curve) scenarios. The gray vertical line represents the relative poverty threshold ( $2 \%$ of average income). The extensive margin represents the share of world population below the relative poverty line, while the intensive margin computes the mean income of population below the poverty line (in percent, as a share of the average income).

Figure 7: Effect of CLC on Income Distribution in 2100

Under the Intermediate and Maximalist scenarios, the numbers amount to 621 and 835 million (i.e., $13.2 \%$ and $17.9 \%$ of the world population), respectively. ${ }^{26}$ In addition, Figure 7 also shows that the intensity of extreme poverty increases. The ratio of average income of the extreme poor to the worldwide average income decreases. On average, the index of relative income of the poorest workers is divided by 1.5 when the temperature increases by $2^{\circ} \mathrm{C}$ (i.e., when comparing the Intermediate to the Minimalist, or when comparing the Maximalist to the Intermediate). ${ }^{27}$ Hence, CLC influences extreme poverty at both extensive and intensive margins.

Mobility responses. It is frequently claimed that CLC will create the largest international refugee crisis in world history. Figure 6 along with Table 2 suggest that this is unlikely to be the case. We predict that CLC will induce large displacement of people

\footnotetext{
${ }^{26}$ If the poverty line equals $1 \%$ of the worldwide average income level, 181 million workers will live in extreme poverty in 2100 under the Minimalist scenario (3.9\% of the world population). This is in comparison to 202 and 272 million workers (4.2\% and 6.0\%) under the Intermediate and Maximalist, respectively.

${ }^{27}$ For instance, low-skilled workers in rural regions of Burundi earn around $0.65 \%$ of the global average income in the Minimalist scenario. This ratio reaches 0.54 in the intermediate scenario and 0.42 in the Maximalist.
} 
from vulnerable to more viable areas on Earth. However, provided migration laws and policies remain constant, we show that most of them will move within their countries.

When compared to the Minimalist scenario, the rising temperature and sea levels in the Intermediate scenario would increase the number of adult movers by 62.2 million people in 2040, 22.0 million in 2070, and 15.7 million in 2100 (i.e., by $1.6 \%, 0.5 \%$, and $0.3 \%$ of the world adult population, respectively). Over the course of the 21 st century, this amounts to a total of 100 million adults (162 million in the Maximalist scenario). When accompanying children are included, we anticipate a total of 200 to 300 million migrants over the century, depending on the scenario. These estimates are remarkably close to those obtained by Rigaud et al. (2018), though their radically different approach focuses on ecological and socioeconomic aspects of the CLC, while we emphasize behavioral economic mechanisms. Rigaud et al. (2018) predict that 65 to 145 million people of all ages could migrate within their own countries by 2050 to escape the slow-onset impacts of CLC. Our model brings two considerable advantages: we can disentangle forced and voluntary movements and distinguish between local, rural-urban, and international mobility responses.

Table 2 indicates that forcibly displaced people account for a large share of climate migration. In the Intermediate scenario, forced displacements due to sea level rise represent $86 \%$ of the total movements observed by 2040 and $72 \%$ of the total over the 21 st century. This also means that voluntary migration is non-negligible, which makes the identification of climate refugees a complex task. This is even more pronounced in the Maximalist scenario, in which the short- and long-run proportions of forced displacements equal $70 \%$ and $51 \%$, respectively.

Table 2 shows that far more people are migrating within their own countries than across borders. Focusing on the Intermediate scenario, $71 \%$ of the total movements observed by 2040 are local displacements within the region of birth (from flooded to nonflooded areas), 20\% are movements between regions (from agriculture to non-agriculture), and only $9 \%$ are long-haul international movements from developing to OECD countries. Over time and under unchanged migration policies in the OECD, local and interregional movement decreases, while international mobility increases. Aggregating over the 21st century, $60 \%$ of the total movements are local displacements, $18 \%$ are interregional, and only $22 \%$ are international. However, it is worth noting that local and interregional movements are cumulative: internal migrants' children form the local population of the next period. In contrast, international migrants' children are considered natives of the host country. This explains why CLC has a much greater cumulative impact on the urban share than on the world proportion of international migrants. In line with Table 1, CLC increases the share of international migrants by 0.2 percentage points. 


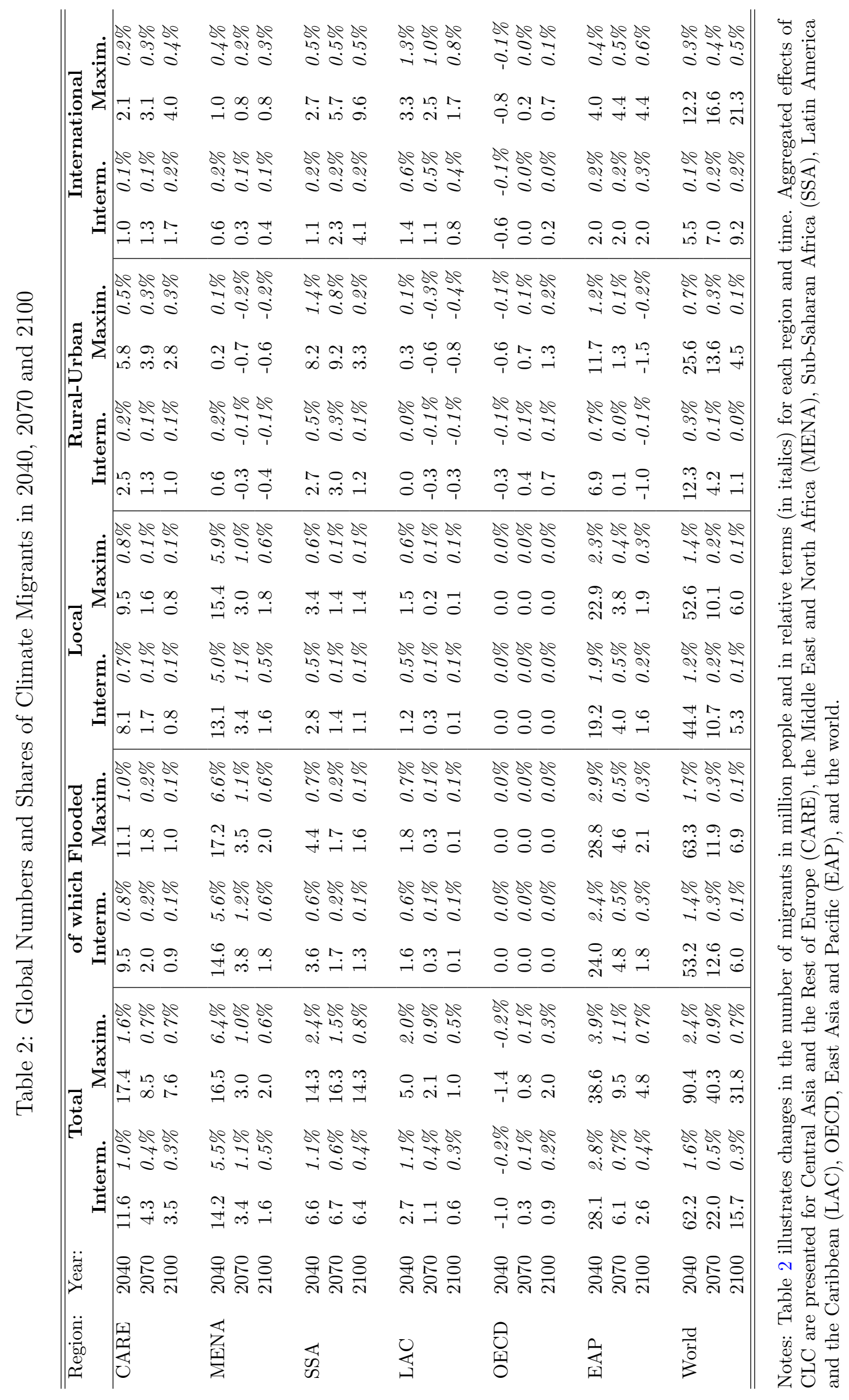


Table 2 also disentangles the climate-driven changes in the world migration stock by region of origin. In the Intermediate scenario and in 2040, $45.2 \%$ of the new migrants originate from East Asia and the Pacific, 22.8\% come from the MENA region, 36.7\% come from Central Asia and Eastern Europe, while only 10.6\% come from sub-Saharan Africa. Over the whole century, these projected shares amount to $36.8 \%$ for East Asia and the Pacific, $19.2 \%$ for the MENA region, $19.4 \%$ for Central Asia and Eastern Europe, and $19.7 \%$ for sub-Saharan Africa.

Figure 8 describes the spatial structure of these secular dyadic flows. Emigration from East Asia and Pacific, as well as from the MENA is mostly local. On the contrary, a larger fraction of sub-Saharan African and Latin American emigrants move long distances. Given the constant dyadic structure of migration costs, these international migrants mostly target the richest OECD countries in Western Europe and North America.

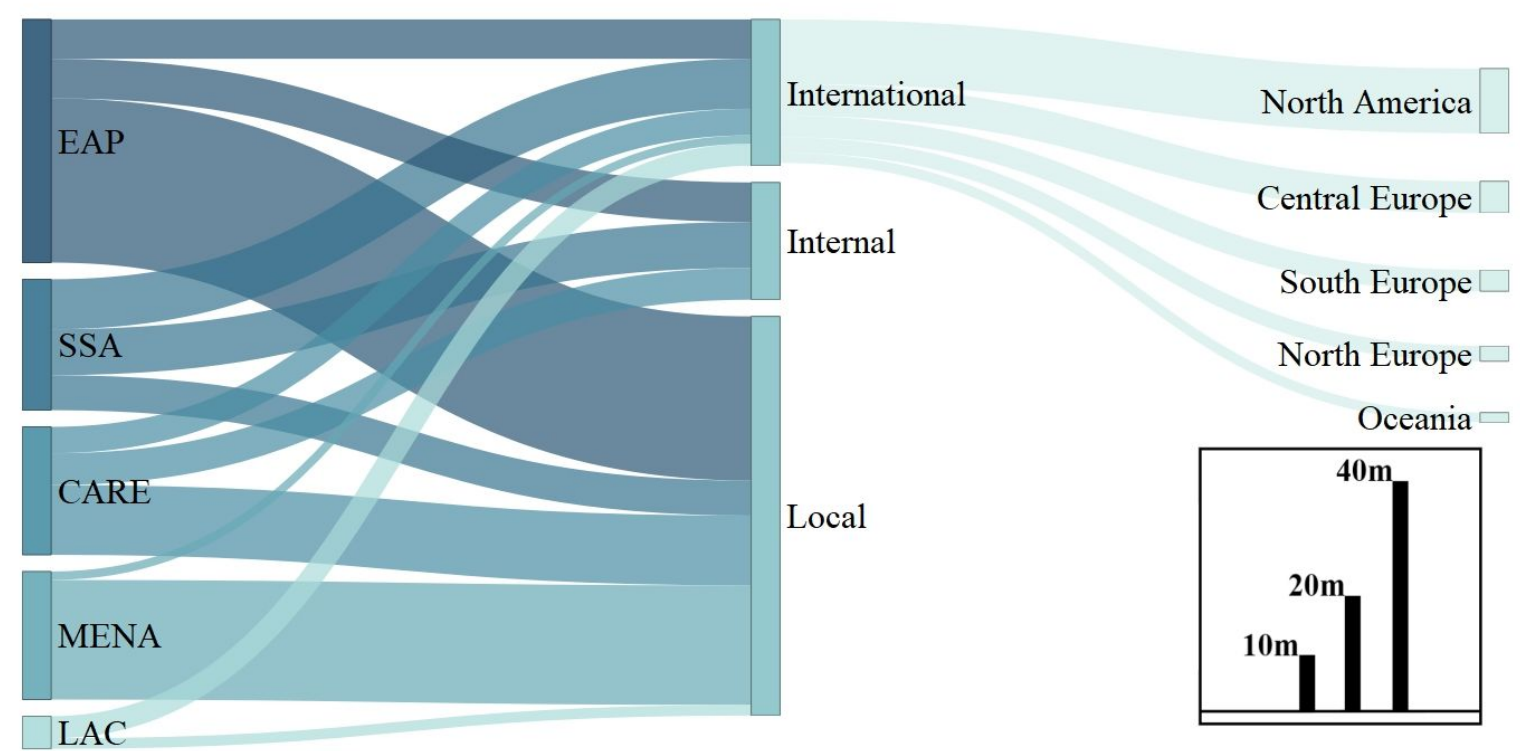

Notes: Figure 8 depicts the projected stocks of international, internal, and local migrants over the 21st century. The thickness of the bars is proportional to the size of the flow; see the legend in bottom right corner (in million people). The following regions are considered: East Asia and Pacific (EAP), SubSaharan Africa (SSA), Central Asia and the Rest of Europe (CARE), the Middle East and North Africa (MENA), Latin America and the Caribbean (LAC).

Figure 8: Spatial Structure of Climate Migration over the 21st Century

Similar but sharper results emerge in the Maximalist scenario. In 2040, 58\% of the total movements are local displacements, $28 \%$ are interregional movements, and only $14 \%$ are long-haul international movements. Over the 21 st century, $51 \%$ of the total projected movements are local, $27 \%$ are interregional, and only $22 \%$ are international. In this case, CLC will increase the world proportion of international migrants by 0.5 percentage points in the long run. 
Although these climate-induced changes in international migration are non-negligible, they are rather small compared to the global changes in international migration stocks. The latter are mostly driven by the differential population growth between developed and developing countries and by the rise in educational attainment (education makes people more migratory partly because migratory policies in OECD countries are less stringent for the highly educated). Over the 21st century and in the Intermediate scenario, the average share of immigrants will be multiplied by a factor of 1.5 in settlement countries (the US, Canada and Australia), and will increase twofold in Europe over the 21st century. However, CLC explains between $1 / 10$ and $1 / 20$ of the total change in the world population's share of immigrants, depending on the scenario.

Table B.3 in the Appendix details these findings by region and country. In the Minimalist scenario, the mean emigration rate from the developing world increases by a factor of 1.5 to 2 during the 21 st century, due to the rise in education levels. When comparing the Intermediate to the Minimalist scenario, CLC plays a minor role. It increases the mean emigration rate by an additional factor of 1.05. As far as OECD countries are concerned, their average share of immigrants increases by a factor of 1.5 to 2 under the Minimalist scenario, due to rising emigration rates in the South and demographic imbalances. Again, the contribution of CLC to increasing immigration is tiny.

These results are highly robust to the magnitude of SLR. In our Intermediate and Maximalist scenarios, we assume a sea level increase of +1.1 and $+1.3 m$, respectively. The Groundwell report of Rigaud et al. (2018) assumes that SLR reaches $2 m$ in 2040. In unreported simulations, we keep the global increase in temperature of $+2.09^{\circ}$ Celsius and consider more extreme SLR hypotheses. In line with Rigaud et al. (2018), our greater SLR variant assumes that SLR reaches $2 m$ in 2040. For subsequent periods, we assume the same relative changes as in the Intermediate scenario; this yields $2.4 \mathrm{~m}$ in 2070 and $2.7 \mathrm{~m}$ in 2100. Our smaller variant assumes no SLR. Compared to the Intermediate scenario, the consideration of extreme SLR variants has a limited impact on worldwide internal and international migration responses. This means that variations in SLR mostly induce local displacements from flooded to non-flooded areas. Hence, the impact of slow-onset CLC variables on international migration is overwhelmingly governed by the temperaturerelated changes in productivity.

\subsection{Fast-onset Mechanisms and Conflicts}

In this section, we start from the Intermediate scenario and enrich it with additional mechanisms related to fast-onset weather shocks and conflicts over resources. The Fast-onset scenario accounts for the correlation between changes in temperature and the frequency of 
natural disasters, as well as the negative effect of heat waves on health and labor productivity. In addition, the Conflict scenario assumes generalized conflicts in seven Western Asian countries and ten countries with the highest exposition to poverty.

Table D.1 in Appendix D summarizes the aggregate effect on the world economy and by region. Remember our Intermediate scenario per se predicts a $2.4 \%$ long-run rise in the worldwide average level of income per worker compared with the Minimalist one. In the Fast-onset scenario, CLC induces a $3.2 \%$ decrease in disposable income per worker due to the costs of natural disasters and heat waves. In the Conflict scenario, CLC decreases income per worker by only $0.6 \%$ as more people forcibly migrate from developing to developed countries. Changes in the world proportion of college graduates and in the average urban share are almost identical to those obtained in the Intermediate scenario. As far as the long-run proportion of international migrants is concerned, it increases by $0.21 \%$ in the Intermediate scenario, against $0.27 \%$ when accounting for fastonset mechanisms, and $0.70 \%$ with conflicts.

Table 3 characterizes the patterns of climate migration under the Fast-onset and Conflict scenarios. Results can be easily compared with those obtained under the Intermediate scenario in Table 2. Remember that over the 21st century, we predict 100 million workingage climate migrants in our Intermediate scenario, including 60.4 million local migrants, 17.6 million interregional migrants, and 21.7 million international migrants. We obtain very similar estimates under the Fast-onset variant: a total of 104.6 million workingage climate migrants, including 27.7 million international migrants. Hence, fast-onset mechanisms increase the stock of international migrants by only 6 million.

On the contrary, climate-related conflicts over resources can potentially increase migration pressures to OECD destinations. The Conflict scenario involves a total of 141.9 million working-age climate migrants, including 60.0 million local migrants, 9.6 million interregional migrants, and 72.4 million international migrants. This results in 44.7 million more migrants than in the Fast-onset scenario and 50.7 million more than in the Intermediate scenario. The latter increment roughly corresponds to $0.5 \%$ of the world population. Unsurprisingly, most of these new migrants originate from the MENA region and sub-Saharan Africa, the two regions at the highest risk of conflict according to Abel et al. (2019), and mostly migrate to Europe. Overall, these estimates suggest that conflicts over resources could become a key component of climate migration pressures. 


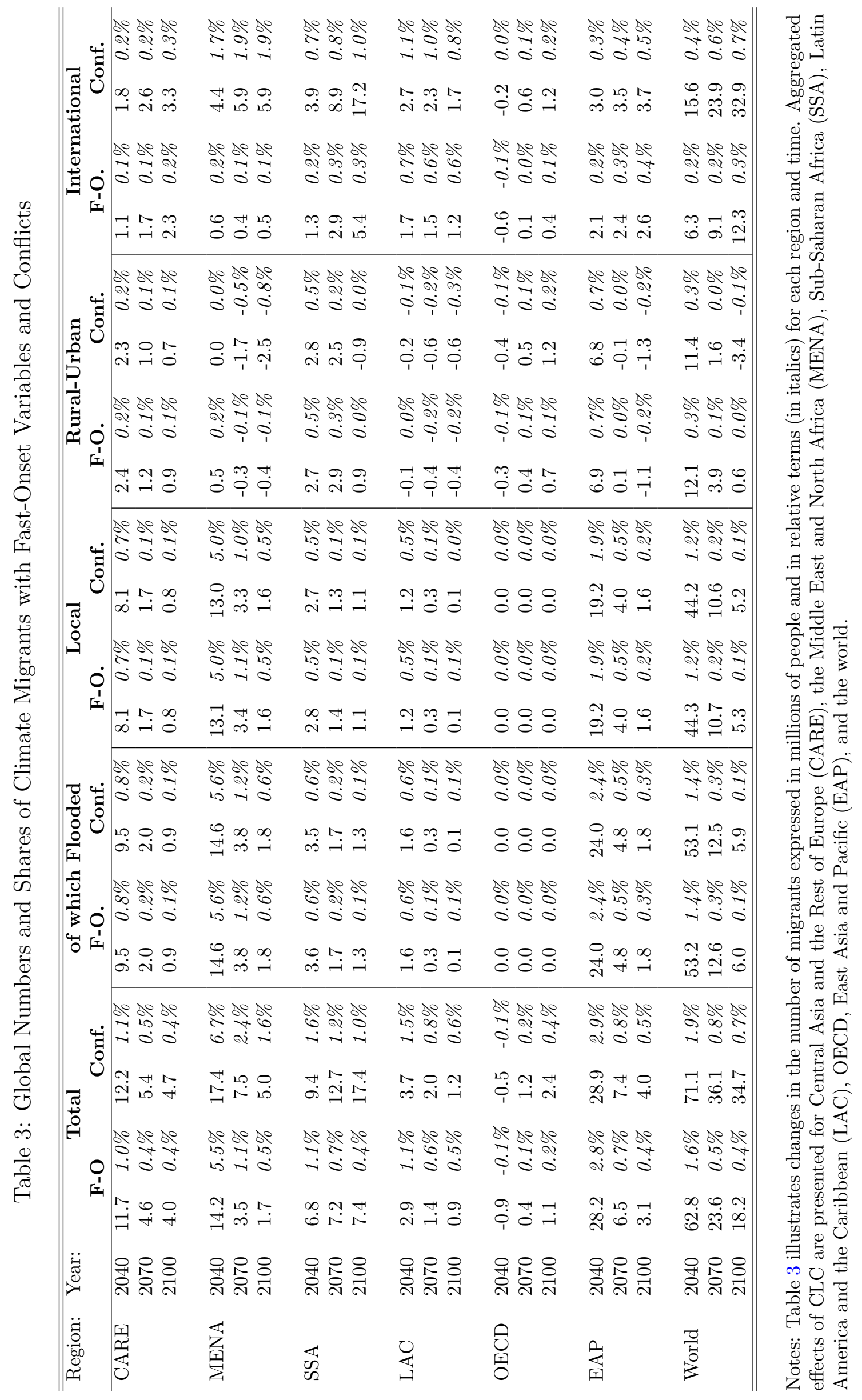




\section{Conclusion}

This paper provides evidence that climate change (CLC) will increase the income gap between the richest and poorest countries by at least $25 \%$ over the course of the 21 st century. It will also increase extreme poverty at both the extensive and intensive margins and force millions of adults to flee their flooded areas of residence. These CLC-related developments create favorable conditions for increasing the internal and international mobility of workers. In this paper, we endogenize the migration responses to CLC at various spatial scales under current migration laws and policies. Our model relies on consensus micro-foundations and is calibrated to match international and urbanization data of the last 30 years, with a focus on long-haul migration from developing countries towards OECD destinations. Depending on the climate scenario, we predict that rising temperature and sea level will lead to voluntary and forced movements of 100 to 160 million working-age individuals during the 21st century. Adding dependent children, this means a total of 200 to 300 million climate migrants. Climate migrants will mostly originate from countries that have contributed the least to CLC, but experience the most damaging effects.

In contrast with previous studies, our model allows us to disentangle forced and voluntary movements and to characterize the spatial structure of these mobility responses. We find that more than $80 \%$ of climate migrants will move internally (within their region of birth or from rural to urban regions), while $20 \%$ will opt for long-haul migration to an OECD destination. This means that over the whole century, we roughly project 22 million international climate migrants aged $25+$ in a scenario involving $+2^{\circ}$ in global temperature and $+1.1 \mathrm{~m}$ in the sea level, and 50 million climate migrants in a scenario involving $+4^{\circ}$ and $+1.3 \mathrm{~m}$. Taking into account the timing of migration and migrants' mortality, these responses translate into average increases in the stock of international migrants of 7 to 17 million throughout the period, depending on the CLC scenario.

Hence, under constant moving costs, international migration is a costly adaptation strategy of last resort. Far more climate migrants will move within their own countries than across borders. This result holds when adding fast-onset mechanisms related to extreme weather events. Accounting for the costs of natural disasters and heat waves increases the secular stock of climate migrants by only 6 million (i.e., an average increase in the stock of international migrants equal to +2 million per year).

In terms of policy implications, these results illustrate the difficulty of defining the status of climate refugee. Indeed, in our Intermediate scenario, more than $80 \%$ of forcibly displaced persons will move internally. In addition, half of non-local, climate-related movements - and more than $90 \%$ of international climate-related movements - are voluntary 
and caused by climate-related deterioration of economic conditions; in other words, only $10 \%$ of international climate-related movements are due to forced displacements. CLC is an additional factor that calls for better coherence between development and environmental policies. Given the difficulty of emigrating from the poorest countries, preventive measures are needed to encourage climate change adaptation, local disaster-risk reduction, sustainable development in general, and urban sustainable development in particular.

Finally, we find that climate-related conflicts over resources can significantly increase future international migration pressures. Although the link between CLC and conflict can be hard to establish in practice, ${ }^{28}$ several studies have documented that climate change increases the potential for conflict and violence in general, and instability in Western Asia and the least developed countries in particular (e.g. Abel et al., 2019; Burke et al., 2015b). Assuming climate change induces generalized and persistent conflicts in 17 countries at risk, we roughly predict 50 million additional climate migrants aged $25+$ over the 21 st century (i.e., an average increase in the stock of international migrants equal to 17 million). Most will originate from the MENA region and sub-Saharan Africa and will migrate to Europe. This suggests that security and humanitarian policy measures are needed if decision-makers are to avoid climate-related humanitarian crises and additional waves of forced displacements.

\section{References}

Abel, G. J., Brottrager, M., Cuaresma, J. C., and Muttarak, R. (2019). Climate, conflict and forced migration. Global Environmental Change, 54:239-249.

Acemoglu, D. (2002). Technical Change, Inequality, and the Labor Market. Journal of Economic Literature, 40(1):7-72.

Autor, D. H., Levy, F., and Murnane, R. J. (2003). The Skill Content of Recent Technological Change: An Empirical Exploration. The Quarterly Journal of Economics, 118(4):1279-1333.

Backhaus, A., Martinez-Zarzoso, I., and Muris, C. (2015). Do climate variations explain bilateral migration? A gravity model analysis. IZA Journal of Migration, 4(1):3.

Barrios, S., Bertinelli, L., and Strobl, E. (2006). Climatic change and rural-urban migration: The case of sub-Saharan Africa. Journal of Urban Economics, 60(3):357-371.

Bazzi, S. (2017). Wealth Heterogeneity and the Income Elasticity of Migration. American Economic Journal: Applied Economics, 9(2):219-55.

Beine, M. and Jeusette, L. (2018). Climatic Factors and Human Mobility: A Meta Analysis of the Literature. Manuscript (in progress).

\footnotetext{
${ }^{28}$ For example, the thesis of a Syrian "climate war" has been challenged in the literature (Fröhlich, 2016; Selby et al., 2017).
} 
Beine, M. and Parsons, C. (2015). Climatic Factors as Determinants of International Migration. The Scandinavian Journal of Economics, 117(2):723-767.

Berlemann, M. and Steinhardt, M. F. (2017). Climate Change, Natural Disasters, and Migration-A Survey of the Empirical Evidence. CESifo Economic Studies, 63(4):353385.

Bertoli, S. and Fernández-Huertas Moraga, J. (2013). Multilateral resistance to migration. Journal of Development Economics, 102:79-100.

Biavaschi, C., Burzyński, M., Elsner, B., and Machado, J. (2019). Taking the skill bias out of global migration. Journal of Development Economics, forthcoming.

Black, R., Arnell, N. W., Adger, W. N., Thomas, D., and Geddes, A. (2013). Migration, immobility and displacement outcomes following extreme events. Environmental Science \& Policy, 27:S32-S43.

Black, R., Bennett, S. R., Thomas, S. M., and Beddington, J. R. (2011). Climate change: Migration as adaptation. Nature, 478(7370):447.

Boppart, T. (2014). Structural Change and the Kaldor Facts in a Growth Model with Relative Price Effects and Non-Gorman Preferences. Econometrica, 82(6):2167-2196.

Burke, M., Dykema, J., Lobell, D. B., Miguel, E., and Satyanath, S. (2015a). Incorporating Climate Uncertainty into Estimates of Climate Change Impacts. Review of Economics and Statistics, 97(2):461-471.

Burke, M., Hsiang, S. M., and Miguel, E. (2015b). Climate and Conflict. Annual Review of Economics, 7(1):577-617.

Burzyński, M., Deuster, C., and Docquier, F. (2019). Geography of skills and global inequality. Journal of Development Economics, forthcoming.

Cai, R., Feng, S., Oppenheimer, M., and Pytlikova, M. (2016). Climate variability and international migration: The importance of the agricultural linkage. Journal of Environmental Economics and Management, 79:135-151.

Cattaneo, C., Beine, M., Fröhlich, C. J., Kniveton, D., Martinez-Zarzoso, I., Mastrorillo, M., Millock, K., Piguet, E., and Schraven, B. (2019). Human Migration in the Era of Climate Change. Review of Environmental Economics and Policy, 13(2):189-206.

Cattaneo, C. and Peri, G. (2016). The migration response to increasing temperatures. Journal of Development Economics, 122:127-146.

Coniglio, N. D. and Pesce, G. (2015). Climate variability and international migration: an empirical analysis. Environment and Development Economics, 20(4):434-468.

Dallmann, I. and Millock, K. (2017). Climate Variability and Inter-State Migration in India. CESifo Economic Studies, 63(4):560-594.

Dao, T., Docquier, F., Maurel, M., and Schaus, P. (2018). Global Migration in the 20th and 21st Centuries: the Unstoppable Force of Demography. FERDI Working Paper 223. 
De La Croix, D. and Doepke, M. (2003). Inequality and Growth: Why Differential Fertility Matters. American Economic Review, 93(4):1091-1113.

De La Croix, D. and Doepke, M. (2004). Public versus private education when differential fertility matters. Journal of Development Economics, 73(2):607-629.

De Melo, J. (2017). Moving on Towards a Workable Climate Regime. In Sustainable Growth in the EU: Challenges and Solutions, pages 231-256. Springer.

DeConto, R. M. and Pollard, D. (2016). Contribution of Antarctica to past and future sea-level rise. Nature, 531(7596):591.

Defrance, D., Ramstein, G., Charbit, S., Vrac, M., Famien, A. M., Sultan, B., Swingedouw, D., Dumas, C., Gemenne, F., Alvarez-Solas, J., et al. (2017). Consequences of rapid ice sheet melting on the Sahelian population vulnerability. Proceedings of the National Academy of Sciences, 114(25):6533-6538.

Dell, M., Jones, B. F., and Olken, B. A. (2012). Temperature Shocks and Economic Growth: Evidence from the Last Half Century. American Economic Journal: Macroeconomics, 4(3):66-95.

Dell, M., Jones, B. F., and Olken, B. A. (2014). What Do We Learn from the Weather? the New Climate-Economy Literature. Journal of Economic Literature, 52(3):740-98.

Delogu, M., Docquier, F., and Machado, J. (2018). Globalizing labor and the world economy: the role of human capital. Journal of Economic Growth, 23(2):223-258.

Desmet, K., Kopp, R. E., Kulp, S. A., Nagy, D. K., Oppenheimer, M., Rossi-Hansberg, E., and Strauss, B. H. (2018a). Evaluating the Economic Cost of Coastal Flooding. Technical report, National Bureau of Economic Research.

Desmet, K., Nagy, D. K., and Rossi-Hansberg, E. (2018b). The Geography of Development. Journal of Political Economy, 126(3):903-983.

Desmet, K. and Rossi-Hansberg, E. (2015). On the spatial economic impact of global warming. Journal of Urban Economics, 88:16-37.

Docquier, F., Müller, T., and Naval, J. (2017). Informality and Long-Run Growth. The Scandinavian Journal of Economics, 119(4):1040-1085.

Fagan, B. (2008). The Great Warming: Climate Change and the Rise and Fall of Civilizations. Bloomsbury Publishing USA.

Fiala, N. (2015). Economic Consequences of Forced Displacement. The Journal of Development Studies, 51(10):1275-1293.

Findley, S. E. (1994). Does Drought Increase Migration? A Study of Migration from Rural Mali During the 1983-1985 Drought. International Migration Review, 28(3):539-553.

Fröhlich, C. J. (2016). Climate migrants as protestors? Dispelling misconceptions about global environmental change in pre-revolutionary Syria. Contemporary Levant, 1(1):3850 . 
Galor, O. (2011). Unified Growth Theory. Princeton University Press.

Galor, O. and Weil, D. N. (2000). Population, Technology, and Growth: From Malthusian Stagnation to the Demographic Transition and Beyond. American Economic Review, 90(4):806-828.

Gemenne, F. (2011). Why the numbers dont add up: A review of estimates and predictions of people displaced by environmental changes. Global Environmental Change, 21:S41S49.

Gleditsch, N. P. (2012). Whither the weather? Climate change and conflict.

Gollin, D., Lagakos, D., and Waugh, M. E. (2014). The Agricultural Productivity Gap. The Quarterly Journal of Economics, 129(2):939-993.

Gray, C. L. and Mueller, V. (2012). Natural disasters and population mobility in Bangladesh. Proceedings of the National Academy of Sciences, 109(16):6000-6005.

Henderson, J. V., Storeygard, A., and Deichmann, U. (2017). Has climate change driven urbanization in Africa? Journal of Development Economics, 124:60-82.

Ibáñez, A. M. and Moya, A. (2006). The Impact of Intra-State Conflict on Economic Welfare and Consumption Smoothing: Empirical Evidence for the Displaced Population in Colombia. Available at SSRN 1392415.

IPCC (2014). Climate Change 2014: Impacts, Adaptation, and Vulnerability. Contribution of Working Group II to the Fifth Assessment Report of the Intergovernmental Panel on Climate Change. Cambridge University Press.

Jayachandran, S. (2006). Selling Labor Low: Wage Responses to Productivity Shocks in Developing Countries. Journal of Political Economy, 114(3):538-575.

Kellenberg, D. and Mobarak, A. M. (2011). The Economics of Natural Disasters. Annual Review of Resource Economics, 3(1):297-312.

Kelley, C. P., Mohtadi, S., Cane, M. A., Seager, R., and Kushnir, Y. (2015). Climate change in the Fertile Crescent and implications of the recent Syrian drought. Proceedings of the National Academy of Sciences, 112(11):3241-3246.

Kennan, J. (2013). Open borders. Review of Economic Dynamics, 16(2):L1-L13.

Klein, P. and Ventura, G. (2009). Productivity differences and the dynamic effects of labor movements. Journal of Monetary Economics, 56(8):1059-1073.

Kubik, Z. and Maurel, M. (2016). Weather Shocks, Agricultural Production and Migration: Evidence from Tanzania. The Journal of Development Studies, 52(5):665-680.

Lobell, D. B. and Burke, M. B. (2010). On the use of statistical models to predict crop yield responses to climate change. Agricultural and forest meteorology, 150(11):14431452.

Lucas, R. E. (1988). On the mechanics of economic development. Journal of Monetary Economics, 22(1):3-42. 
Lucas, R. E. (2009). Trade and the Diffusion of the Industrial Revolution. American Economic Journal: Macroeconomics, 1(1):1-25.

Marchiori, L., Maystadt, J.-F., and Schumacher, I. (2012). The impact of weather anomalies on migration in sub-Saharan Africa. Journal of Environmental Economics and Management, 63(3):355-374.

Marchiori, L., Maystadt, J.-F., and Schumacher, I. (2017). Is environmentally induced income variability a driver of human migration? Migration and Development, 6(1):3359.

McFadden, D. L. (1974). Conditional Logit Analysis of Qualitative Choice Behavior. Frontiers in Econometrics, P. Zarembka (ed.), Chapter 2:105-142.

McGranahan, G., Balk, D., and Anderson, B. (2007). The rising tide: assessing the risks of climate change and human settlements in low elevation coastal zones. Environment and Urbanization, 19(1):17-37.

Mendelsohn, R., Nordhaus, W. D., and Shaw, D. (1994). The Impact of Global Warming on Agriculture: A Ricardian Analysis. The American economic review, pages 753-771.

Miguel, E., Satyanath, S., and Sergenti, E. (2004). Economic Shocks and Civil Conflict: An Instrumental Variables Approach. Journal of Political Economy, 112(4):725-753.

Millock, K. (2015). Migration and Environment. Annual Review of Resource Economics, $7: 35-60$.

Moss, R. H., Edmonds, J. A., Hibbard, K. A., Manning, M. R., Rose, S. K., Van Vuuren, D. P., Carter, T. R., Emori, S., Kainuma, M., Kram, T., et al. (2010). The next generation of scenarios for climate change research and assessment. Nature, 463(7282):747756 .

Mueller, V., Gray, C., and Kosec, K. (2014). Heat stress increases long-term human migration in rural Pakistan. Nature Climate Change, 4(3):182.

Mueller, V. and Quisumbing, A. (2011). How Resilient are Labour Markets to Natural Disasters? The Case of the 1998 Bangladesh Flood. The Journal of Development Studies, 47(12):1954-1971.

Nordhaus, W. D. and Boyer, J. (2000). Warming the World.

Ottaviano, G. I. and Peri, G. (2012). Rethinking the Effect of Immigration on Wages. Journal of the European Economic Association, 10(1):152-197.

Perch-Nielsen, S. L., Bättig, M. B., and Imboden, D. (2008). Exploring the link between climate change and migration. Climatic Change, 91(3-4):375.

Piguet, E., Pécoud, A., and De Guchteneire, P. (2011). Migration and Climate Change: An Overview. Refugee Survey Quarterly, 30(3):1-23.

Restuccia, D. and Vandenbroucke, G. (2013). The Evolution of Education: A Macroeconomic Analysis. International Economic Review, 54(3):915-936. 
Rigaud, K., Jones, B., Bergmann, J., Clement, V., Ober, K., Schewe, J., Adamo, S., McCusker, B., Heuser, S., and Midgley, A. (2018). Groundswell: Preparing for Internal Climate Migration.

Schelling, T. C. (2007). Climate Change: The Uncertainties, the Certainties and What They Imply About Action. The Economists' Voice, 4(3).

Selby, J., Dahi, O. S., Fröhlich, C., and Hulme, M. (2017). Climate change and the Syrian civil war revisited. Political Geography, 60:232-244.

Shayegh, S. (2017). Outward migration may alter population dynamics and income inequality. Nature Climate Change, 7(11):828.

Stern, N. (2013). The Structure of Economic Modeling of the Potential Impacts of Climate Change: Grafting Gross Underestimation of Risk onto Already Narrow Science Models. Journal of Economic Literature, 51(3):838-59.

Stocker, T. F., Qin, D., Plattner, G.-K., Tignor, M., Allen, S. K., Boschung, J., Nauels, A., Xia, Y., Bex, V., and Midgley, P. M. (2013). Climate Change 2013: The Physical Science Basis. Contribution of Working Group I to the Fifth Assessment Report of the Intergovernmental Panel on Climate Change.

Stott, P. (2016). How climate change affects extreme weather events. Science, 352(6293):1517-1518.

Taylor, K. E., Stouffer, R. J., and Meehl, G. A. (2012). An Overview of CMIP5 and the Experiment Design. Bulletin of the American Meteorological Society, 93(4):485-498.

Vermeer, M. and Rahmstorf, S. (2009). Global sea level linked to global temperature. Proceedings of the National Academy of Sciences, 106(51):21527-21532.

Vollrath, D. (2009). How important are dual economy effects for aggregate productivity? Journal of Development Economics, 88(2):325-334.

Young, A. (2005). The Gift of the Dying: The Tragedy of AIDS and the Welfare of Future African Generations. The Quarterly Journal of Economics, 120(2):423-466.

Young, A. (2013). Inequality, the Urban-Rural Gap, and Migration. The Quarterly Journal of Economics, 128(4):1727-1785. 


\section{Online Appendix}

\section{A Calibration details}

\section{A.1 Temperature scenarios}

The CCKP projections are organized in 20-year climatological windows for 2020 to 2039, 2040 to 2059, 2060 to 2079, and 2080 to 2099. These projections are obtained from the Coupled Model Intercomparison Project Phase 5 (CMIP5) distribution (Taylor et al., 2012) which distinguishes between several scenarios for the Representative Concentration Pathways (RCP) (Moss et al., 2010). The median-emission scenario is called RCP-4.5. In addition, for each RCP, the CCKP provides data for 16 models obtained from different research institutes. Figure A.1a depicts the evolution of the worldwide mean surfacetemperature predicted by each of the 16 models of the median (RCP-4.5) package. The dashed black curve describes our baseline scenario. Overall, all models under RCP-4.5 predict an increase in temperature levels. We proceed to two adjustments before plugging the temperature data into our model:

Firstly, the climate literature suggests that aggregate (unweighted) country levels of temperature may not reflect accurately the impact of CLC (Dell et al., 2014). Particularly in large countries with regions of heterogeneous population densities, the aggregate measure poorly captures the intensity of the phenomenon. Hence, we weight the monthly future temperature levels by population. To do this, we extract from the CCKP the monthly mean air temperature levels for the climatological window for 1991 to 2015. We weight equally the monthly observations to obtain a yearly temperature level for each country. Furthermore, Dell et al. (2012) provide a data set with population-weighted data on temperature levels. We compute the country-specific averages of these temperature levels for the years between 1995 and 2005. We then construct a scale factor for each country by dividing these population-weighted temperature levels by the temperature levels from the CCKP. In order to obtain future population-weighted measures, we multiply each of the monthly temperature levels for the future 20-year climatological windows with the country-specific scale factor.

Secondly, the OLG model described in Section 3 must be fed with data in 30-year intervals (a period that is meant to represent the length of one generation), starting in 2010. Therefore, the last step consists in allocating the 20-year climatological windows to fit the temporal structure of the model. We assimilate the 2040-2059 climatological window to 2040, the 2060-2079 climatological window to 2070, and the 2080 to 2099 climatological window to 2100 , respectively. In this way we obtain monthly populationweighted levels of temperature for the 179 countries in our data set. When averaged over all countries and months, our baseline temperature data predicts an increase in global temperature of $2.09^{\circ} \mathrm{C}$ by the end of the 21 st century. ${ }^{29}$

\footnotetext{
${ }^{29}$ Under the RCP-4.5 scenario the projected anomalies range from $0.83{ }^{\circ} \mathrm{C}$ for the minimalist model of the 16 models to $3.20^{\circ} \mathrm{C}$ for the Maximalist model as illustrated on Figure A.1a.
} 


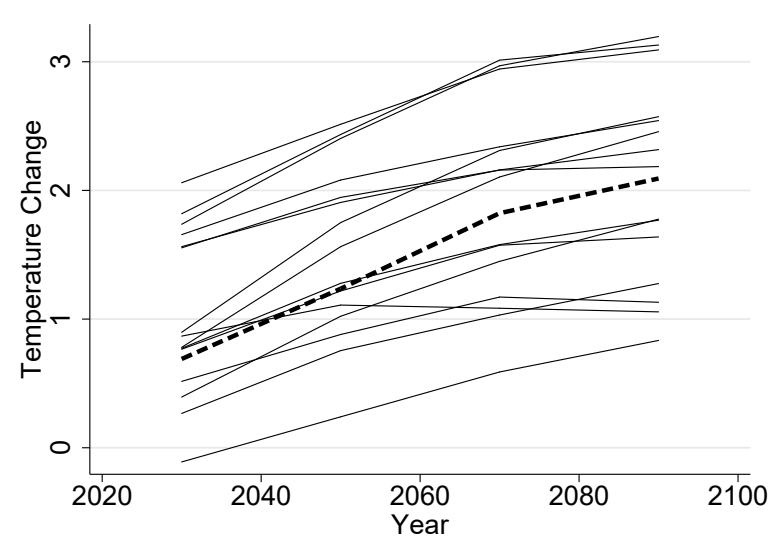

(a) Worldwide mean temperature in RCP-4.5

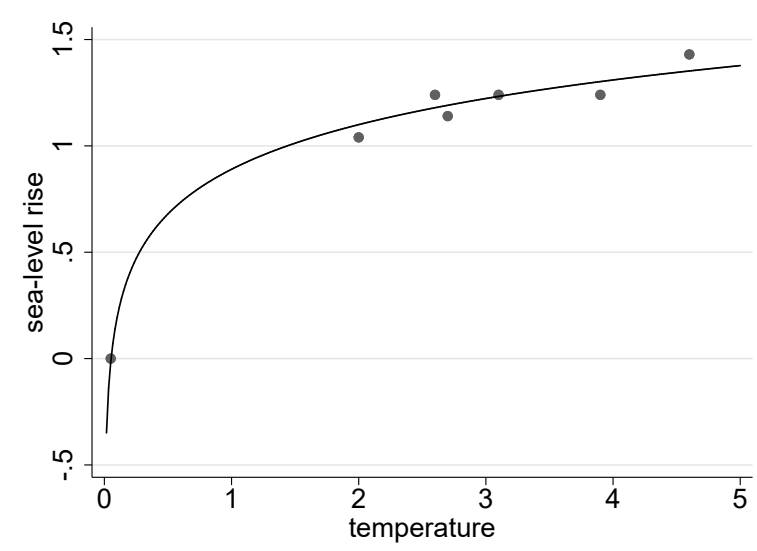

(b) Variation in temperature and in sea level

Sources: CCPK for Figure A.1a, and Vermeer and Rahmstorf (2009) for Figure A.1b

Figure A.1: CLC Scenarios (2010-2100)

\section{A.2 Parameterization of the model}

In this section, we describe our parameterization strategy for 145 developing countries and for the entire set of 34 OECD countries modeled as a single entity. ${ }^{30}$ Our model relies on consensual specifications for the production and migration technologies. However, as shown in Definition 1, it includes a large number of skill- and region-specific parameters. ${ }^{31}$ These parameters are calibrated to match some moments. In particular, we force our model to exactly match the recent trends in human capital accumulation, income disparities, and population movements (including internal and international migrations). We use socio-demographic and economic data for 1980 and 2010, as well as socio-demographic prospects for 2040. Hence, we use all the degrees of freedom of the data to identify the parameters needed. Consequently, our model is exactly identified. In Burzyński et al. (2019), we use a simplified version of this model and check the reasonableness of the distribution of our calibrated parameters. We show that the identified parameters exhibit realistic correlations with traditional explanatory variables from the econometric literature. We also illustrate the ability of our model to match historical mobility trends. Table A.1 summarizes the calibration outcomes.

Data. - We collect data on the socio-demographic and economic characteristics of 179 countries in 1980 and 2010. We use data on Gross Domestic Product (GDP) for all countries from the Economic Research Service of the United States Department of Agriculture (USDA) ${ }^{32}$ Data on the agriculture share in value added are taken from the Food and Agriculture Organization of the UN (FAOSTAT). As for the structure of the

\footnotetext{
${ }^{30}$ With the exceptions of Macao, North-Korea, Somalia and Taiwan, all countries that are not covered by our sample have less than 100,000 inhabitants.

${ }^{31}$ There are 14 parameters by country (TFP scale factor by region, skill-bias scale factor by region, internal migration costs for both skill groups, international migration costs for both skill groups and by region, access to education by region, quality of education by region and 179 countries). This means 2,506 country-specific parameters.

${ }^{32}$ For a few missing observations we impute values by making use of the Maddison database and data from the World Bank.
} 
resident labor force by education level and by sector, we use the estimates described in Burzyński et al. (2019). Data on wages by education level $\left(\varpi_{r, 2010}\right)$ are obtained from Biavaschi et al. (2019) for the non-agricultural sector, and from the Gallup World Polls for the agricultural sector.

We model international migration to OECD countries only. From the Database on Immigrants in OECD and non-OECD countries (DIOC), we extract the number of emigrants by education level to OECD countries for all countries in our sample and for 2010. The DIOC does not identify the region of origin of migrants (urban versus rural). However, for the majority of countries in our sample, skill- and region-specific information on the desire to emigrate can be extracted from the Gallup World Polls. Assuming the structure of migration aspirations is identical to the structure of actual emigration stocks, we split the number of emigrants to OECD countries by region of origin and by education level. As for urbanization, net internal migration is then the difference between the "beforemigration" population $\left(N_{r, s, 2010}\right)$ in 2010 and the sum of the resident population and the international migrants $\left(\sum_{r, s}\left(L_{r, s, 2010}+M_{r f, s, 2010}\right)\right)$ in 2010 .

To proxy the average fertility rate $\left(\bar{n}_{1980}\right)$, we divide the total native population of adults in $2010\left(\sum_{r, s} N_{r, s, 2010}\right)$ by the resident population of adults in $1980\left(\sum_{r, s} L_{r, s, 1980}\right){ }^{33}$ Moreover, our calibration requires data on the skill- and region-specific fertility for each country. By construction, we have $\bar{n}_{t} \equiv \sum_{r, s} L_{r, s, t} n_{r, s, t} / \sum_{r, s} L_{r, s, t}$. We use the Gallup World Polls and extract the Gallup-based average number of children per household in urban and rural regions by skill level for 2010. We compute the fertility of the college educated workers by fitting the sector-specific, low/high-skilled fertility differentials from the Gallup database. In this way, we obtain the fertility rates for each country for 1980 . From 2010 onward, the number of children is endogenous. Once skill-specific fertility rates are calibrated, we use (10) to compute the employment levels $\left(\ell_{r, s, 2010}\right)$ and the skill ratio $\left(z_{r, 2010}\right)$ in all regions.

Technological parameters. - Output in each sector depends on the size and skill structure of employment. To calibrate the set of technological parameters, we proceed in two steps.

First, we calibrate the parameters affecting the private returns to higher education. For each sector, we combine our estimates for $\ell_{r, s, t}$ with cross-country data on the income gap between college graduates and the less educated. We calibrate the elasticity of substitution between college graduates and less educated workers relying on existing studies. As for the non-agricultural sector, there is a large number of influential papers that propose specific estimates for industrialized countries (i.e., countries where the employment share of agriculture is small). Ottaviano and Peri (2012) suggest setting $\sigma_{n}$ close to 2.0. As for the agricultural sector, it is usually assumed that the elasticity of substitution is much larger. For example, Vollrath (2009) or Lucas (2009) assume perfect substitution between skill groups. In line with the existing literature, we assume $\sigma_{n}=2$ and $\sigma_{a}=\infty$. Once the elasticities are chosen, we use our proxies for $\varpi_{r, 2010}$ and $z_{r, 2010}$ to identify $\eta_{r, 2010}$ from (3). Regressing the log of $\eta_{r, 2010}$ on the $\log$ of $z_{r, 2010}$ yields insignificant effect in agriculture, and a correlation of 0.38 in non-agriculture. We thus rule out the possibility of skill-biased technical change in agriculture $\left(\kappa_{a}=0\right)$, and assume a linear technology with a constant $\eta_{a, 2010}=\bar{\eta}_{a}=1.3$ for all countries and all periods. This value is given by

\footnotetext{
${ }^{33}$ There is no mortality in the model. The average fertility rate at time $t, \bar{n}_{t}$, should be seen as a net population growth rate.
} 
the population-weighted average of $\varpi_{a, 2010}$. In nonagriculture, we assume that half the correlation between the $\log$ of $\eta_{n, 2010}$ on the $\log$ of $z_{n, 2010}$ is due to the skill-bias externality (i.e., $\kappa_{n}=0.19$ ), and we calibrate $\bar{\eta}_{n}$ as a residual from (5) in each region. We find that this scale factor is positively associated with the share of researcher in the labor force.

In the second step, we use data on income by sector in 2010 and identify the TFP levels $\left(A_{r, t}\right)$ as a residual from Equation (1). There is a clear positive relationship between TFP and the skill ratio in both sectors. Indeed, regressing the log of $A_{r, t}$ on the log of $z_{r, t}$ gives a coefficient of 0.57 in the non-agricultural sector, and 0.66 in agriculture. We assume that half the correlation between TFP and the share of college-educated workers is due to the schooling externality (i.e., $\epsilon_{n}=0.28$ and $\epsilon_{a}=0.33$ ). We calibrate $\bar{A}_{n}$ as a residual from (4). This scale factor exhibits realistic correlations with proxies for infrastructure and with the cost of starting a business.

Preference parameters. - The literature indicates some common values of several preference parameters. We assign the following values to the parameters that are timeinvariant and equal for all countries: $\theta=0.25, \lambda=0.5$ and $\phi=0.14 .^{34}$ From (12) and (13), the scale parameter of the distribution of migration tastes $(\mu)$ is the inverse of the elasticity of bilateral migration to the wage rate. Bertoli and Fernández-Huertas Moraga (2013) find a value between 0.6 and 0.7 for this elasticity. Hence, we use $\mu=1.4$.

The parameters $\pi_{r}$ and $\psi_{r, t}$ affect fertility and education decisions. We calibrate them to match population dynamics between 1980 and 2010, i.e., the transition from the resident population in 1980 and the native population in 2010. From Equations (11) and (17), the fertility rate in the model depends on the product of $\pi_{r} \psi_{r, t}$. Once fertility rates are matched we are able to identify the product $\pi_{r} \psi_{r, t}$. We then calibrate $\pi_{r}$ and $\psi_{r, t}$ in order to match the educational structure of the native population in 2010, imposing the given value to the ratio of probabilities of becoming high-skilled across regions. OLS regressions show that the calibrated cost of education $\psi_{r, t}$ decreases with government spending in education, increases with the pupil-to-teacher ratio, and is greater in the rural sector. The quality of education $\pi_{r}$ exhibits opposite correlations Burzyński et al. (2019).

As for internal migration costs, we assume there is only migration from rural to urban regions (i.e., $x_{a n, s, t}<1$ and $x_{n a, s, t}=1$ ). We obtain internal migration costs for ruralurban migration from Equation (13). To determine the international migration costs $\left(x_{a f, s, t}\right.$ and $\left.x_{n f, s, t}\right)$, we begin by retrieving the utilities achievable abroad. We set these utilities equal to the skill-specific weighted average utilities of the OECD countries. The weights consist in the respective population sizes of the OECD countries. We then obtain the international migration costs from Equation (13). In line with Delogu et al. (2018), the calibrated costs exhibit realstic correlations with standard gravity determinants (distance, common language, colonial links, visa restrictions). In Burzyński et al. (2019), we use the calibrated migration technology to predict the variation in the stock of migrants between 1980 and 2010, and find that our predicted variations almost coincide with the observed ones.

To the best of our knowledge there is no information on the relative income loss experienced by individuals displaced by floods. However, in cases of armed conflicts, Fiala

\footnotetext{
${ }^{34}$ Given the expression in (9), this assumption reflects setting the bound of the maximal number of children equal to 7 (i.e., 14 children per couple). See Docquier et al. (2017) for a brief review of studies using similar parameter values.
} 
(2015) finds that displaced households incur a loss of consumption ranging between $28 \%$ and 35\%. For Colombia, Ibáñez and Moya (2006) find that a displacement is associated with a loss of $50 \%$ of income. Kellenberg and Mobarak (2011) characterize the willingness to pay for investments in disaster prevention to around $24 \%$ of income. We use these studies to proxy the local relocation cost due to a climate-driven forced displacement. Given this micro evidence, we pessimistically assume $x_{r^{\circ} r^{\circ}, s, t}^{f}=0.5$ (i.e., relocating within the region of birth induces an income loss equal to $50 \%$ of the lifetime utility).

Table A.1: Common and Country-Specific Parameters

\begin{tabular}{|c|c|c|c|c|}
\hline & Description & Mean & s.d. & Source/Moment matches \\
\hline \multicolumn{5}{|c|}{ Parameters without country variations } \\
\hline$\sigma_{n}$ & Elast. subst. in nonagr. & 2.00 & - & Ottaviano and Peri (2012) \\
\hline$\sigma_{a}$ & Elast. subst. in agr. & $\infty$ & - & Vollrath (2009) or Lucas (2009) \\
\hline$\epsilon_{n}$ & Aggregate externality in nonagr. & 0.28 & - & Half correl. betw. $\ln A_{n, t} \& \ln \Gamma_{n, t}^{\ell}$ \\
\hline$\epsilon_{n}$ & Aggregate externality in agr. & 0.33 & - & Half correl. betw. $\ln A_{a, t} \& \ln \Gamma_{a, t}^{\ell}$ \\
\hline$\kappa_{n}$ & Skill-biased externality in nonagr. & 0.19 & - & Half correl. betw. $\ln \Gamma_{n, t}^{\eta} \& \ln \Gamma_{n, t}^{\ell, c}$ \\
\hline$\kappa_{a}$ & Skill-biased externality in agr. & 0.00 & - & Half correl. betw. $\ln \Gamma_{a, t}^{\eta, t} \& \ln \Gamma_{a, t}^{\ell, t}$ \\
\hline$\theta$ & Preference for children & 0.25 & - & Docquier et al. (2017) \\
\hline$\lambda$ & Elast. training technology & 0.50 & - & Docquier et al. (2017) \\
\hline$\phi$ & Time to raise a child & 0.14 & - & Docquier et al. (2017) \\
\hline$\mu$ & 1/Elast. mig. to wages & 1.40 & - & Bertoli \& Fernández-HM (2013) \\
\hline$x_{r^{\circ} r^{\circ}, s}^{f}$ & Utility loss due to forced displ. & 0.50 & - & Fiala (2015), Ibáñez and Moya (2006) \\
\hline \multicolumn{5}{|c|}{ Parameters with some country variations } \\
\hline $\bar{A}_{n}$ & Scale factor in TFP & 216,969 & 267,723 & Residual from (4) \\
\hline $\bar{A}_{a}$ & Scale factor in TFP & 89,025 & 320,698 & Residual from (4) \\
\hline $\bar{\Gamma}_{n}^{\eta}$ & Scale factor in skill bias & 1.878 & - & Residual from (3) \\
\hline $\bar{\Gamma}_{a}^{\eta}$ & Scale factor in skill bias & 1.326 & - & Residual from (3) \\
\hline$\pi_{n}$ & Scale factor training technology & 0.025 & 0.041 & Match fertility/educ. in (11) \\
\hline$\pi_{a}$ & Scale factor training technology & 0.043 & 0.142 & Match fertility/educ. in (11) \\
\hline$\psi_{n}$ & Education cost & 13.74 & 67.27 & Match fertility/educ. in (11) \\
\hline$\psi_{a}$ & Education cost & 46.22 & 148.98 & Match fertility/educ. in (11) \\
\hline$x_{a n, h}$ & Internal mig. cost, high-skilled & 0.712 & 1.989 & Match urbanization (WDI) \\
\hline$x_{a n, l}$ & Internal mig. cost, low-skilled & 0.928 & 0.163 & Match urbanization (WDI) \\
\hline$x_{n f, h}$ & International mig. cost, high-skilled & 0.416 & 4.422 & Match migration data (DIOC) \\
\hline$x_{a f, h}$ & International mig. cost, high-skilled & 0.829 & 1.065 & Match migration data (DIOC) \\
\hline$x_{n f, l}$ & International mig. cost, low-skilled & 0.947 & 0.281 & Match migration data (DIOC) \\
\hline$x_{a f, l}$ & International mig. cost, low-skilled & 0.985 & 0.066 & Match migration data (DIOC) \\
\hline
\end{tabular}

Projections parameters. - Our parameter set is such that the model matches the geographic disparities in income, population and human capital in 2010, and their evolution between 1980 and 2010. The philosophy of our baseline projection exercise is to predict the future trends in income, population and human capital if all parameters remain constant, with the exception of the parameters governing access to education. More precisely, we constrain our baseline trajectory to be compatible with medium-term official demographic projections, as reflected by the UN projections of the national adult population and proportion of college graduates for 2040. Hence, we allow for country-specific 
proportional adjustments in $\psi_{r, t}(r=a, n)$ (i.e., the same relative change in both sectors) that minimizes the sum of squared differences in population and human capital between the baseline simulations and the UN projections for 2040. Remember $\psi_{r, t}$ determines the cost of education in the region. Comparing the new levels of $\psi_{r, 2010}$ with those obtained in 1980 (i.e., $\psi_{r, 1980}$ ), we identify a conditional convergence process in the access to education. We see it as a likely consequence of the Millennium Development policy. We estimate two quadratic, region-specific convergence equations considering the US as the benchmark frontier:

$$
\ln \left(\psi_{r, t+1} / \psi_{r, t}\right)=\alpha_{r}+\beta_{r} \ln \left(\psi_{r, t}^{U S A} / \psi_{r, t}\right)+\gamma_{r}\left(\ln \left(\psi_{r, t}^{U S A} / \psi_{r, t}\right)\right)^{2} .
$$

We obtain $\gamma_{a}=0.032, \gamma_{n}=0.046, \beta_{a}=-0.195$ and $\beta_{n}=-0.223$, where all parameters are highly significant. For subsequent years, our baseline scenario assumes a continuation of this quadratic convergence process, in line with the new Sustainable Development Agenda. Under this assumption, Burzyński et al. (2019) show that the model simulations fit the official sociodemographic projections very well. This is a proof of concept that such a stylized model does a good job in generating realistic projections of population, human capital, and urbanization.

\section{B Additional results with slow-onset mechanisms}

The left panels of Table B.1 list for each of the 179 countries the income per worker in the Intermediate scenario as well as the difference in income per worker between the Intermediate and the Minimalist scenarios, and between the Maximalist and the Minimalist scenarios for 2100. The right panel gives natives' average emigration rates for each country under the three scenarios of Section 4.1 and for 2100. Note that in OECD countries, changes in emigration rates are more than offset by increasing immigration rates (not reported here). The effects need not be linear. For example, compared to the Minimalist scenario, the emigration rate in France increases by 0.2 percentage points under the Intermediate, and decreases by 0.1 percentage points under the Maximalist scenario. Note that in OECD countries, changes in emigration rates are more than offset by increasing immigration rates (not reported in Table B.1). Compared to the Minimalist scenario, Table B.3 shows that the immigration rate to France increases by 0.5 percentage points under the Intermediate, and decreases by 1.0 percentage point under the Maximalist scenario.

Table B.2 gives the effect of CLC on the country-wide level of income per worker for the 20 most adversely affected countries (the ranking is based on the effect in 2100). It documents the relative difference in income per worker between the Intermediate and the Minimalist scenarios, and between the Maximalist and the Minimalist scenarios. The table shows that poorer countries close to the equator experience a substantial decrease in income per worker in the long-term. 
Table B.1: Effects on Income per Worker and Emigration Rates in 2100 (1/4)

\begin{tabular}{|c|c|c|c|c|c|c|}
\hline \multirow[t]{2}{*}{ Iso } & \multicolumn{3}{|c|}{ Income per worker in 2100} & \multicolumn{3}{|c|}{ Emigration rates in 2100} \\
\hline & Interm & Interm/Minim & Maxim/Minim & Minim & Interm & Maxim \\
\hline AFG & 3,698 & 3.2 & 5.2 & 4.7 & 4.5 & 4.5 \\
\hline ALB & 26,818 & 2.3 & 2.4 & 45.6 & 46.0 & 46.6 \\
\hline DZA & 35,125 & 0.1 & -1.8 & 8.5 & 8.6 & 8.8 \\
\hline AGO & 22,692 & -10.0 & -19.8 & 5.6 & 6.4 & 7.5 \\
\hline ARG & 55,540 & -1.1 & -4.3 & 3.0 & 3.1 & 3.2 \\
\hline ARM & 18,535 & 14.1 & 26.1 & 33.9 & 32.5 & 31.3 \\
\hline AUS* & 379,325 & 4.2 & 4.7 & 3.8 & 3.9 & 3.9 \\
\hline AUT* & 339,813 & 8.0 & 14.4 & 5.2 & 5.0 & 4.8 \\
\hline AZE & 33,184 & 3.1 & 4.8 & 15.8 & 15.8 & 15.9 \\
\hline BHS & 110,197 & -11.0 & -23.8 & 19.7 & 20.7 & 22.1 \\
\hline BHR & 131,119 & -7.1 & -15.3 & 3.1 & 3.3 & 3.5 \\
\hline BGD & 5,580 & -11.6 & -23.9 & 1.8 & 2.1 & 2.5 \\
\hline BRB & 74,853 & -13.8 & -27.5 & 32.1 & 34.2 & 37.4 \\
\hline BLR & 47,806 & 13.6 & 25.4 & 9.7 & 9.3 & 9.0 \\
\hline BEL* & 386,471 & 11.0 & 19.7 & 5.6 & 5.5 & 5.4 \\
\hline BLZ & 17,914 & -14.1 & -28.0 & 32.3 & 35.6 & 40.0 \\
\hline BEN & 3,081 & -10.3 & -21.6 & 1.2 & 1.4 & 1.7 \\
\hline BTN & 20,462 & -2.8 & -7.2 & 2.3 & 2.3 & 2.3 \\
\hline BOL & 14,992 & -4.8 & -12.2 & 7.6 & 8.1 & 8.7 \\
\hline $\mathrm{BIH}$ & 24,810 & 4.2 & 6.6 & 25.8 & 24.6 & 23.8 \\
\hline BWA & 43,962 & -6.8 & -15.0 & 1.6 & 1.7 & 1.8 \\
\hline BRA & 77,814 & -9.2 & -20.6 & 1.0 & 1.1 & 1.2 \\
\hline BRN & 299,267 & -14.8 & -29.4 & 6.4 & 7.3 & 8.4 \\
\hline BGR & 51,942 & 9.1 & 16.0 & 14.8 & 14.5 & 14.3 \\
\hline BFA & 3,847 & -10.3 & -20.4 & 0.7 & 0.8 & 1.0 \\
\hline BDI & 496 & -9.3 & -17.7 & 0.8 & 0.8 & 0.9 \\
\hline KHM & 2,848 & -12.7 & -24.3 & 5.6 & 6.8 & 8.6 \\
\hline CMR & 7,479 & -11.8 & -24.3 & 3.4 & 3.8 & 4.3 \\
\hline CAN* $^{*}$ & 277,634 & 17.1 & 34.2 & 4.3 & 4.0 & 3.7 \\
\hline CPV & 38,301 & -8.6 & -18.9 & 40.8 & 42.8 & 45.4 \\
\hline CAF & 806 & -13.0 & -25.9 & 1.3 & 1.6 & 1.9 \\
\hline TCD & 1,834 & -11.7 & -23.4 & 0.2 & 0.3 & 0.3 \\
\hline CHL* & 84,839 & 10.0 & 17.7 & 4.1 & 4.0 & 4.0 \\
\hline CHN & 33,910 & -0.3 & -0.5 & 1.5 & 1.5 & 1.5 \\
\hline HKG & 170,854 & -8.8 & -18.5 & 19.0 & 19.7 & 20.5 \\
\hline COL & 81,090 & -8.9 & -19.5 & 4.3 & 4.6 & 5.1 \\
\hline $\mathrm{COM}$ & 2,696 & -11.8 & -23.0 & 16.3 & 19.5 & 24.0 \\
\hline $\mathrm{COG}$ & 14,677 & -13.2 & -26.7 & 3.3 & 3.7 & 4.2 \\
\hline COD & 1,407 & -11.8 & -24.2 & 1.6 & 1.9 & 2.2 \\
\hline CRI & 54,616 & -11.0 & -23.5 & 3.8 & 4.2 & 4.7 \\
\hline HRV & 84,653 & 3.7 & 5.3 & 11.9 & 11.7 & 11.7 \\
\hline CUB & 31,525 & -15.4 & -31.2 & 15.5 & 17.0 & 18.9 \\
\hline CYP & 144,720 & -4.3 & -10.7 & 14.4 & 15.0 & 15.7 \\
\hline CZE* & 163,846 & 17.0 & 33.1 & 4.7 & 4.3 & 4.1 \\
\hline CIV & 3,818 & -12.0 & -23.7 & 2.3 & 2.7 & 3.3 \\
\hline
\end{tabular}

Notes: Income per worker (level and percentage deviation from the Minimalist), emigration as percentage of native population aged 25 to 64 . The asterisks mark the 34 OECD member countries. 
Table B.1: Effects on Income per Worker and Emigration Rates in 2100 (2/4)

\begin{tabular}{|c|c|c|c|c|c|c|}
\hline \multirow[t]{2}{*}{ Iso } & \multicolumn{3}{|c|}{ Income per worker in 2100} & \multicolumn{3}{|c|}{ Emigration rates in 2100} \\
\hline & Interm & Interm/Minim & Maxim/Minim & Minim & Interm & Maxim \\
\hline $\mathrm{DNK}^{*}$ & 378,559 & 13.8 & 26.6 & 5.5 & 5.2 & 4.9 \\
\hline DJI & 9,214 & -11.9 & -24.7 & 3.2 & 3.6 & 4.0 \\
\hline DOM & 27,454 & -16.6 & -32.9 & 18.0 & 19.8 & 21.9 \\
\hline ECU & 28,264 & -10.9 & -24.0 & 13.6 & 14.9 & 16.5 \\
\hline EGY & 10,922 & -0.6 & -6.2 & 1.6 & 1.7 & 1.7 \\
\hline SLV & 19,936 & -16.0 & -31.5 & 38.8 & 42.4 & 46.3 \\
\hline GNQ & 9,470 & -14.0 & -28.3 & 10.8 & 12.1 & 13.9 \\
\hline ERI & 2,113 & -9.4 & -19.1 & 7.2 & 7.8 & 8.8 \\
\hline EST* $^{*}$ & 136,205 & 12.4 & 24.1 & 10.5 & 9.7 & 9.1 \\
\hline ETH & 1,331 & -8.3 & -16.6 & 1.7 & 1.8 & 1.9 \\
\hline FJI & 15,634 & -15.0 & -29.6 & 37.9 & 41.3 & 45.4 \\
\hline FIN* & 280,830 & 2.2 & 3.6 & 4.7 & 4.7 & 4.8 \\
\hline FRA* & 274,992 & 8.0 & 14.1 & 5.1 & 4.9 & 4.8 \\
\hline GAB & 55,546 & -14.6 & -29.5 & 3.8 & 4.3 & 4.8 \\
\hline GMB & 2,430 & -18.2 & -35.9 & 10.3 & 11.6 & 13.3 \\
\hline GEO & 11,801 & 3.9 & 6.8 & 26.3 & 26.4 & 26.5 \\
\hline DEU* & 333,740 & 5.6 & 9.7 & 9.4 & 8.9 & 8.5 \\
\hline GHA & 7,025 & -16.5 & -32.7 & 5.0 & 5.7 & 6.6 \\
\hline GRC* & 272,062 & 0.6 & -0.8 & 2.6 & 2.7 & 2.8 \\
\hline GRD & 36,071 & -17.1 & -24.6 & 50.8 & 54.2 & 59.2 \\
\hline GTM & 15,702 & -9.0 & -18.2 & 16.8 & 18.3 & 20.3 \\
\hline GIN & 2,122 & -9.8 & -19.3 & 2.4 & 2.8 & 3.5 \\
\hline GNB & 3,229 & -10.1 & -25.1 & 9.6 & 11.3 & 13.4 \\
\hline GUY & 12,580 & -14.3 & -27.5 & 57.2 & 62.8 & 69.0 \\
\hline HTI & 4,556 & -12.9 & -26.2 & 19.5 & 21.0 & 22.8 \\
\hline HND & 11,976 & -12.8 & -26.1 & 19.6 & 21.8 & 24.7 \\
\hline HUN* & 103,835 & 6.1 & 10.2 & 6.2 & 6.1 & 6.0 \\
\hline ISL* & 393,815 & 40.9 & 96.6 & 16.6 & 15.4 & 14.4 \\
\hline IND & 7,428 & -11.9 & -24.0 & 1.5 & 1.7 & 2.0 \\
\hline IDN & 20,025 & -12.5 & -25.4 & 0.4 & 0.5 & 0.5 \\
\hline IRN & 62,010 & 2.2 & 2.5 & 4.0 & 4.0 & 4.0 \\
\hline IRQ & 25,839 & -2.2 & -6.1 & 7.4 & 7.7 & 7.9 \\
\hline $\mathrm{IRL}^{*}$ & 452,346 & 13.8 & 25.8 & 14.6 & 14.0 & 13.5 \\
\hline ISR* & 237,257 & 0.7 & -1.5 & 5.0 & 5.1 & 5.3 \\
\hline ITA* & 357,925 & 2.9 & 3.4 & 6.9 & 6.9 & 6.9 \\
\hline JAM & 21,336 & -13.7 & -25.9 & 48.4 & 52.3 & 57.1 \\
\hline JPN* & 286,260 & 0.8 & 0.4 & 1.0 & 1.0 & 1.0 \\
\hline JOR & 28,054 & 0.1 & -1.9 & 5.2 & 5.3 & 5.4 \\
\hline $\mathrm{KAZ}$ & 39,085 & 1.9 & 3.4 & 31.5 & 32.2 & 32.7 \\
\hline KEN & 7,369 & -8.5 & -17.1 & 3.4 & 3.5 & 3.7 \\
\hline KWT & 229,316 & -3.8 & -8.5 & 4.8 & 5.0 & 5.2 \\
\hline KGZ & 3,111 & -1.2 & -1.4 & 19.8 & 20.9 & 21.8 \\
\hline LAO & 7,493 & -9.4 & -19.8 & 16.2 & 17.4 & 18.9 \\
\hline LVA & 44,384 & 5.4 & 12.1 & 16.2 & 15.3 & 14.6 \\
\hline LBN & 60,102 & -3.1 & -8.9 & 14.6 & 15.1 & 15.9 \\
\hline
\end{tabular}

Notes: Income per worker (level and percentage deviation from the Minimalist), emigration as percentage of native population aged 25 to 64 . The asterisks mark the 34 OECD member countries. 
Table B.1: Effects on Income per Worker and Emigration Rates in 2100 (3/4)

\begin{tabular}{|c|c|c|c|c|c|c|}
\hline \multirow[t]{2}{*}{ Iso } & \multicolumn{3}{|c|}{ Income per worker in 2100} & \multicolumn{3}{|c|}{ Emigration rates in 2100} \\
\hline & Interm & Interm/Minim & Maxim/Minim & Minim & Interm & Maxim \\
\hline LSO & 4,494 & -3.2 & -6.9 & 0.2 & 0.2 & 0.2 \\
\hline LBR & 1,310 & -15.3 & -30.2 & 8.0 & 9.5 & 11.5 \\
\hline LBY & 116,403 & -0.9 & -4.1 & 3.7 & 3.8 & 4.0 \\
\hline LTU & 69,204 & 7.9 & 14.7 & 15.1 & 14.4 & 13.8 \\
\hline LUX* & 604,595 & 8.4 & 14.6 & 8.6 & 8.4 & 8.2 \\
\hline MKD & 22,851 & 3.7 & 5.8 & 20.5 & 20.4 & 20.4 \\
\hline MDG & 2,112 & -6.6 & -14.7 & 2.3 & 2.4 & 2.6 \\
\hline MWI & 1,619 & -8.8 & -18.1 & 0.6 & 0.6 & 0.7 \\
\hline MYS & 62,246 & -16.7 & -33.1 & 5.3 & 6.0 & 6.8 \\
\hline MDV & 42,646 & -6.1 & -21.2 & 1.6 & 2.0 & 2.3 \\
\hline MLI & 2,856 & -12.4 & -25.0 & 2.9 & 3.3 & 3.8 \\
\hline MLT & 129,087 & 1.1 & -0.6 & 22.1 & 22.5 & 23.0 \\
\hline MRT & 6,555 & -9.8 & -22.2 & 2.7 & 3.0 & 3.4 \\
\hline MUS & 21,322 & -12.9 & -25.5 & 22.9 & 24.7 & 27.1 \\
\hline MEX* & 76,766 & -2.0 & -6.4 & 11.3 & 11.7 & 12.3 \\
\hline FSM & 13,498 & -9.8 & -19.2 & 35.8 & 41.9 & 49.7 \\
\hline MNG & 19,210 & 15.4 & 30.4 & 3.3 & 3.1 & 2.9 \\
\hline MNE & 40,985 & 3.7 & 5.4 & 4.8 & 4.8 & 4.8 \\
\hline MAR & 18,972 & -1.0 & -3.9 & 16.2 & 16.6 & 17.1 \\
\hline MOZ & 1,428 & -8.7 & -17.8 & 0.9 & 1.1 & 1.3 \\
\hline MMR & 8,630 & -11.3 & -23.4 & 0.8 & 0.9 & 1.1 \\
\hline NAM & 31,231 & -8.8 & -18.4 & 1.9 & 2.1 & 2.3 \\
\hline NPL & 1,235 & -17.3 & -32.1 & 4.0 & 4.5 & 5.3 \\
\hline NLD* & 451,235 & 6.7 & 11.1 & 4.8 & 4.7 & 4.6 \\
\hline NZL* & 334,407 & 8.0 & 13.6 & 19.3 & 18.8 & 18.5 \\
\hline NIC & 7,942 & -16.8 & -32.5 & 12.8 & 15.1 & 18.1 \\
\hline NER & 659 & -10.7 & -21.6 & 0.2 & 0.2 & 0.2 \\
\hline NGA & 13,969 & -10.8 & -21.6 & 1.5 & 1.7 & 2.1 \\
\hline $\mathrm{NOR}^{*}$ & 475,745 & 1.7 & 3.6 & 4.5 & 4.6 & 4.6 \\
\hline OMN & 129,932 & -11.0 & -22.6 & 0.5 & 0.5 & 0.6 \\
\hline PAK & 5,138 & -6.1 & -13.4 & 2.9 & 3.1 & 3.3 \\
\hline PSE & 17,640 & -2.2 & -6.7 & 1.4 & 1.4 & 1.5 \\
\hline PAN & 58,022 & -13.8 & -27.6 & 8.6 & 9.8 & 11.3 \\
\hline PNG & 3,355 & -8.1 & -17.8 & 1.6 & 1.7 & 1.9 \\
\hline PRY & 17,934 & -11.5 & -24.0 & 4.8 & 5.4 & 6.1 \\
\hline PER & 42,001 & 7.5 & 11.5 & 6.1 & 6.1 & 6.2 \\
\hline PHL & 12,396 & -16.4 & -32.6 & 11.8 & 13.2 & 15.1 \\
\hline $\mathrm{POL}^{*}$ & 86,600 & 9.3 & 17.1 & 14.7 & 14.1 & 13.6 \\
\hline PRT* & 197,097 & 3.4 & 4.6 & 20.2 & 20.3 & 20.5 \\
\hline QAT & 34,394 & -7.3 & -15.5 & 0.6 & 0.6 & 0.7 \\
\hline $\mathrm{KOR}^{*}$ & 76,315 & 2.7 & 3.9 & 3.9 & 3.9 & 3.9 \\
\hline MDA & 7,867 & 6.5 & 11.3 & 24.6 & 23.9 & 23.5 \\
\hline ROU & 49,314 & 4.7 & 7.9 & 22.8 & 22.6 & 22.5 \\
\hline RUS & 46,992 & 14.3 & 28.0 & 4.1 & 3.7 & 3.4 \\
\hline RWA & 3,182 & -9.0 & -17.7 & 1.6 & 1.8 & 1.9 \\
\hline
\end{tabular}

Notes: Income per worker (level and percentage deviation from the Minimalist), emigration as percentage of native population aged 25 to 64 . The asterisks mark the 34 OECD member countries. 
Table B.1: Effects on Income per Worker and Emigration Rates in 2100 (4/4)

\begin{tabular}{|c|c|c|c|c|c|c|}
\hline \multirow[t]{2}{*}{ Iso } & \multicolumn{3}{|c|}{ Income per worker in 2100} & \multicolumn{3}{|c|}{ Emigration rates in 2100} \\
\hline & Interm & Interm/Minim & Maxim/Minim & Minim & Interm & Maxim \\
\hline LCA & 50,268 & -8.3 & -16.9 & 23.9 & 26.2 & 29.6 \\
\hline VCT & 45,703 & -10.9 & -23.0 & 44.8 & 47.4 & 50.7 \\
\hline WSM & 24,116 & -9.0 & -17.9 & 48.3 & 52.6 & 58.3 \\
\hline STP & 4,529 & -19.8 & -38.0 & 31.1 & 34.9 & 39.2 \\
\hline SAU & 120,306 & -6.5 & -14.2 & 1.1 & 1.1 & 1.2 \\
\hline SEN & 3,609 & -10.7 & -21.4 & 7.8 & 9.4 & 11.7 \\
\hline SRB & 29,005 & 5.6 & 9.4 & 13.1 & 12.8 & 12.7 \\
\hline SLE & 1,093 & -11.8 & -22.8 & 4.3 & 5.2 & 6.6 \\
\hline SGP & $1,151,453$ & -17.0 & -33.3 & 0.0 & 0.0 & 0.0 \\
\hline SVK* & 116,102 & 6.9 & 12.4 & 13.2 & 12.8 & 12.5 \\
\hline $\mathrm{SVN}^{*}$ & 222,034 & 7.8 & 13.6 & 4.4 & 4.2 & 4.1 \\
\hline SLB & 8,112 & -12.0 & -24.3 & 2.3 & 2.9 & 3.8 \\
\hline ZAF & 45,803 & -2.8 & -7.4 & 4.8 & 4.8 & 5.0 \\
\hline $\mathrm{ESP}^{*}$ & 371,685 & 1.8 & 1.4 & 2.4 & 2.5 & 2.5 \\
\hline LKA & 20,759 & -13.6 & -26.9 & 6.3 & 7.5 & 9.3 \\
\hline SDN & 8,180 & -12.0 & -23.9 & 1.1 & 1.3 & 1.6 \\
\hline SUR & 38,188 & -9.0 & -19.5 & 46.4 & 50.5 & 54.4 \\
\hline SWZ & 31,710 & -5.8 & -13.5 & 0.7 & 0.7 & 0.7 \\
\hline SWE* & 271,332 & 1.3 & 3.0 & 5.4 & 5.5 & 5.5 \\
\hline $\mathrm{CHE}^{*}$ & 548,846 & 15.3 & 29.8 & 7.6 & 7.1 & 6.6 \\
\hline SYR & 17,482 & -0.4 & -2.5 & 3.2 & 3.3 & 3.4 \\
\hline TJK & 1,969 & -0.2 & 0.1 & 17.7 & 18.3 & 18.6 \\
\hline TZA & 2,838 & -8.5 & -16.6 & 0.5 & 0.5 & 0.6 \\
\hline THA & 47,831 & -12.5 & -25.4 & 1.6 & 1.8 & 2.1 \\
\hline TLS & 6,551 & -10.0 & -19.5 & 5.5 & 6.6 & 8.3 \\
\hline TGO & 2,107 & -11.3 & -22.0 & 2.8 & 3.4 & 4.2 \\
\hline TON & 36,927 & -9.8 & -20.2 & 57.3 & 60.4 & 64.3 \\
\hline TTO & 174,280 & -10.8 & -22.0 & 31.4 & 34.3 & 38.5 \\
\hline TUN & 33,124 & -1.0 & -4.2 & 8.4 & 8.6 & 8.9 \\
\hline TUR* & 85,377 & 3.2 & 5.0 & 5.5 & 5.5 & 5.6 \\
\hline TKM & 28,103 & 0.0 & -0.9 & 7.5 & 7.6 & 7.7 \\
\hline UGA & 2,492 & -9.3 & -17.9 & 1.3 & 1.4 & 1.6 \\
\hline UKR & 24,656 & 8.6 & 15.1 & 9.7 & 9.5 & 9.3 \\
\hline ARE & 551,078 & -8.5 & -17.8 & 0.6 & 0.7 & 0.8 \\
\hline GBR* $^{*}$ & 270,646 & 10.6 & 19.5 & 7.4 & 7.0 & 6.7 \\
\hline USA* & 361,427 & 0.5 & 0.7 & 0.6 & 0.7 & 0.7 \\
\hline URY & 84,881 & 0.4 & -2.9 & 7.8 & 8.1 & 8.5 \\
\hline UZB & 6,010 & 0.4 & 0.6 & 11.9 & 12.1 & 12.3 \\
\hline VUT & 21,728 & -10.8 & -21.7 & 4.6 & 5.5 & 6.7 \\
\hline VEN & 64,072 & -17.8 & -34.9 & 4.8 & 5.3 & 5.9 \\
\hline VNM & 7,839 & -8.7 & -20.1 & 7.4 & 8.1 & 9.0 \\
\hline YEM & 8,047 & -8.9 & -18.6 & 1.1 & 1.2 & 1.3 \\
\hline ZMB & 2,651 & -9.2 & -18.2 & 1.3 & 1.5 & 1.6 \\
\hline ZWE & 6,412 & -7.2 & -15.5 & 6.5 & 6.8 & 7.1 \\
\hline
\end{tabular}

Notes: Income per worker (level and percentage deviation from the Minimalist), emigration as percentage of native population aged 25 to 64 . The asterisks mark the 34 OECD member countries. 
Table B.2: Most Adversely Affected Countries in 2040 and 2100 (Percentage Deviation from the Minimalist Scenario)

\begin{tabular}{llllllc}
\hline \hline & Country & \multicolumn{2}{c}{ Interm/Minim } & Country & \multicolumn{2}{c}{ Maxim/Minim } \\
& & 2040 & 2100 & & 2040 & 2100 \\
\hline 1 & Sao Tome and Principe & -20.6 & -19.8 & Sao Tome and Principe & -34.6 & -38.0 \\
2 & Gambia & -11.7 & -18.2 & Gambia & -25.0 & -35.9 \\
3 & Venezuela & -13.8 & -17.8 & Venezuela & -28.0 & -34.9 \\
4 & Nepal & -15.9 & -17.3 & Singapore & -28.7 & -33.3 \\
5 & Grenada & -13.4 & -17.1 & Malaysia & -28.7 & -33.1 \\
6 & Singapore & -14.3 & -17.0 & Dominican Republic & -27.3 & -32.9 \\
7 & Nicaragua & -15.3 & -16.8 & Ghana & -31.8 & -32.7 \\
8 & Malaysia & -14.3 & -16.7 & Philippines & -30.7 & -32.6 \\
9 & Dominican Republic & -13.5 & -16.6 & Nicaragua & -30.2 & -32.5 \\
10 & Ghana & -15.9 & -16.5 & Nepal & -31.1 & -32.1 \\
11 & Philippines & -15.3 & -16.4 & El Salvador & -27.8 & -31.5 \\
12 & El Salvador & -14.0 & -16.0 & Cuba & -26.0 & -31.2 \\
13 & Cuba & -12.7 & -15.4 & Liberia & -36.3 & -30.2 \\
14 & Liberia & -18.6 & -15.3 & Fiji & -24.7 & -29.6 \\
15 & Fiji & -12.0 & -15.0 & Gabon & -25.8 & -29.5 \\
16 & Brunei Darussalam & -14.4 & -14.8 & Brunei Darussalam & -29.0 & -29.4 \\
17 & Gabon & -12.5 & -14.6 & Equatorial Guinea & -30.4 & -28.3 \\
18 & Guyana & -14.2 & -14.3 & Belize & -29.7 & -28.0 \\
19 & Belize & -14.2 & -14.1 & Panama & -26.7 & -27.6 \\
20 & Equatorial Guinea & -14.5 & -14.0 & Barbados & -25.7 & -27.5 \\
\hline \hline
\end{tabular}

Notes: Simulation results based on the moderate CLC scenarios defined in Section 2.1. Ranking based on income per worker in 2100.

Table B.3 reports emigration and immigration rates by region. The top panel shows that the mean emigration rates from the developing world will increase during the 21st century. The regional emigration rates will be multiplied by a factor of 1.5 to 2 . This can be explained by the rise in education (highly educated people are more mobile) and by CLC. To identify the effect of CLC, the last two columns compare the predictions of the two alternative CLC scenarios in 2100. Comparing the Intermediate to the Minimalist and Maximalist scenarios, CLC affects the emigration rates from Latin America and, to a lesser extent, from Asia and sub-Saharan Africa. However, on average, CLC multiplies emigration rates by a factor of 1.05 , which is a small fraction of the total rise in emigration rates.

The bottom panel documents the change in the proportion of immigrants in selected OECD countries. We assume emigrants to the OECD aggregate entity are allocated across countries on the basis of the dyadic shares of 2010. Over the 21st century and at current migration policies and laws, the average share of immigrants should be multiplied by a factor of 1.5 in settlement countries (the US, Canada and Australia), and should increase twofold in Europe. These changes are mostly explained by demographic imbalances and by the progress in education. Comparing the CLC scenarios for 2100, we show that the contribution of CLC to increasing immigration is small. CLC explains about 1/20 of the total change in the share of immigrants in the population. The rise in the sea level induces minor effects on international migration, as most of the forcibly displaced people will relocate locally.

Table B.4 lists the countries with the highest emigration responses to CLC for 2040 and 2100. In 2040, countries that send the greatest numbers of emigrants abroad under 
Table B.3: International Migration Rates by Region and by Country

\begin{tabular}{|c|c|c|c|c|c|c|}
\hline & \multicolumn{4}{|c|}{ Intermediate } & \multirow{2}{*}{$\begin{array}{c}\text { Minim } \\
2100\end{array}$} & \multirow{2}{*}{$\begin{array}{c}\text { Maxim } \\
2100\end{array}$} \\
\hline & 2010 & 2040 & 2070 & 2100 & & \\
\hline \multicolumn{7}{|l|}{ Emigration rates } \\
\hline Latin America & 3.8 & 5.3 & 6.1 & 6.7 & 6.3 & 6.7 \\
\hline Sub-Saharan Africa & 1.3 & 1.8 & 2.1 & 2.2 & 2.0 & 2.2 \\
\hline MENA & 2.8 & 4.0 & 4.3 & 4.6 & 4.4 & 4.6 \\
\hline Asia & 1.1 & 1.9 & 2.5 & 3.0 & 2.8 & 3.0 \\
\hline OECD & 4.7 & 5.6 & 5.2 & 4.7 & 4.8 & 4.7 \\
\hline \multicolumn{7}{|l|}{ Immigration rates } \\
\hline United States & 16.0 & 21.4 & 23.0 & 23.1 & 22.7 & 23.6 \\
\hline Canada & 18.7 & 26.5 & 28.5 & 28.4 & 28.2 & 28.6 \\
\hline Australia & 24.9 & 29.4 & 29.2 & 28.1 & 27.8 & 28.5 \\
\hline European Union & 12.1 & 18.6 & 21.9 & 23.6 & 23.2 & 24.1 \\
\hline EU15 & 13.6 & 20.3 & 23.3 & 24.6 & 24.2 & 25.1 \\
\hline Germany & 15.0 & 22.5 & 25.4 & 26.4 & 26.1 & 26.8 \\
\hline France & 12.2 & 18.8 & 20.5 & 22.1 & 21.6 & 22.6 \\
\hline United Kingdom & 14.6 & 22.2 & 25.4 & 26.6 & 26.3 & 26.9 \\
\hline Italy & 10.9 & 17.2 & 20.6 & 22.5 & 21.9 & 23.1 \\
\hline Spain & 14.0 & 20.6 & 23.3 & 24.3 & 23.8 & 24.8 \\
\hline
\end{tabular}

Notes: Simulation results based on the moderate scenarios defined in Section 2.1. Emigration as a percent of native population aged 25 to 64 , immigration as a percent of resident population aged 25 to 64 .

the more pessimistic scenarios are usually those with higher fractions of forcibly displaced workers and/or those located close to the equator. By the end of the century, these general results do not markedly change. Some of the small Caribbean islands are among the group of the most adversely affected economies in $2100 .{ }^{35}$

\section{Modeling conflicts}

To account for conflicts over ressources, we follow Dao et al. (2018) who show that severe armed conflicts increase the emigration stock twofold in the long-term. In our model, migration decisions from region $r^{\circ}$ are governed by:

$$
\begin{aligned}
N_{r^{\circ}, s, t} & =M_{r^{\circ} r^{\circ}, s, t}+M_{r^{\circ} r, s, t}+M_{r^{\circ} F, s, t} \\
& =M_{r^{\circ} r^{\circ}, s, t}\left(1+m_{r^{\circ} r, s, t}+m_{r^{\circ} F, s, t}\right),
\end{aligned}
$$

where $m_{r^{\circ} F, s, t}=\left(v_{F, s, t} / v_{r^{\circ}, s, t}\right)^{1 / \mu}\left(1-x_{r^{\circ} F, s, t}\right)^{1 / \mu}$ denotes the migrant-to-stayer ratio, and $N_{r^{\circ}, s, t}$ is the native (pre-migration) population (given at the beginning of each period). We can express the emigrant stock as:

$$
M_{r^{\circ} F, s, t}=m_{r^{\circ} F, s, t} M_{r^{\circ} r^{\circ}, s, t}=\frac{m_{r^{\circ} F, s, t} N_{r^{\circ}, s, t}}{1+m_{r^{\circ} r, s, t}+m_{r^{\circ} F, s, t}} .
$$

\footnotetext{
${ }^{35}$ Interestingly, Micronesia is among the top positively affected countries in the short-run and the top negatively affected countries in the long-run.
} 
Table B.4: Largest Changes in the Stock of Emigrants (Percentage Deviation from the Minimalist Scenario)

\begin{tabular}{lllllll}
\hline \hline & Country & \multicolumn{2}{c}{ Interm/Minim } & Country & \multicolumn{2}{c}{ Maxim/Minim } \\
& 2040 & 2100 & & 2040 & 2100 \\
\hline 1 & Guyana & 16.9 & -15.6 & Guyana & 35.1 & -34.5 \\
2 & Suriname & 17.3 & -13.0 & Suriname & 32.2 & -26.1 \\
3 & Grenada & 13.5 & -9.5 & Tonga & 16.1 & -18.3 \\
4 & Tonga & 7.8 & -8.9 & Samoa & 24.2 & -16.7 \\
5 & Russia & -10.3 & -8.0 & Jamaica & 23.4 & -15.7 \\
6 & Micronesia & 23.8 & -6.5 & Grenada & 21.8 & -14.8 \\
7 & Samoa & 10.6 & -6.5 & Micronesia & 44.8 & -14.7 \\
8 & Jamaica & 10.9 & -6.3 & Russia & -18.3 & -14.4 \\
9 & Czech Republic & -9.3 & -5.8 & El Salvador & 24.8 & -11.2 \\
10 & Mongolia & -9.4 & -5.2 & Mongolia & -16.6 & -9.9 \\
11 & Latvia & -0.2 & -4.4 & Czech Republic & -15.9 & -9.5 \\
12 & Lesotho & -6.5 & -4.3 & Latvia & -4.4 & -7.6 \\
13 & El Salvador & 11.4 & -4.2 & Cape Verde & 19.2 & -7.4 \\
14 & Cape Verde & 11.0 & -4.1 & St Vinc \& Gren & 19.8 & -6.9 \\
15 & Estonia & -9.1 & -3.8 & Lesotho & -10.2 & -6.6 \\
16 & Denmark & -8.9 & -3.8 & Estonia & -15.9 & -6.3 \\
17 & Albania & 6.1 & -3.7 & Denmark & -15.5 & -6.1 \\
18 & St Vinc \& Gren & 10.4 & -3.4 & Canada & -24.1 & -5.7 \\
19 & Lithuania & -3.7 & -3.2 & Lithuania & -8.0 & -5.6 \\
20 & Afghanistan & -4.3 & -3.0 & Fiji & 24.0 & -5.5 \\
\hline \hline
\end{tabular}

Notes: Simulation results based on the moderate scenarios defined in Section 2.1. Ranking based on 2100 .

Everything else equal, we constrain $M_{r^{\circ} F, s, t}$ to increase by a factor of 2 after the conflict (i.e. $\bar{M}_{r^{\circ} F, s, t}=2 M_{r^{\circ} F, s, t}$ ). Assuming that conflicts affects symmetrically (i) highand low-skilled workers and (ii) it all regions leaves the relative attractiveness of rural and urban areas unchanged (i.e. $m_{r^{\circ} r, s, t}$ is constant). We have to find the new level of $\bar{m}_{r^{\circ} F, s, t}$ that is compatible with $\bar{M}_{r^{\circ} F, s, t}$. The solution is:

$$
\begin{gathered}
\frac{\bar{m}_{r^{\circ} F, s, t} N_{r^{\circ}, s, t}}{1+m_{r^{\circ} r, s, t}+\bar{m}_{r^{\circ} F, s, t}}=\frac{2 m_{r^{\circ} F, s, t} N_{r^{\circ}, s, t}}{1+m_{r^{\circ} r, s, t}+m_{r^{\circ} F, s, t}} \\
\Longrightarrow \bar{m}_{r^{\circ} F, s, t}=\frac{2\left(1+m_{r^{\circ} r, s, t}\right) m_{r^{\circ} F, s, t}}{1+m_{r^{\circ} r, s, t}-m_{r^{\circ} F, s, t}}=Z_{r^{\circ} F, s, t} m_{r^{\circ} F, s, t}
\end{gathered}
$$

Considering that the effect of the conflict is governed by a change in migration costs and net amenities $\left(x_{r^{\circ} F, s, t} \rightarrow \bar{x}_{r^{\circ} F, s, t}\right)$, this requires:

$$
\left(1-\bar{x}_{r^{\circ} F, s, t}\right)=\left(1-x_{r^{\circ} F, s, t}\right) Z_{r^{\circ} F, s, t}^{\mu} .
$$

\section{Additional results with fast-onset mechanisms and conflicts}

In Section 4.2, we start from the Intermediate scenario and enrich it with additional mechanisms related to fast-onset weather shocks and conflicts over resources. The aggregate impact of CLC is presented in Table D.1, which gives the average effects on the world 
economy and by regions. The structure is identical to that of Table 1 . The values in bold characters are the projections obtained in the Minimalist scenario, involving constant temperature and sea levels. The values below are the variations induced by the Fast-onset and Conflict scenarios, expressed as percentage deviation from the Minimalist scenario (for GDP and population) or as percentage points of variation (for the share of college graduates, the urban share, or the international emigration rate). The bottom lines of this table give the worldwide average responses. Therefore, the Conflict scenario is a conjunction of slow-onset, fast-onset and conflict mechanisms. This conflict scenario would then represent the most pessimistic case for the Intermediate projection of global temperatures. 


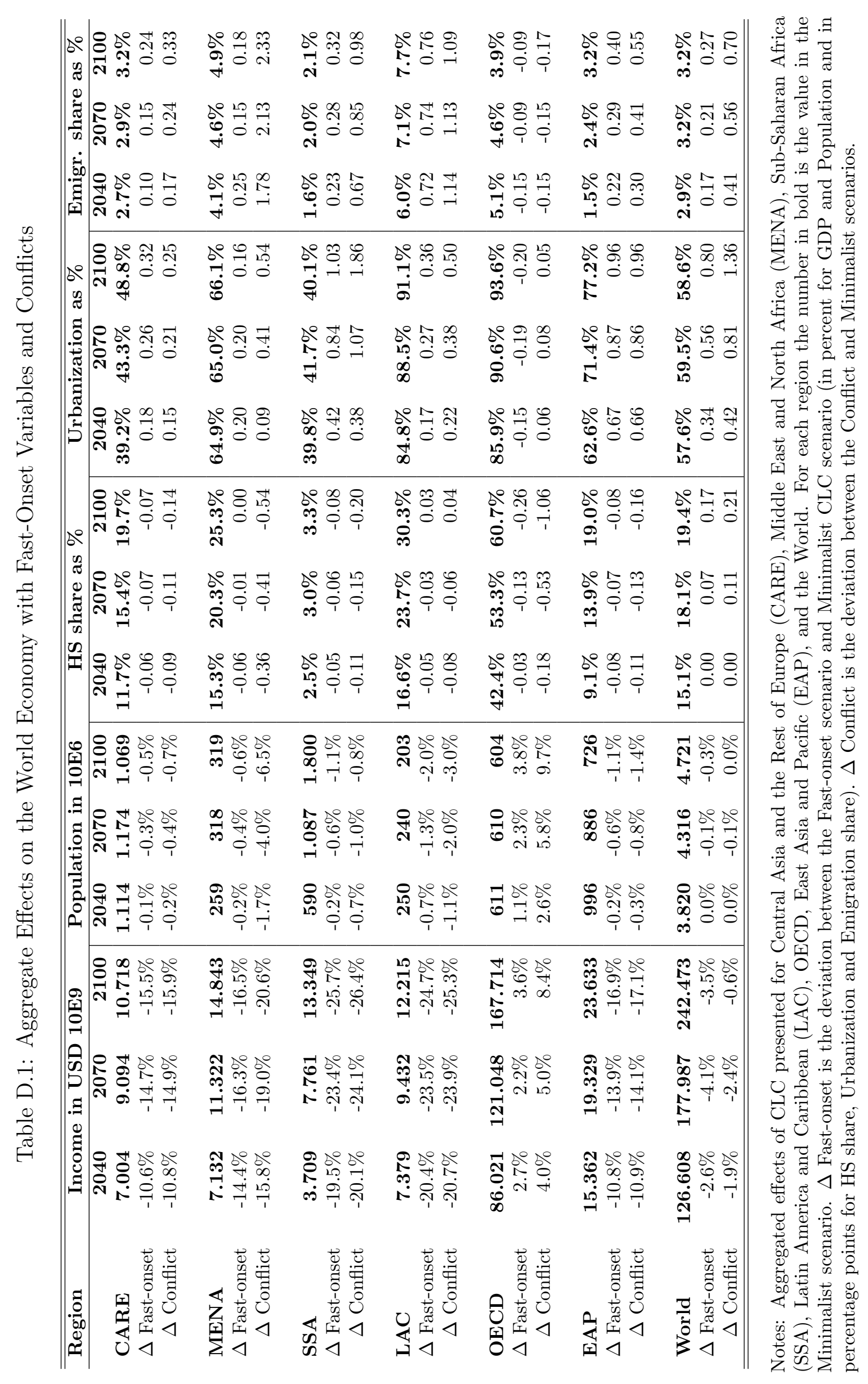


"Sur quoi la fondera-t-il l'économie du monde qu'il veut gouverner? Sera-ce sur le caprice de chaque particulier? Quelle confusion! Sera-ce sur la justice? Il l'ignore."

Pascal

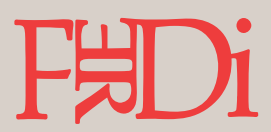

Created in 2003, the Fondation pour les études et recherches sur le développement international aims to promote a fuller understanding of international economic development and the factors that influence it.

\section{$\hookrightarrow$ Contact}

www.ferdi.fr

contact@ferdi.fr

+33 (0)4 73177530 